\title{
Environmental engagement through behaviour change interventions: A case study of litter reduction in New Zealand Schools
}

\author{
By \\ Rachel Maree Thomas \\ Thesis \\ ENVIRONMENTAL STUDIES 593
}

2018

A 90 point thesis submitted to Victoria University of Wellington in partial fulfilment of requirements for the degree of Master of Environmental Studies

School of Geography, Environment and Earth Sciences

Victoria University of Wellington

August 2018 



\begin{abstract}
Litter has serious implications for the environment and is recognised as a significant form of marine and terrestrial pollution. A major source of litter pollution is recreational litter. Although litter is identified as an environmental problem, the propensity to litter continues within society. Behaviour change interventions have significant potential to influence the production of recreational litter. A shift in littering behaviour is necessary to reduce the environmental impact litter has on terrestrial and marine ecosystems.
\end{abstract}

This research used the framework Community-Based Social Marketing to identify the barriers and benefits of littering as well as interventions to increase the reduction of littering in a school setting. The behaviour change interventions hypocrisy and goal setting were selected and separately implemented in two Intermediate schools in the Greater Wellington Region of New Zealand. Behaviour change was assessed using pre, post, and follow up litter counts on school grounds, and supported by interviews with student, teacher and parent participants. Results found both interventions to be significant in reducing the rate of recreational littering when used in conjunction with education. Goal setting was also found to be significant in reducing wrappers in school lunches. Cognitive, situational, and personal variables, as well as key stakeholders, were also recognised as influencing the litter and packaging behaviour of participants. Findings from this research can be used to support the selection and implementation of future behaviour change interventions and campaigns, specifically those targeting the behaviour of littering in a school setting.

Keywords: Behaviour change interventions; education; hypocrisy; goal setting; litter reduction; packaging reduction; schools; Wellington; New Zealand 


\section{Acknowledgements}

There are a number of people I would like to recognise for their contribution to this research. I would not have been able to do this without your support, guidance and generosity.

Firstly, I would like to thank Avalon Intermediate and Raroa Normal Intermediate for your willingness to come on board with this study. Thank you for collaborating with me, and for maintaining the work that we achieved during and past the projects' completion. In particular, I would like to thank Kelsey, Alix, Ian, and Ariana for your time and effort. The passion and work these teachers provide and achieve beyond this research is highly commendable.

Secondly, I would like to thank my supervisors Wokje Abrahamse and Ralph Chapman for your invaluable knowledge, guidance and feedback which provided valued inputs into this thesis.

To those who occupied CO102A, I couldn't imagine being put in an office with a better bunch of individuals, all providing their own unique insight into topics, humour, care and support, baking, and interesting quiz answers. You all individually inspired and supported me, whether through your different backgrounds and upbringings, or through dark humour and extreme measures to stay on task, the memories I have will always be appreciated.

To my friends dotted all around the globe, thank you for the messages of encouragement, late night phone or video calls, brunch catch ups and the occasional wines, thank you for being so supportive and understanding.

To my family and partner, when I say I can't thank you enough, I truly mean it. Thank you for your words of encouragement, for believing in me, for being there when ever where ever. The smallest of acts did not go unnoticed and I will be forever grateful to you all. Although 
Adam you did all of the above, you really did go above and beyond to help me and I appreciate it beyond words. I am so lucky to have you, and I can't wait for our future. 


\section{Table of Contents}

Chapter 1 Introduction ..............................................................................1

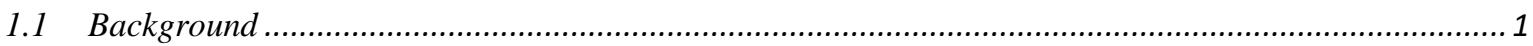

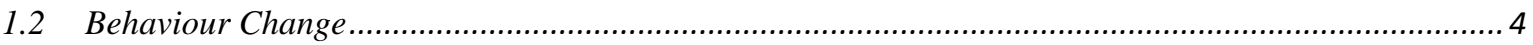

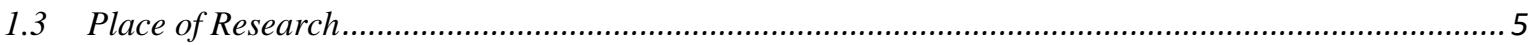

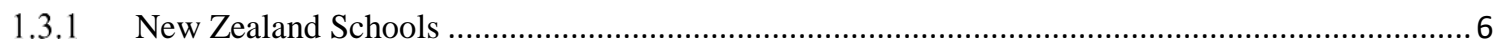

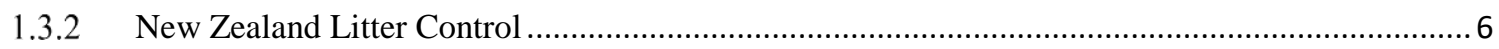

1.4 Research Aims, Questions and Contributions ...............................................................................

1.5 Thesis Outline

Chapter 2 Framework.............................................................................10

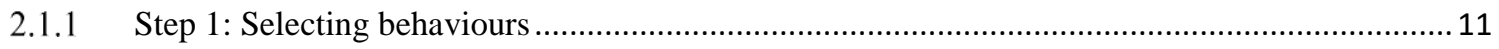

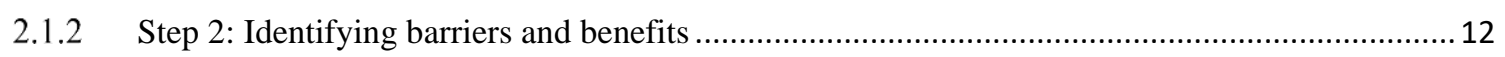

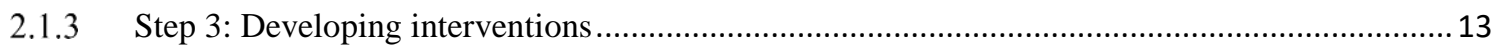

2.1.4 Step 4: Programme piloting …………………................................................................... 13

2.1.5 Step 5: Broad-scale implementation and evaluation ................................................................... 14

Chapter 3 Literature Review....................................................................15

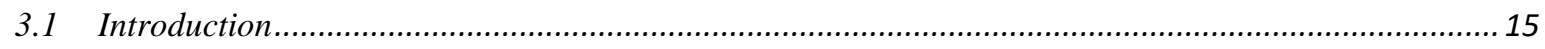

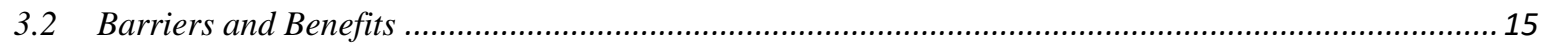

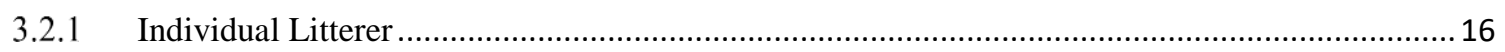

3.2.2 Individual Litterer and Environment................................................................................. 19

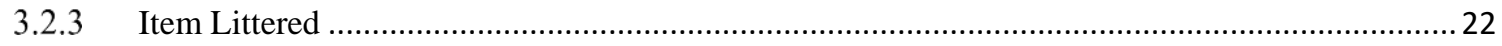

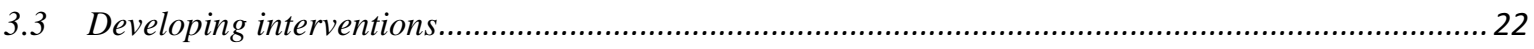

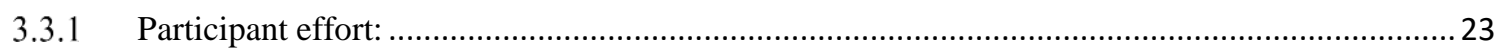

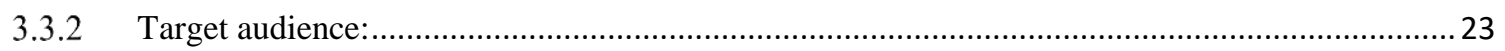

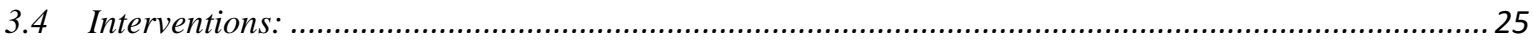

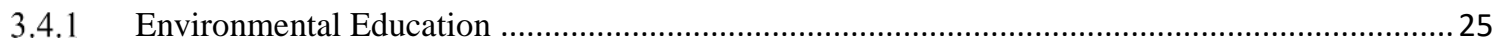

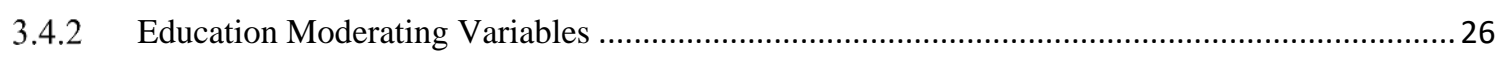




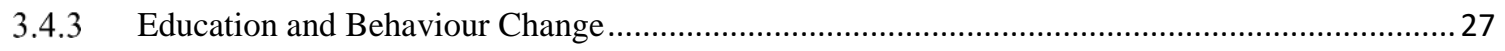

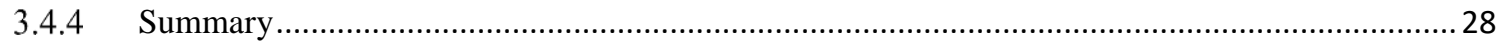

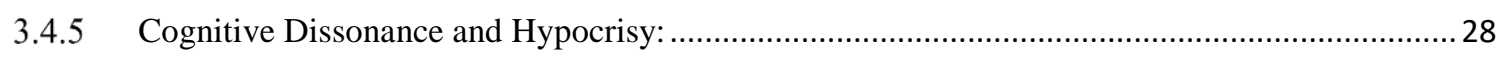

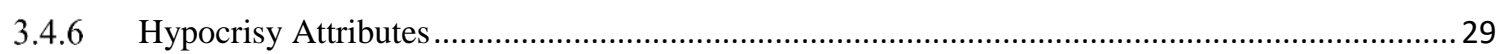

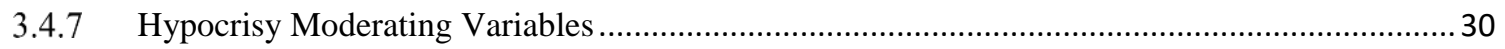

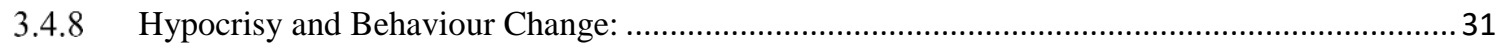

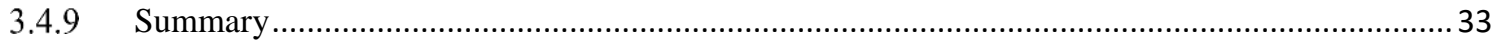

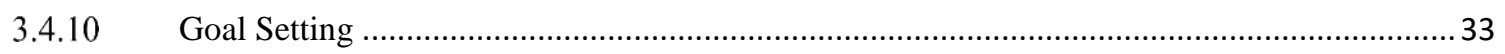

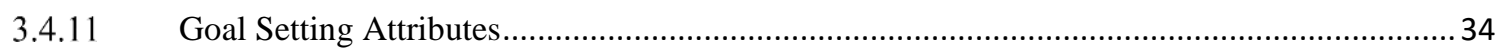

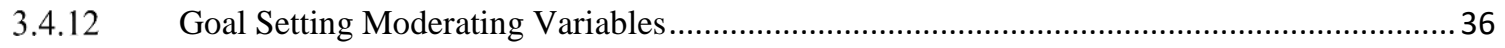

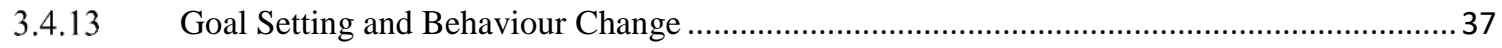

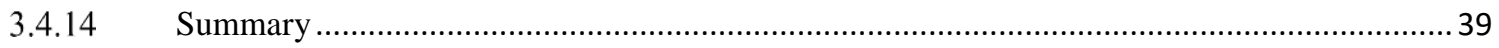

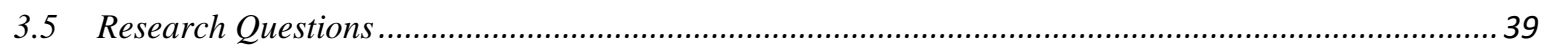

Chapter 4 Methodology and Research Design...............................................40

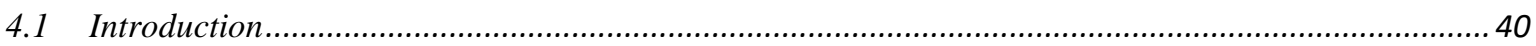

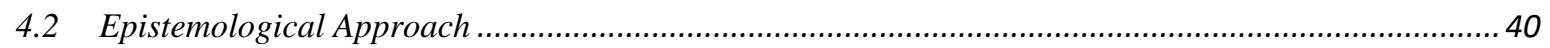

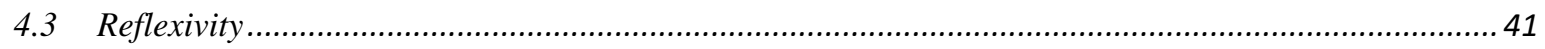

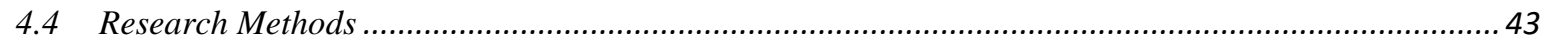

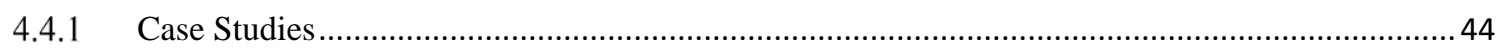

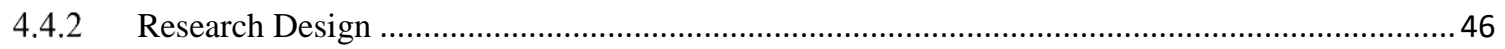

4.4.3 Case Study One: Avalon Intermediate School.................................................................47

4.4.4 Case Study Two: Raroa Normal Intermediate School .....................................................5 55

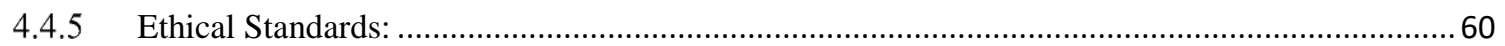

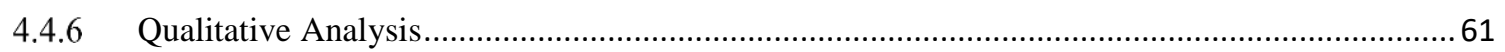

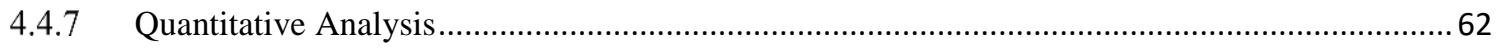

\section{Chapter 5 Results...............................................................................................63}

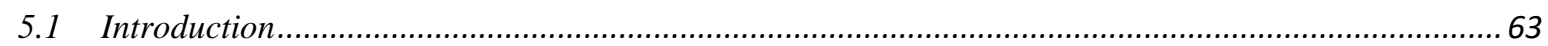

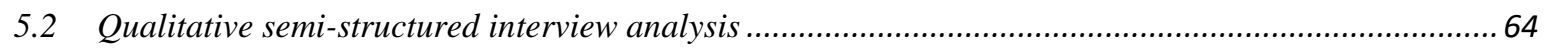

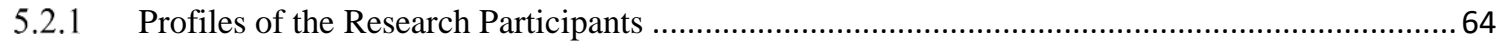

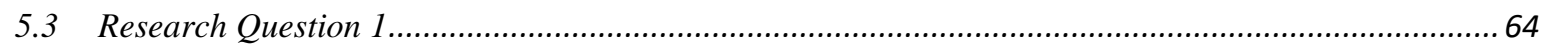

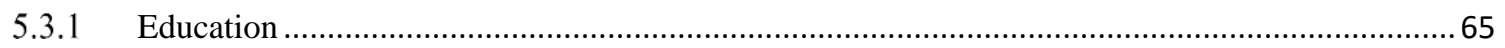

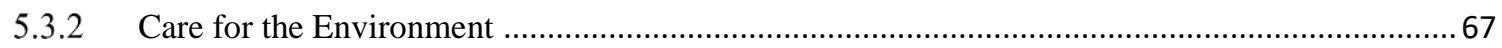

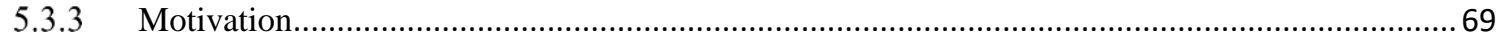




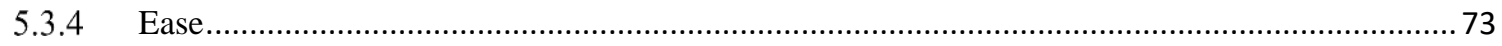

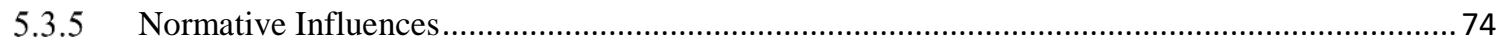

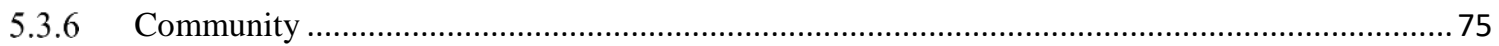

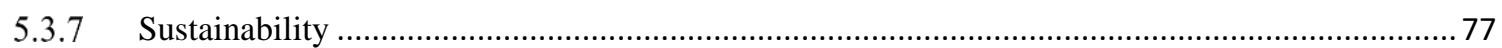

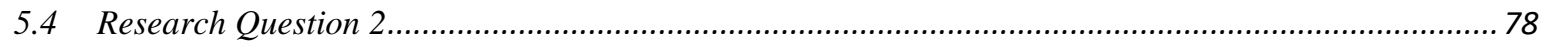

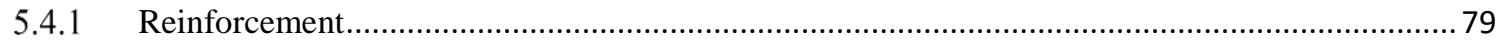

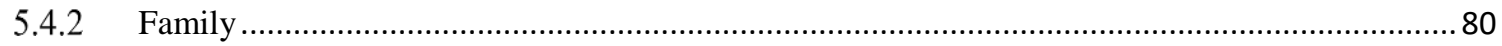

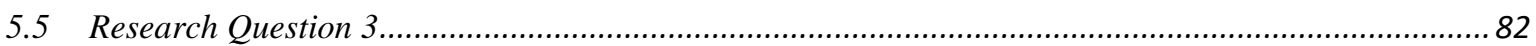

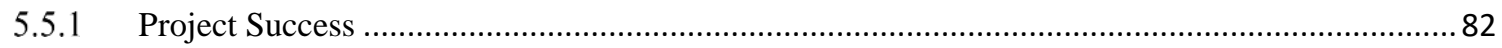

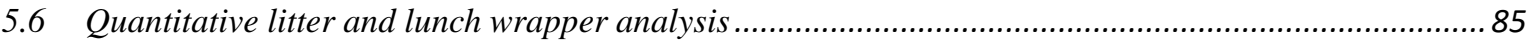

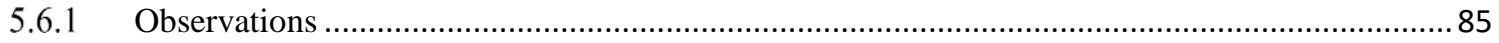

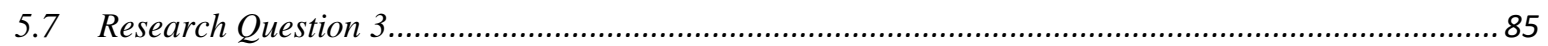

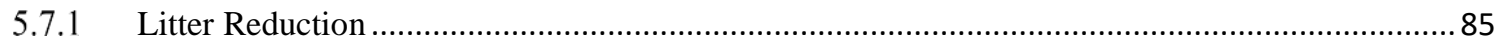

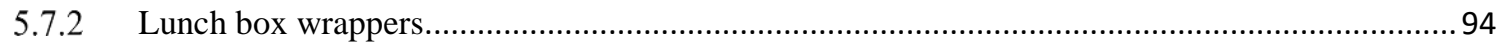

Chapter 6 Discussion and Conclusion ...........................................................99

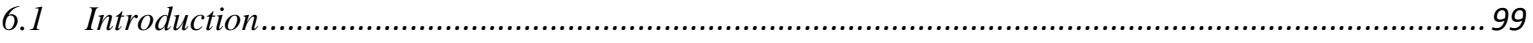

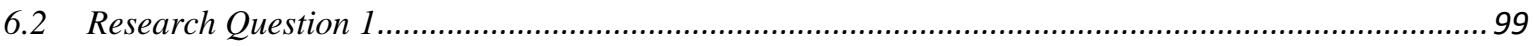

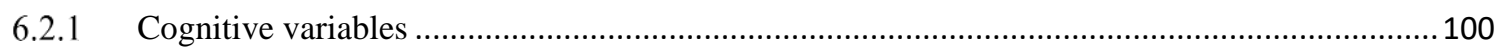

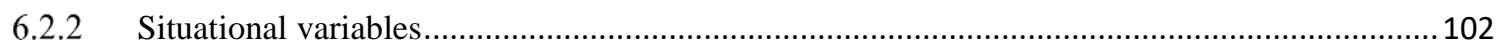

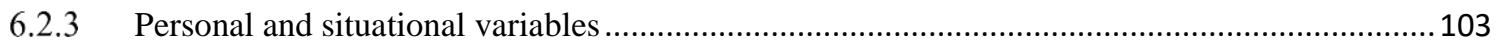

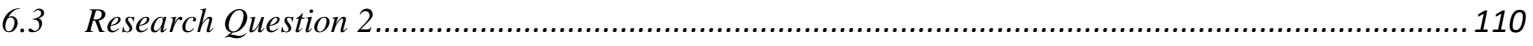

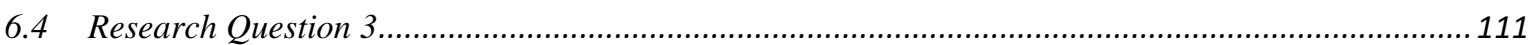

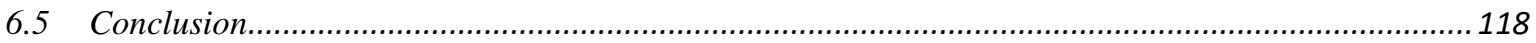

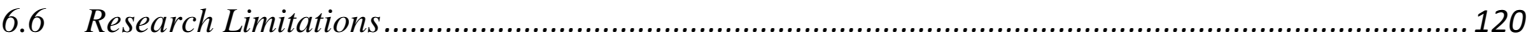

6.7 Research Contributions and Recommendations........................................................................ 121

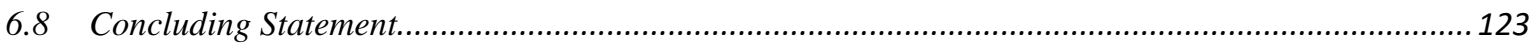

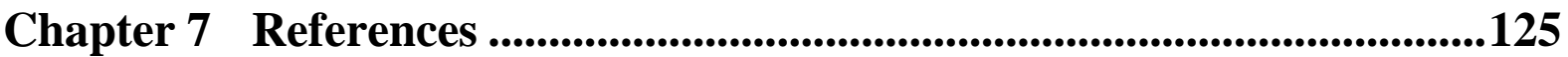

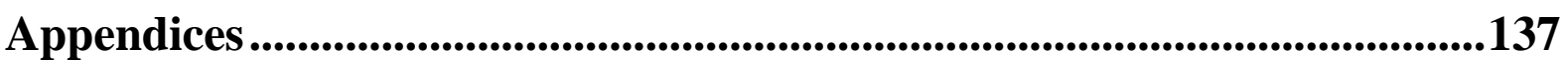




\section{List of Figures}

Figure 1 Map of the Greater Wellington Region showing the Territorial Authorities in the Region (GWRC, 2018)

Figure 2 Step by step breakdown of the application of the CBSM framework in this study.

Figure 3 Case study locations in the Greater Wellington Region, New Zealand. AI (red dot) located in Avalon,

Lower Hutt City, and RNI (blue dot) located in Johnsonville, Wellington City (GWRC, 2018).............46

Figure 4 Triangulation Design: Convergence Model (Creswell \& Plano Clark, 2007)...................................46

Figure 5 AI School in Lower Hutt City (school boundary and observation sites highlighted in yellow) (Google

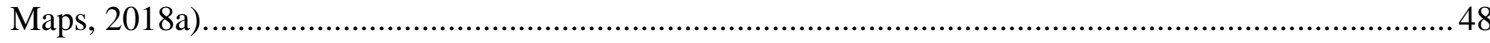

Figure 6 AI Room 6 written personal commitment from a student from the intervention, featured in a classroom window. 53

Figure 7 RNI School in Wellington City (school boundary and observation sites highlighted in yellow) (Google

Maps, 2018b). 56

Figure 8 AI litter observation before intervention; percentage of littered items........................................... 86

Figure 9 AI litter observation directly proceeding the intervention; percentage of littered items. ...................... 87

Figure 10 AI litter observation follow up from the intervention; percentage of littered items. .........................8 88

Figure 11 RNI litter observation before the intervention; percentage of littered items. ..................................90

Figure 12 RNI litter observation directly proceeding the intervention; percentage of littered items..................91

Figure 13 RNI litter observation follow up from the intervention; percentage of littered items. ...................... 92

Figure 14 RNI wrapperless lunch observation before the intervention; percentage of items. ...........................95

Figure 15 RNI wrapperless lunch observation directly proceeding the intervention; percentage of items..........96

Figure 16 RNI wrapperless lunch observation follow up from the intervention; percentage of items. ...............97

\section{List of Tables}

Table 1 Litter count sheet AI School.

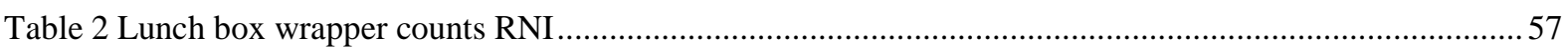

Table 3 Research participants interviewed for qualitative data collection from case study one and two.

Table 4 Qualitative thematic analysis: dark blue boxes represent the overarching themes under research question 1 and the light blue boxes represent the sub-themes under the larger themes.

Table 5 Qualitative thematic analysis: dark blue boxes represent the overarching themes under research question

2 and the light blue boxes represent the sub-themes under the larger themes.

Table 6 Qualitative thematic analysis: dark blue boxes represent the overarching themes under research question

3 and the light blue boxes represent the sub-themes under the larger themes. 82

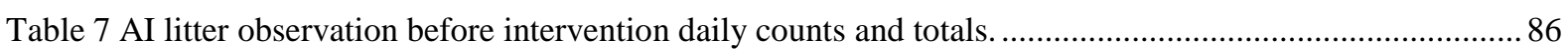

Table 8 AI litter observation directly proceeding the intervention daily counts and totals. .87 
Table 9 AI litter observation follow up from the intervention daily counts and totals.

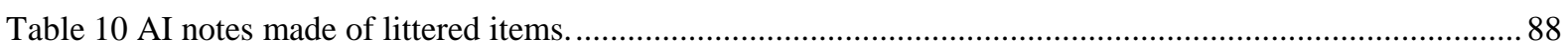

Table 11 RNI litter observation before intervention daily counts and totals. .............................................90

Table 12 RNI litter observation directly proceeding the intervention daily counts and totals. .........................91

Table 13 RNI litter observation follow up from the intervention daily counts and totals...............................92

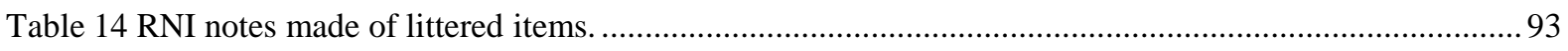

Table 15 RNI lunch observation before the intervention daily counts and totals. ...........................................95

Table 16 RNI lunch observation directly proceeding the intervention daily counts and totals. .........................96

Table 17 RNI lunch observation follow up from the intervention daily counts and totals. ............................97

\section{List of Abbreviations}

KNZB - Keep New Zealand Beautiful

EE - Environmental Education

CBSM - Community Based Social Marketing

$\mathrm{AI}$ - Avalon Intermediate

RNI - Raroa Normal Intermediate

USA - United States of America

POPs - persistent organic pollutants 



\section{Chapter 1 Introduction}

\subsection{Background}

Litter pollution is a pervasive global issue, with increasingly severe social and environmental consequences (Schultz, Bator, Large, Bruni, \& Tabanico, 2013). Resulting from waste that is incorrectly disposed of, litter is primarily a consequence of neglectful human behaviour. Sources of litter pollution include pedestrians, motorists, uncovered trucks, households, construction and demolition sites and industry (Christchurch City Council, 2016). There is evidence to suggest that a substantial amount of litter is connected with individuals' disposal of litter (MSW Consultants, 2009). A recent United States analysis of the sources of litter along roadsides and at transit points (bus stops) attributed $70 \%$ and $90 \%$ respectively to individuals (Schultz et al., 2013). The findings from this study highlight the importance of individual behaviour as a source of litter.

Attempting to minimise the volume of litter pollution entering the environment presents a challenge for modern societies, although the implications of high rates of litter pollution are apparent. Most important is the severe and long-lasting environmental impacts created by litter pollution (Schultz et al., 2013). Litter can be hazardous and unhealthy for our environment. Terrestrial litter has been known to cause vehicle accidents and injuries, start fires, attract rodents and harmful bacteria, smother or kill flora and injure or kill fauna (Levin, 
2006; Schultz et al., 2013). Litter can also cause the contamination of groundwater, blocking storm-water drains and causing flooding (Levin, 2006). Marine litter which is either directly tossed into the marine environment $(\sim 20 \%)$ or indirectly displaced from land into the marine environment $(\sim 80 \%)$ has the potential to travel long distances, damaging boat motors, getting caught in fishing nets, transporting invasive species and harmful pathogens, and negatively affecting marine life (Allsopp, Walters, Santillo, \& Johnsto, 2006; Derraik, 2002; Ministry for the Environment, 2016). Marine organisms can become entangled in litter, causing strangulation. Ingestion of litter can also cause blockages and disruptions, which can lead to illness and death. Numerous studies and sightings of organisms throughout the food chain indicate that various animal species such as whales, birds, fish and small filter-feeding mussels are negatively affected or ultimately killed by litter (Derraik, 2002; Gall \& Thompson, 2015; Gregory, 2009).

More specifically, the most apparent environmental effect created by litter is plastic marine pollution. Plastic is harmful to marine life and constitutes the majority of anthropogenic litter found in the global marine environment, with a minimum estimate of 5.25 trillion plastic particles in the world's oceans (Derraik, 2002; Eriksen et al., 2014). The detrimental effects associated with plastic pollution are numerous (Derraik, 2002). Specific to New Zealand, a study implemented in Kaikōura found New Zealand fur seals frequently came ashore tangled in plastic debris and nets, with entanglement rates of the Pinniped (Seal) clade estimated to be among the highest reported in the world (Boren, Morrissey, Muller, \& Gemmell, 2006).

Plastics are hydrophobic, allowing the absorption of low-soluble pollutants such as persistent organic pollutants (POPs) onto the surface of the plastics. Once ingested by organisms, POPs can be transferred into the tissues and organs of organisms as well as their predators (Eriksen et al., 2014). Ingestion allows both plastic and POPs to be transferred throughout the food 
chain including to humans, with the effect of POPs increasing up the food chain through biomagnification (the increase in the concentration of a pollutant) (Schneider, 2014; USGS, 2015).

Litter pollution also causes direct impacts on society. High rates of litter are regarded as aesthetically offensive and may hinder the economic development of areas (Pandey, 1990). This is observed in communities and tourist areas where litter pollution can deter businesses from investing in developing communities or can affect the appeal of tourist locations (Skogan, 2012). Litter pollution is also predictive of greater crime rates in communities, with studies showing the presence of litter may be associated with the rate of antisocial behaviours such as theft (Keizer, Lindenberg, \& Steg, 2008).

The economic, social, and environmental impacts of litter have led to campaigns in most countries targeting cleaning up and combatting the issue, resulting in, street and beach cleanups (Williams, 1996). The increasing scale of the problem means these events, while being effective in temporarily reducing litter, are becoming increasingly expensive. The expenses of cleaning up and combatting litter in New Zealand were recently estimated to be an annual sum of over $\$ 5$ million for Auckland City’s population of 1.6 million (Denne \& Wright, 2016) and \$3.6 million for Christchurch City’s population of 340, 000 citizens (Christchurch City Council, 2016).

In principle, the most effective method for significantly reducing litter pollution consists of preventing the initial production of litter, rather than minimising the downstream effects of the pollutant. 


\subsection{Behaviour Change}

Given the significant economic, social and environmental effects that result from litter, a considerable amount of research has focused on understanding and combating it. Various environmental problems including littering are rooted in human behaviour (Steg \& Vlek, 2009), and therefore can be influenced by minimising the relevant behaviour or changing it to reduce its impacts.

Individual behaviour change is an essential aspect of environmental protection, as most individuals cannot directly or materially influence government or corporate policy. However, all people consume energy and materials, and can therefore in principle implement behaviours that reduce their environmental impact. Although behaviour change is a viable option for individuals to positively influence environmental protection, the majority of people do not adequately contribute to protection (Osbaldiston \& Schott, 2012).

Environmental psychology and behaviour change research can help to understand and motivate people to engage in pro-environmental behaviours (Osbaldiston \& Schott, 2012). Over the past 40 years, litter pollution has been explored by a range of systematic behavioural research (Schultz et al., 2013). Initial studies investigated beliefs, attitudes, and self-reported behaviours associated with litter (e.g. Public Opinion Surveys, 1968). These studies were subsequently used to develop litter reduction projects (e.g. Geller, Winett, \& Everett, 1982). Since the development of behavioural research, multiple behaviour change interventions have been used to promote litter reduction (Cialdini, 2003; Duncan, 1997; Huffman, Grossnickle, Cope, \& Huffman, 1995; Sibley \& Liu, 2003). 


\subsection{Place of Research}

This study was carried out in the Greater Wellington Region of New Zealand (Figure 1).

Greater Wellington is highly urbanised and is New Zealand's third largest region, with a population of 500,000 (StatsNZ, 2018). The proportion of New Zealand residents living in urban areas has increased throughout the $20^{\text {th }}$ and $21^{\text {st }}$ centuries, with 86 percent of New Zealand's population occupying urban areas in 2001 (Cochrane \& Maré, 2018). Urban centres have been found to have high rates of litter due to a high concentration of people who contribute to the litter problem (Chapman \& Risley, 1974). In a National Litter Survey by Keep New Zealand Beautiful (KNZB), Wellington City and Region showed a moderate level of littering, sitting between the rates of Auckland (highest rate of littering), and Canterbury (lowest rate of littering) (Yates, 2018).

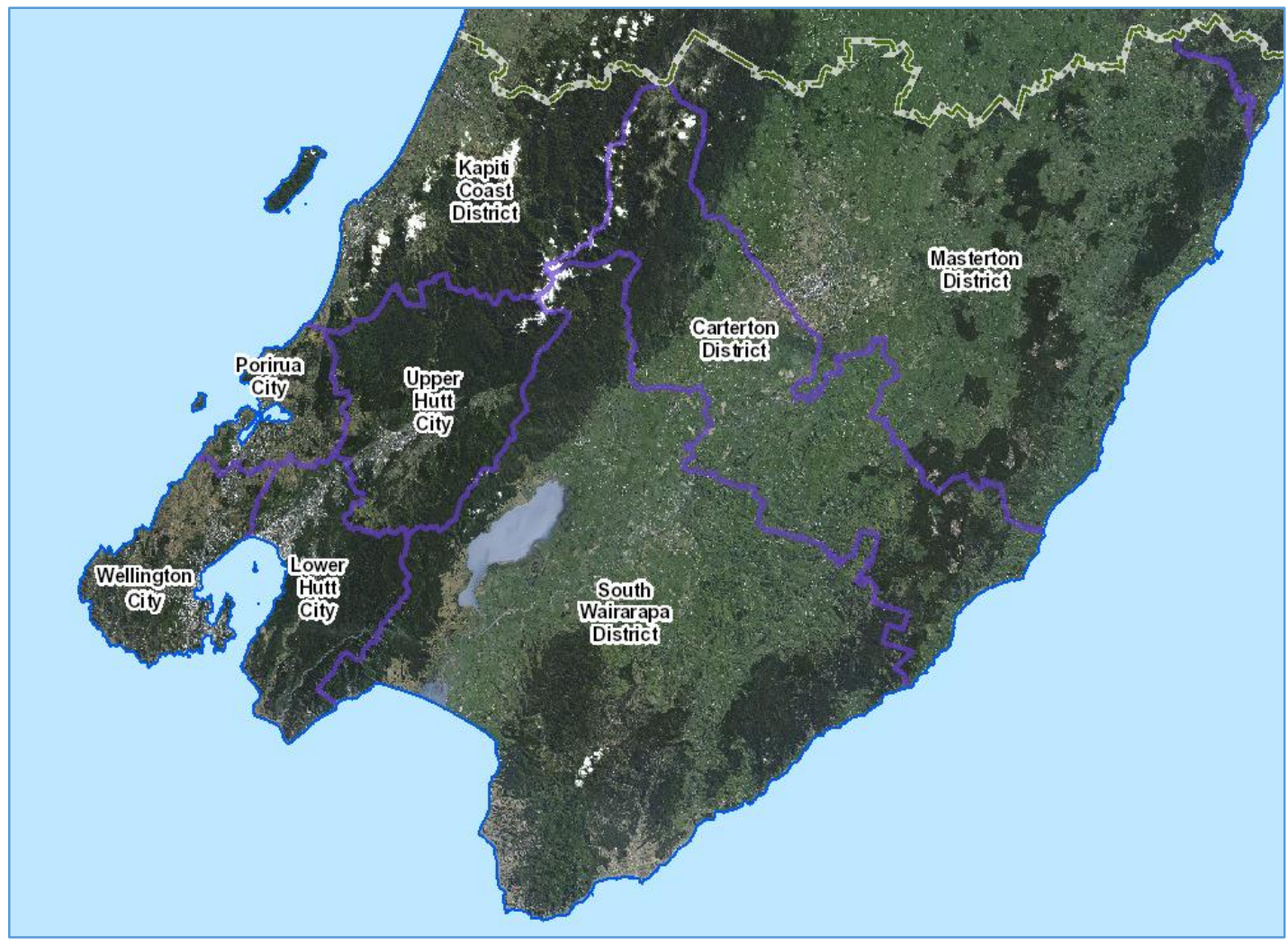

Figure 1 Map of the Greater Wellington Region showing the Territorial Authorities in the Region (GWRC, 2018). 


\subsubsection{New Zealand Schools}

New Zealand schools have identified difficulties managing litter. Schools in Wellingtons Kāpiti Coast have noted that a standard 'litter-full' lunch box produces approximately $30 \mathrm{kgs}$ of waste per year, with a medium sized school spending around $\$ 5,000$ each year to manage this waste (Kāpiti Coast District Council, 2018).

Many schools are beginning to coordinate regular litter clean-ups within schools, at local beaches, and streams or reserves with the intention of reducing litter's effects within, and outside school grounds. These initiatives are generally organised by teachers or community leaders (Kāpiti Coast District Council, 2018; Tauranga City Council, 2018).

\subsubsection{New Zealand Litter Control}

At the central government policy level, New Zealand developed the New Zealand Litter Act (1979) to reduce litter pollution in the country's ecosystems. Section 4 of the Litter Act states "KNZB Incorporated shall be the body primarily responsible for the promotion of litter control in New Zealand" (Litter Act 1979, s4, p.1). KNZB was originally founded in 1969 as the Litter Council with the aim to promote litter control throughout New Zealand. KNZB uses education and advertisement based approaches and the provision of infrastructure to promote litter control. In the past, KNZB has aimed to educate New Zealand children on being 'Tidy Kiwis', to clean and restore public areas, to sustain or plant gardens, green spaces and trees, and to install infrastructure to promote litter reduction and recycling in public spaces (Keep New Zealand Beautiful, 2018).

New Zealand charity, Sustainable Coastlines, conducted a review of the interventions in New Zealand aimed at fostering behaviour change to reduce littering. The study found litter interventions most frequently implemented education, promotion, regulation, or provision of infrastructure as behaviour change techniques (Britain, Webster, \& Vetter, 2017). The 
interventions reviewed did not consistently evaluate the project's success in creating behaviour change, and most projects were not based on a model of behaviour change. The interventions mainly used education and were small-scale and local (school or community level). Interventions which reported assessing behaviour change did not significantly induce behaviour change. Although a small number of national or broadly delivered projects were identified in the above report, based on a national survey by KNZB, 74\% of survey respondents were not aware of any litter prevention campaigns in New Zealand (Yates, 2018).

Both the national survey by KNZB and the review by Sustainable Coastlines stated the need for understanding how and why people litter and further research into the design and evaluation of behaviour change interventions to provide an example of best practice litter interventions in New Zealand (Yates, 2018; Sustainable Coastlines, 2017).

A lack of research on litter reduction, and the lack of understanding of the effects of litter in New Zealand is a key motive for this study. This paucity of research provides an opportunity to explore the effectiveness of behaviour change strategies in reducing littering behaviour in New Zealand.

\subsection{Research Aims, Questions and Contributions}

The primary aim of this research is to test the effect of behaviour change interventions on littering in a New Zealand school setting and understand the drivers and implications behind the behaviour. In order to achieve these aims the following research questions were identified as key areas of interest:

i. What are the barriers and benefits for participants and key stakeholders to perform the desired litter and packaging disposal behaviours? 
ii. What influence do key stakeholders have on intervention desired litter and packaging disposal behaviours?

iii. Does the use of behaviour change interventions influence the litter and packaging behaviour of intermediate aged school students, and if so, do such behaviours continue in the future?

Utilising the Community Based Social Marketing (CBSM) framework this research aimed to explore the influence of behaviour change interventions on litter and packaging behaviours. As well as aiming to understand the barriers to and perceived benefits of littering, and the influence of key stakeholders in reducing the rate of littering and wrapper use in New Zealand schools.

The current scientific literature lacks analysis of litter reduction interventions employed in a New Zealand context. This research aimed to contribute to the literature an understanding of why New Zealand school children litter and the effect of behaviour change interventions in a New Zealand school setting. The results generated by this thesis are of interest to researchers, intervention planners or practitioners, and policymakers wanting to reduce litter and more specifically to those designing interventions to encourage the reduction of littering and packaging use in a school setting.

\subsection{Thesis Outline}

This research will address the three aforementioned research questions through the implementation of behaviour change techniques hypocrisy and goal setting in combination with education. The research will be assessed and understood through a mixed methods approach employing semi-structured interviews and litter and wrapper counts. Chapter 1 
provides an outline of the research context and the significance of this study. Chapter 2 provides a description of the chosen framework CBSM. Chapter 3 follows steps two and three of the CBSM framework, reviewing both the barriers to and perceived benefits of littering, and the three selected behaviour change interventions. Chapter 4 follows steps four and five of CBSM, describing a pilot of the methods and the reviewed and finalised methods employed to conduct and analyse the research. Chapter 5 presents the semi-structured interview and litter and wrapper count results from this research. Chapter 6 interprets and discusses the research results in the context of the literature reviewed in Chapter 2 and concludes by providing the researches conclusions; highlighting the main findings of this thesis, the research limitations, and its relevance for practical application and future research. 


\section{Chapter 2 Framework}

The Community Based Social Marketing (CBSM) framework utilised in this thesis developed by environmental psychologist Doug McKenzie-Mohr, was based on insights and principles from behavioural science, predominantly social psychology. A guiding principle behind CBSM is that individual behaviour change is essential to achieving a sustainable future (McKenzie-Mohr, 2000).

McKenzie-Mohr recognised that behaviour change programme designers were selecting target behaviours and interventions based on intuition or their perception of "best practice". Programme designers would also invest time and money predominately into interventions to increase knowledge, to promote a positive attitude towards an issue or behaviour, or to highlight the economic advantages of a behaviour.

A number of studies have established that providing information, promoting supportive attitudes and the economic advantages of a behaviour often have little or no impact on actual behaviour (Frantz et al., 2016; McKenzie-Mohr, 2000). Instead, CBSM proposes a pragmatic approach based on the premise that interventions are most effective when delivered at a personal level through community involvement. Evaluation studies of the CBSM approach have found that it has produced effective results in encouraging behaviour change (Kennedy, 2010).

The CBSM framework encourages programme designers to approach behaviour change systematically and empirically, to maximise the effectiveness of a programme. The approach contains five steps: selecting behaviours, identifying barriers and benefits, developing 
strategies, programme piloting, and broad-scale implementation and evaluation (Figure 2).

Effective use of the CBSM framework determines which behaviours should be promoted through investigating a selection of factors which create the most significant environmental impact and will be effectively influenced. In addition, effective use encourages the application of behaviour change techniques shown to positively influence the selected behaviour (McKenzie-Mohr, 2011). The next section provides a summary of the steps in the

\section{CBSM.}

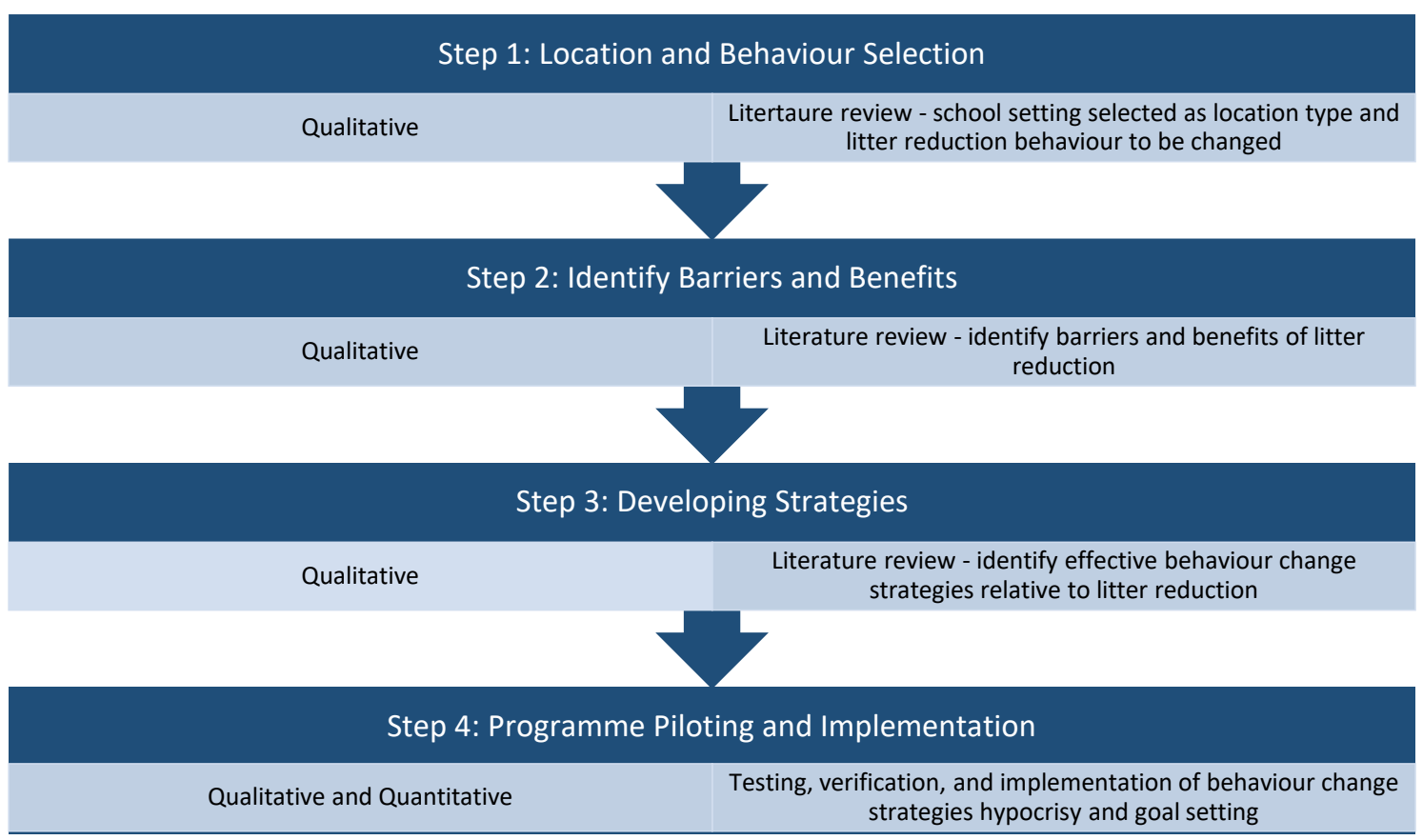

Figure 2 Step by step breakdown of the application of the CBSM framework in this study.

\subsubsection{Step 1: Selecting behaviours}

To be effectively implemented, the step of selecting behaviours requires a systematic approach. The researcher should start by determining which specific environmental impact they wish to target. An example of a specific impact is marine pollution. Once the environmental problem has been identified, the next step will estimate which behaviours 
could be promoted, e.g. behaviours which account for the most significant amount of marine pollution (McKenzie-Mohr, 2011).

The next requirement for step 1 involves comparing behaviours to determine which could be the most effective, e.g. in reducing marine pollution. Three measures are used to evaluate each behaviour, being the environmental impact, the probability of behaviour change based on programmes, and the proportion of people who do not perform the desired behaviour. The preferred method to assess environmental impact involves collecting comprehensive quantitative information. Assessing the probability of behavioural change involves reviewing past programmes in order to assess their effectiveness in encouraging the targeted behaviour

change. Lastly, the proportion of people who do not perform a behaviour can be determined by conducting observations and surveys of a target audience. CBSM promotes focusing on behaviours with the best combination of impact, probability of effect and opportunity for penetration to ensure the envisioned outcome (McKenzie-Mohr, 2011).

\subsubsection{Step 2: Identifying barriers and benefits}

Step two of the CBSM framework involves identifying key perceived barriers and benefits associated with the target behaviour (McKenzie-Mohr, 2011; Oskamp et al., 1991). CBSM recognises there may be multiple benefits and barriers relevant to the targeted audience in any sustainable behaviour, and these benefits and barriers will vary for different individuals (McKenzie-Mohr, 2011). For example, in a school setting a perceived barrier of placing litter in a bin may be conformity with what a student's friends do with their litter, whereas staff may be less influenced by peers and may not perceive this to be a barrier (Frantz et al., 2016). Once the barriers and benefits of a selected behaviour have been identified relevant to the target audience, behaviour change tools can then be considered in order to promote the selected behaviour (McKenzie-Mohr, 2011). 


\subsubsection{Step 3: Developing interventions}

This step involves developing a behaviour change intervention that will address the barriers and emphasise the benefits specific to the selected behaviour and target audience. An effective strategy will use up-to-date and peer-reviewed psychological research on behaviour change. For instance, influencing social norms and publicising peer participation in a particular behaviour tends to motivate people to change their behaviour; people are more likely to perform a particular behaviour if they see someone else performing it first (Aronson \& O’Leary, 1982; Goldstein, Griskevicius, \& Cialdini, 2007; Harré, 2011).

A programme using behaviour change techniques needs to be sure the chosen techniques directly address the barrier it is trying to change. Additionally, it can be beneficial to design a strategy that promotes the barriers and discourages the benefits of the alternative, less desired behaviour.

The motivations of those designing strategies and individual's perceived benefits of performing a behaviour may not align. The programme should promote the benefits that are a stronger motivator to the target audience. Once a strategy is complete, focus groups can be implemented with the target audience to receive feedback on the proposed strategy. If the strategy obtains approval, and no further refinements are recommended, it can be pilot tested (McKenzie-Mohr, 2011).

\subsubsection{Step 4: Programme piloting}

This step involves piloting and assessing the effectiveness of the behaviour change strategy. The pilot study helps identify potential problems on a smaller scale before investing in a resource-intensive public programme (McKenzie-Mohr, 2011). 


\subsubsection{Step 5: Broad-scale implementation and evaluation}

The final step of the CBSM involves the widespread implementation of the intervention across the community. This step involves an ongoing evaluation of the strategy and emerging barriers and benefits. New barriers and benefits can arise, and strategies that were once effective can become ineffective over time. The information gathered during the evaluation can be used to refine the strategy further or to remove strategies which are ineffective (McKenzie-Mohr, 2011). 


\section{Chapter 3 Literature Review}

\subsection{Introduction}

This chapter reviews the literature surrounding the topic of littering and behaviour change guided by the CBSM framework (Figure 2). This literature review has three sections, beginning with the identification of relevant barriers and benefits of littering, section one reviewed the barriers and benefits of an individual litterer, the environmental context, and the item littered. Following this, intervention strategies were refined based on the relevant barriers and benefits identified, participant effort required for the target behaviour, and the chosen target audience. Explored interventions included environmental education, hypocrisy, and goal setting. More specifically, interventions attributes, moderating variables and influence on behaviour change were reviewed. Lastly, based on the literature review conducted, a series of key questions for this research were identified.

\subsection{Barriers and Benefits}

Once the environmental behaviour of littering was selected, step two of the CBSM framework required identifying the relevant barriers and benefits of performing the behaviour. Three main factors can influence littering behaviour: the individual litterer, the environment, and the item littered (Wever, Van Onselen, Silvester, \& Boks, 2010). The individual litterer is influenced by cognitive variables, demographic variables, situational variables, and personal variables, further discussed below. 


\subsubsection{Individual Litterer}

\subsubsection{Cognitive Variables}

Cognitive variables including litter concern, awareness, and willingness to act against litter, often positively influence the behaviour of littering. Individuals who have low litter concern, awareness or willingness to act against litter are more likely to litter (Khawaja \& Shah, 2013). It is beneficial for an individual to be aware of the environmental problems associated with littering, and how to act to reduce their rate of littering (Kollmuss \& Agyeman, 2002; Robinson, 1976). A comprehensive body of research shows that education and information provision can assist in litter reduction in different environmental contexts (Dodge, 1972; Liu \& Sibley, 2004; Manning, 2003; Robinson, 1976; Roggenbuck, 1992; Sibley \& Liu, 2003).

\subsubsection{Demographic Variables}

Demographic variables including age, gender, education level, residence, and religious beliefs have all been found to affect the behaviour of littering (Khawaja \& Shah, 2013; Robinson, 1976; Schultz et al., 2013; Slavin, Grage, \& Campbell, 2012), though evidence surrounding some of the effects of these variables is not conclusive (Anderson, 1982; Schultz et al., 2013).

The widely recognised recurrence from observational studies is that young people, males, and those living in rural areas (vs cities) litter more often than others (Finnie, 1973; Geller, Witmer, \& Tuso, 1977; Schultz et al., 2013; Slavin et al., 2012).

Young adults, between the ages of 18 and 29, have been found to litter more often than older individuals, as found by a recent meta-analysis by Beck (2007). It has also been hypothesised by Beck (2007) that younger individuals litter more than older individuals as they may not have developed an awareness of prevailing social norms surrounding littering behaviour and environmental care (Slavin et al., 2012). Younger individuals also may not feel the same 
level of responsibility associated with littering that older individuals may feel (Slavin et al., 2012).

Within the literature, males have consistently been found to litter more than females, and females are more likely to pick up litter in a group. These results are considered a consequence of females greater care for the natural environment (Schultz et al., 2013; Slavin et al., 2012).

The claim that individuals residing in urban areas litter more than those residing in rural areas has been supported and refuted in several studies conducted in New York, United States of America (USA), and Tasmania, Australia (Anderson, 1982; Brown, Ham, \& Hughes, 2010). Geller et al. (1982) argue urban residents are more likely to litter due to littered urban areas being more socially acceptable and widespread.

\subsubsection{Personal Variables}

Personal variables, such as motivation, attitudes, social influence, and responsibility have all been found to affect the behaviour of littering (Khawaja \& Shah, 2013; Long, Harré, \& Atkinson, 2014; Pelletier, Tuson, Green-Demers, Noels, \& Beaton, 1998; Schultz et al., 2013).

Individuals behave consciously towards the environment for different reasons. Results from active research show contextual variables account for approximately $15 \%$ (site-level) of general littering acts while personal qualities account for approximately $85 \%$ (e.g., gender, age, motivation, and attitudes) (Schultz et al., 2013). Concerning both pro-environmental and non-environmental behaviours however, Kollmuss and Agyeman (2002) found that people are motivated by both situational and internal factors $(80 \%)$.

\section{Motivations and Attitudes}


Individuals can be motivated intrinsically to perform a behaviour such as putting litter in the bin, or through external motivators such as being rewarded for picking up litter on the ground (Pelletier et al., 1998).

An individual's attitudes and feelings can also affect their response to littering. A study performed in Australia found that individuals' emotions and beliefs towards the environment were a key indicator of the individual's environmental interaction (Pooley \& O'Connor, 2000). Based on the research that individuals are influenced by their motivations and attitudes, several authors suggest when educating people about the environment individuals emotions and beliefs should be targeted (Kollmuss \& Agyeman, 2002; Pooley \& O'Connor, 2000).

\section{Social Influence}

Social influence which includes social modelling, observational learning, social rewards, and punishments also affect an individual's response to littering (Cialdini, Reno, \& Kallgren, 1990). Individuals observing other's behaviour in novel situations often provides a cue about what is socially accepted or is the right thing to do, providing the opportunity for mimicry (Cialdini, 2003).

Relationships between peers, specifically friends are stated as particularly important for young individuals and are highly relevant in school playgrounds where littering can be prominent, and friends and other pupils are salient (Long et al., 2014).

\section{Responsibility}

Individuals with a broader sense of personal responsibility are more likely to perform environmentally responsible behaviours (Kollmuss \& Agyeman, 2002). Various researchers have explored the role of responsibility in relation to littering (Khawaja \& Shah, 2013). For example, laziness has been found to influence the proper disposal of litter. Individuals often 
claim this lazy behaviour is excusable due to a lack of bins around or that it is common practice; 'everyone else does it' (Khawaja \& Shah, 2013).

Individuals have also been found to litter more when the personal cost of putting litter in a bin is high regarding energy and time (Khawaja \& Shah, 2013). Littering also occurs more often when an individual is in a rush, an individual is under the impression someone else will pick it up, or when the item is not recyclable or biodegradable (Khawaja \& Shah, 2013). Furthermore, an individual's locus of control has been associated with responsible proenvironmental behaviour. People with an external locus of control believe their actions are inconsequential, and only powerful others can bring about change. Whereas individuals with a strong locus of control feel that their behaviour will create change (Kollmuss \& Agyeman, 2002).

\subsubsection{Individual Litterer and Environment}

\subsubsection{Situational variables}

Situational variables including public messages, personal and social norms, environmental context and setting have been found to affect the behaviour of littering (Brown et al., 2010; Clayton, Litchfield, \& Geller, 2013; Long et al., 2014).

\section{Public Messages}

Public messages concerning littering behaviour have been found to be effective in some environmental settings, such as camp sites, nature parks and public places (Roggenbuck, 1992). Research also suggests that messages delivered before behaviour performance will be more effective in promoting a message than messages that are received significantly earlier or later than the performed behaviour (Geller et al., 1977).

Normative Influences 
A number of studies have shown that triggering personal and social norms (descriptive and injunctive norms ${ }^{1}$ ) can decrease littering in certain situations (Cialdini, 2003). This can be achieved either through role modelling, e.g. modelling using a bin correctly in front of potential litterers, in a physical context, e.g. by maintaining a clean and litter-free area or through other means, e.g. appealing to an individual's sense of pride (Cialdini, 2003).

The majority of studies focusing on littering norms have been performed with adults, and little is known about how normative influence effects young people's behaviour. It is stated, however, the complexities of competing norms including from parents, peers, and teachers whom all play a role in influencing attitudes, motivations and behavioural outcomes cannot be captured in laboratory or field experiments (Long et al., 2014).

\section{Influence of others}

The approval or disapproval of others has also been found to be a possible punisher/reinforcer of littering (Clayton et al., 2013). For example, the research conducted in Auckland, New Zealand by Long et al. (2014) found that individuals can actively attempt to influence the littering behaviour of others. The authors found that high school participants could be influenced through hostile behaviours such as bullying and teasing, peer pressure, praising or encouraging the behaviour, in order to promote pro-environmental change or to assist in group homogeneity.

\section{Environmental Context}

Environmental context has also been found to affect littering behaviour. The environmental context of a country and community can influence pro-environmental behaviour through social influences, environmental legislation, and the availability of 'green' goods and services (Kollmuss \& Agyeman, 2002). It is has been found across different communities and

\footnotetext{
${ }^{1}$ Descriptive norms include what people typically do and injunctive norms include what people typically approve or disapprove (Cialdini, 2003).
} 
countries (USA, Latin America, Europe, and Australasia) that environmental behaviour is influenced by environmental beliefs and values, which differ between cultures, communities, and countries (Cordano, Welcomer, Scherer, Pradenas, \& Parada, 2010; Diamantopoulos, Schlegelmilch, Sinkovics, \& Bohlen, 2003).

\section{Environmental Setting}

The environmental setting in which littering occurs has been mentioned throughout the literature as being highly relevant in influencing litter behaviour (Cialdini et al., 1990; Heberlein, 1972; Reiter \& Samuel, 1980; Robinson, 1976). The environmental setting relates to where the act of littering occurs, such as the location type and the position and occurrence of litter bins.

Litter reduction has been found to be more common in an environmentally clean setting than in a littered setting (Anderson, 1982; Cialdini, 2003). Research conducted by Cialdini et al. (1990) in the USA found participants were more likely to litter in environments with litter than in clean environments. In the same study, the authors stated their findings correspond with motivational accounts described in other research. These being that individuals litter more often in a littered setting due to the perception that their waste will do less harm in a dirty environment than in a clean environment.

Another environmental setting that differs in effect when determining behaviour is providing environmental education in a classroom compared to outdoors. Two studies performed in the USA found self-reported environmental attitudes and behaviours were significantly connected to active participation in environmental actions outside the classroom and activities in nature (Dresner \& Gill, 1994; Jordan, Hungerford, \& Tomera, 1986). A metaanalysis by Zelezny (1999) examined educational interventions in both classrooms and nontraditional settings (workshops, nature camps, field studies), and assessed the effectiveness of active participation. All classroom interventions reported an improvement in pro- 
environmental behaviour. Just under half (44\%) of non-traditional setting interventions reported improved behaviour, and just over half (56\%) reported no effects. In this study, interventions which actively involved participants were more effective in improving proenvironmental behaviour than those which did not (Zelezny, 1999).

Physical context of the environment has also been shown to influence the rate of littering in an environment, a study conducted in New York, USA by Keizer et al. (2008) found that disordered environments, in particular, those with shopping trolleys left unreturned or graffiti promoted littering. The number and presence of physical bins are also an influence on littering (Cialdini et al., 1990). For example, a review by Schultz et al. (2013) found that a large number of bins does not necessarily influence litter reduction positively. Instead, one well-placed bin is more likely to influence litter reduction positively.

\subsubsection{Item Littered}

The type of item being littered has also been found to influence the frequency of littering and resistance to change behaviour. This area of influence has been subject to relatively few studies, however, it has been found that the characteristics of an item influence the behaviour of individual littering (Wever et al., 2010). For example, Williams, Curnow, and Streker (1997) found organic items, cigarettes, and small items were littered most often. The study also found an individual's perception once an item had been used affected how they disposed of it. An example of this is; food wrappers once used, were disposed of due to their messiness, whereas plastic bottles were often reused and taken away (Wever et al., 2010).

\subsection{Developing interventions}

Once the environmental behaviour of littering was selected and the barriers and benefits of performing the behaviour have been identified, intervention strategies can be refined based on the relevant barriers and benefits. 
Many behaviour change interventions have been identified to be effective in creating proenvironmental behaviour change (De Young et al., 1993; Gardner \& Stern, 1996; Geller, 2002; Harré, 2011; Osbaldiston \& Schott, 2012; Schultz, 2014; Vlek, 2000). Key techniques include cognitive dissonance and goal setting. Additional variables of information provision, instruction, justification, written and verbal prompts, making it easy, structural design, feedback, rewards, penalties, message framing, normative messages, and social modelling are not discussed in this thesis, however are discussed further in a review of litter reduction interventions by Thomas (2017).

\subsubsection{Participant effort:}

In accordance with creating or implementing an environmental intervention, it is not only important to assess the effectiveness of the techniques but also to determine which techniques require the most effort from participants, as well as considering which participants will generate the most impact (Osbaldiston \& Schott, 2012).

Some techniques engage participants at a minimal level (e.g., information provision, prompts, justifications), while other techniques require much more of an effort from participants (e.g., commitment, goal setting). Osbaldiston and Schott (2012) ranked the level of engagement required from ten treatments, with key techniques; cognitive dissonance, and goal setting requiring high individual engagement. In general low-effort behaviours require lowengagement techniques, and high-effort behaviours require high-engagement techniques to provide effective outcomes (Osbaldiston \& Schott, 2012).

\subsubsection{Target audience:}

Adults have the most significant impact on the environment; therefore, it is imperative to make them aware, get them motivated and involved through different programmes. Adults, 
however, are much more adverse to change their attitudes and behaviours (including towards environmental problems) than children are (Öllerer, 2015).

\section{Children}

Compared with adults, younger individuals are more interested in improving the environment and environmental issues and are more willing to present pro-environmental attitudes and behaviours if that is more socially desirable. Children also act as future agents to promote environmentally responsible behaviour in others, bringing a new approach from programmes into their family and community environments (Aivazidis, Lazaridou, \& Hellden, 2006; Damerell, Howe, \& Milner-Gulland, 2013; Zelezny, 1999).

Children are frequently targeted by environmental interventions, due to the above factors, as well as the fact they are less likely to have deep-rooted environmentally destructive behaviours to unlearn. Children also have a longer period in which to influence their environmental knowledge and protection (Damerell et al., 2013; Zelezny, 1999). Children are heavily influenced by interventions as they acquire new pro-environmental behaviours more readily than adults (Zelezny, 1999). Interventions targeting participants who are eighteen years or younger have been found to be more effective than those which targeted adults (Zelezny, 1999). Interventions with young participants are typically longer than with adults which may influence the intervention outcomes (Zelezny, 1999).

\section{Children and Parents}

There is growing evidence that a bi-directional approach between children and parents is effective in changing attitudes and behaviours (Payne, 2005). Natural features within a home, parenting practices, life histories and functional relationships have been recognised as having a significant effect on children's cognitive functioning and response to educational 
interventions (Emmel, 1995; Öllerer, 2015; Payne, 2005). A study produced by Damerell et al. (2013) examined the influence of wetland-related environmental education, which was attained through wetland activities on the knowledge of children and their parents and household behaviour in the Seychelles. The study found parents with children who had undertaken wetland work had significantly higher wetland knowledge than those with children who did not take part in wetland activities.

\subsection{Interventions:}

A literature review conducted prior to this research investigated 16 treatment types and their effect on environmental behaviour change, specifically related to litter reduction (Thomas, 2017). This literature review determined the importance of education, cognitive dissonance (hypocrisy), and goal setting as significant techniques in inducing behaviour change.

Environmental education was recognised by this study to be an essential prerequisite for environmental behaviour change and a fundamental part of a comprehensive litter reduction campaign (Gregory, 1974; Osbaldiston \& Schott, 2012). Cognitive dissonance (hypocrisy) and goal setting were identified as two of the most effective techniques to use alongside education to induce environmental behaviour change.

\subsubsection{Environmental Education}

Environmental education (EE) aims to influence an individual's knowledge of environmental impacts and solutions to increase awareness and create attitude change towards the environment (McGuire, 2015; Pooley \& O’Connor, 2000; Steg \& Vlek, 2009). 


\subsubsection{Education Moderating Variables}

When implementing EE, many authors have identified audience characteristics, message content and delivery, and theoretical grounding as important moderators for education to be effective (Marion \& Reid, 2007).

\section{Audience}

Understanding an audience's level of environmental knowledge and how their beliefs influence their behaviour allows an educator to select content and how to communicate the content so it will resonate best with the specified audience (Ham \& Krumpe, 1996).

\section{Message Content}

Message content is another key component to effective environmental education. Educational messages are most effective when clear, concise, engaging, and useful information is used (Doucette \& Cole, 1993; Gramann \& Vander Stoep, 1986; Oliver, Roggenbuck, \& Watson, 1985). EE messages should also be designed specifically for a defined audience and should explain desirable and undesirable behaviours, as well as practices and issues that are least understood by the target audience (Christensen \& Cole, 2000; Confer, Mowen, Graefe, \& Absher, 2000). Furthermore, when promoting environmental protection message content should focus on ecological rationales instead of social rationales (Christensen \& Cole, 2000).

\section{Message Delivery}

Message delivery has also been found to play an important part in the effect of EE (Doucette $\&$ Cole, 1993). Face-to-face message delivery has been found to have the greatest potential for influence, due to the impact of non-verbal signals, including body language, vocal tone, and the physical appearance of the presenter (Ciccia, Step, \& Turkstra, 2003). Although faceto-face communication remains a useful method, some studies found face-to-face 
communication no more effective than written content (Roggenbuck \& Berrier, 1981). EE messages promoting behaviour should also be repetitious and widespread to maximise effectiveness (McAvoy, 1984).

Lastly, theoretical grounding is also a key element in EE message effectiveness. A comprehensive understanding of relevant theoretical models can assist in developing more persuasive messages and delivery techniques (Kamp, Johnson, \& Swearingen, 1994).

\subsubsection{Education and Behaviour Change}

EE has been found to be effective in increasing the environmental knowledge of a group, in comparison to those who have not received the education (Gregory, 1974; Lee, 2016; Osbaldiston \& Schott, 2012; Richter, Rendigs, \& Maminirina, 2015). Despite this, EE has been observed to be ineffective in initiating behaviour change. Many studies show being informed is only marginally and often unreliably predictive of a related behaviour (Cone \& Hayes, 1980; McGuire, 2015; McKenzie-Mohr, 2011; Schultz et al., 2013).

Evidence from a meta-analysis by Zelezny (1999) refutes this, finding school-based education interventions produced small results in inducing behaviour change. Additionally, Zelezny (1999) reported two classroom interventions by Asch and Shore (1975), and Horsley (1977) that measured actual behaviour and used reasonably strong research methods both found respectable effects sizes (.81 and .81 respectively). These results suggest that if education is designed and distributed carefully, it can change certain types of environmental behaviour to a modest level. When barriers are present such as significant financial cost or the inconvenience of performing a behaviour however, little or no effect has been achieved when using education (Stern, 1999).

Although EE has been met with generally disappointing results when used alone, EE is argued as an essential prerequisite for environmental behaviour change, with many 
environmental psychologists and educators agreeing EE is linked to environmental behaviour change (Richter et al., 2015; Zelezny, 1999). EE has also been acknowledged as an important part of litter reduction interventions in the Asia-Pacific and USA (Fien, 2001; Levin, 2006; Loughland, Reid, Walker, \& Petocz, 2003). EE can create awareness of a litter problem, change attitudes towards litter and littering, teach individuals not to litter, motivate people to pick up litter, and influence or support norms for cleaning up litter and reducing littering (Cialdini, 2003; Hemmert, 2004; Huffman et al., 1995).

\subsubsection{Summary}

$\mathrm{EE}$ has been recognised as an essential prerequisite for environmental behaviour change and an important part of litter reduction interventions. EE has therefore been chosen as the underlying intervention strategy for two behaviour change projects implemented in this thesis. EE will lay the informational foundations to engage in litter reduction and is paired with subsequent behaviour change techniques to create behaviour change, which will be discussed in the following sections.

The objective of the education interventions should not be to control the participant's behaviour, instead provide the cognitive basis as well as the behavioural techniques to encourage appropriate low impact behaviour, in this instance to litter less, reduce packaging consumption and to clean more (Marion \& Reid, 2007).

\subsubsection{Cognitive Dissonance and Hypocrisy:}

Behaviour change interventions can be paired with education to incentivise individuals and communities to engage in litter reduction. Cognitive dissonance has been found to be highly effective in promoting behaviour change (Elliot Aronson, 1999; Osbaldiston, 2003; Osbaldiston \& Schott, 2012). 
The theory of cognitive dissonance was first described by Leon Festinger (1957) as the psychological inconsistency between two cognitions (e.g. beliefs, actions); when an individual realises an inconsistency between one of their beliefs or actions, it produces a threat to their self-concept and self-integrity resulting in a negative state of cognitive discomfort.

The discomfort or tension an individual feels because of the inconsistency between their beliefs and actions promotes changing either their beliefs or actions to be aligned. Festinger hypothesised that the psychological methods people use to align their beliefs and actions could result in meaningful and long-lasting changes in the way people act and observe their social world (Festinger, 1957).

\subsubsection{Hypocrisy Attributes}

Hypocrisy is a useful paradigm under the rubric of the cognitive dissonance theory, which was first theorised by Elliot Aronson (Aronson, 1992; E Aronson, 1999; Aronson, Fried, \& Stone, 1991).

Hypocrisy promotes cognitive dissonance by making an individual conscious of a preexisting contradiction between their belief and their behaviour. People can be made conscious of their contradiction through two tasks.

Firstly, an individual is asked to advocate the importance of a pro-social/environmental behaviour publicly. For example, individuals could provide a small speech to convince others of the importance of performing a behaviour which they consider will positively affect the health and wellbeing of specific individuals or the whole of society. Publicly advocating a message to an audience (in combination with task two of hypocrisy) provides more cognitive dissonance and thus induces behaviour change, compared to simply reading about the significance of completing the behaviour (Aronson et al., 1991; Stone, Aronson, Crain, Winslow, \& Fried, 1994; Stone, Wiegand, Cooper, \& Aronson, 1997). 
The second task of the hypocrisy technique seeks to make individuals mindful of their past failures to perform the behavioural standards they have previously advocated (Stone \& Fernandez, 2008). This can be achieved by making an individual create a list of their explanations for not performing the target behaviour when they had the opportunity. In order for an individual to identify their previous behaviour as different from their public advocacy, they must concentrate on their own past failures to perform the targeted behaviour. Concentrating on other individuals past failures to perform a behaviour may cause an individual to conclude that most individuals do not support the behaviour, or that most individuals fail to perform the behaviour; therefore dissonance may not be triggered (Stone \& Fernandez, 2008; Stone et al., 1997).

Many cognitive dissonance studies show that when individuals are made aware of the inconsistency between their beliefs and behaviour, in order to justify their lack of behavioural consistency, individuals will change their beliefs and attitudes to be consistent with the discrepant behaviour (Cooper \& Fazio, 1984; Festinger \& Carlsmith, 1959; Tavris \& Aronson, 2008). In contrast, hypocritical inconsistencies have been found to motivate people to take the required steps to make their behaviour consistent with their attitudes and beliefs. Thus, an act of hypocrisy provokes a form of dissonance that drives people to take action (Stone \& Fernandez, 2008).

\subsubsection{Hypocrisy Moderating Variables}

Several variables have been found to affect the influence of the hypocrisy condition at changing behaviour. There are two factors following the influence of hypocrisy that make behaviour change the primary strategy to reduce dissonance. 
Firstly, when an individual advocates a pro-social/environmental behaviour to others, the use of well-established normative standards for promoting the behaviour can make the cognitions challenging to change or alter, thus promoting behaviour change.

However, if a past behaviour is accepted as a normative standard, an individual may not feel dissonance. An individual's view of a normative standard is highly influenced by the normative perceptions of others (Stone \& Fernandez, 2008). Others normative perceptions can have a big influence on individuals' engagement in advocating for a behaviour and accepting personal responsibility for past behaviour (McKimmie et al., 2003).

Secondly, when an individual is made mindful of their past failures to practice an advocated behaviour, the contradiction between their past behaviour and the advocated behaviour triggers highly significant cognitions connected to their perceptions of self-integrity. According to Stone et al. (1997), an individual's perception of self-integrity stems from their beliefs about sincerity and honesty. Maintaining or restoring perceptions of self-integrity after a hypocritical act requires an individual to act more sincerely and honestly than in the past. Therefore when an individual realises they did not act in line with their beliefs, they will be encouraged to be sincere and honest about how to perform the target behaviour, which is most directly achieved by an individual changing their behaviour to align with the advocated behaviour (Stone \& Fernandez, 2008)

\subsubsection{Hypocrisy and Behaviour Change:}

The hypocrisy condition provides a framework for advocating, understanding, and performing relevant behaviours. Hypocrisy has been used to induce behaviour change in many areas including targeting social behaviours (Aronson et al., 1991), and environmental management (Dickerson, Thibodeau, Aronson, \& Miller, 1992). Literature presents multiple studies which show that when applied appropriately, the hypocrisy condition is effective in 
motivating individuals to either learn about a behaviour's benefits and how it is performed, start and continue a new behaviour, or improve how often or the level of performance a target behaviour is completed (Stone \& Fernandez, 2008).

A consensus is yet to be formed regarding how well hypocrisy motivates behaviour change in the long term however, presenting an important consideration for the use of this technique (e.g. Aronson et al., 1991; Kantola, Syme, \& Campbell, 1984).

Studies intended to influence conservation and natural resource management have shown some of the most direct evidence that the hypocrisy technique motivates behaviour change (Dickerson et al., 1992; Kantola, Syme, \& Campbell, 1984).

One example, performed by Dickerson et al. (1992), intended to promote water conservation in a campus recreational pool. Female swimmers were questioned in the women's changing rooms about their opinion on water conservation. Once the experimenter established the participants supported water conservation, half were randomly allocated to a mindfulness group as a part of the hypocrisy condition. Those participants completed a survey which highlighted the individual's past failures to conserve water (e.g. "Do you always make your showers as quick as possible, or do you sometimes shower longer than necessary?") (Dickerson et al., 1992, p. 846). After this, half of all participants were asked to advocate water conservation publicly on campus by writing their name on a flyer which read: "Please conserve water. Take shorter showers. Turn showers off while soaping up. If I can do it, so can you!" (Dickerson et al., 1992, p. 847).

To assess water use, the length of a participant's shower and the frequency the shower was turned off, was measured. The results showed, the hypocrisy group had significantly shorter showers and turned the shower off significantly more while they applied soap or shampoo compared to the no-treatment control groups. Both the reminder of past failures and the 
public advocacy to conserve water were no more successful when in combination than when used alone.

\subsubsection{Summary}

Across a range of settings and subjects, research shows the hypocrisy condition to be an effective technique for promoting behaviour change towards pro-social/environmental behaviours. Additionally, studies have found the hypocrisy technique is most effective when individuals advocate the significance of a target behaviour publicly and then are privately made mindful of their past failures to complete the targeted behaviour (Stone \& Fernandez, 2008).

Importantly for this thesis, there are significant gaps in the published literature regarding the application of the hypocrisy technique. Cognitive dissonance has been found to be among the most effective techniques within the domain of pro-environmental behaviour. However, it is one of two strategies which have been stated as least studied (Osbaldiston \& Schott, 2012). Additionally, there are no published cognitive dissonance/hypocrisy studies which have focused on litter or packaging reduction, worked with young participants in a school setting (below university level), or combine the two. There are also no cognitive dissonance/hypocrisy studies in the environmental domain, which have used follow-up assessment, and few cognitive dissonance/hypocrisy studies located in New Zealand.

\subsubsection{Goal Setting}

The theory of goal setting was first theorised as a cognitive theory of motivation by Locke and Latham (1990). A goal is defined as an aim or objective of an action (Latham \& Locke, 1991), for example, to achieve a specified target of expertise, within a stated time (Locke \& Latham, 2002). Goal-setting theory was developed from a series of organisational and industrial psychology experiments (Locke \& Latham, 2002), which were used and adapted to 
explain and modify behaviour across many fields of work over the past four decades (Epton, Currie, \& Armitage, 2017), including environmental behaviour (McEwan et al., 2015; Osbaldiston \& Schott, 2012).

The process of setting goals promotes behaviour change and facilitates in achieving performance outcomes by directing individuals' actions, encouraging the formation of strategies, initiating effort on-task, and facilitating task perseverance (Locke \& Latham, 2002; Locke \& Latham, 2006; Locke, Shaw, Saari, \& Latham, 1981).

\subsubsection{Goal Setting Attributes}

Goals have two core attributes in relation to promoting performance; content and intensity (Latham \& Locke, 1991; Locke \& Latham, 1990, 2013).

\section{Content}

Goal content is defined as the result or object being attained (e.g. increased litter pick-up by 30\%). Content as an attribute has two aspects; difficulty and specificity. Goal content can be considered easy (attempt to complete five answers in 5 minutes), moderate (attempt to complete 10), difficult (attempt to complete 15), or unachievable (attempt to complete 50). Goal content can fluctuate from specific (attempt to complete this task in the next 20 minutes with a score of 40 correct'), to vague ('work on this task') (Locke \& Latham, 2013).

\section{Difficulty}

Goal difficulty is defined as the level to which the goal that is set exceeds that which would usually be achieved (Epton et al., 2017). Difficulty is an individually subjective control over the effectiveness of goal setting theory. The difficulty of a goal or task is dependent on each individual's experience and ability relative to a specified goal. Results from numerous studies portray a consistent linear relationship between the degree of goal difficulty and task performance. Given an individual has acceptable commitment and ability to achieving the 
goal, and the more difficult the goal, the better the performance of a goal (Locke \& Latham, 2013).

A meta-analysis found difficult goals have a stronger effect on behaviour change than easier goals. Easy and moderate goals were effective but presented a small effect compared to difficult goals (Epton et al., 2017). These findings have been attributed to individuals modifying the amount of effort they provide, dependent on the difficulty of a goal (Latham \& Locke, 1991).

Specificity

The second aspect of goal content is that specific and difficult goals are more effective in promoting performance behaviour than vague and difficult/easy goals or no goals being set. This effect is quantified in a number of studies, including Locke et al. (1981), who found $96 \%$ (51 out of 53) of studies reviewed reported the advantage of participants receiving a specific and difficult goal.

In contrast, vague goals have a subjective definition, therefore what constitutes performance success is also subjective and can be compatible with many outcomes, including performance results that are less than an individual's actual best (Latham \& Locke, 1991; Locke \& Latham, 2013). By setting a specific difficult goal, the ambiguity of what constitutes the appropriate level of performance is removed (Latham \& Locke, 1991; Locke \& Latham, 2013).

\section{Intensity}

The second overarching attribute of goal setting is intensity. Goal intensity refers to the mental process of making a goal, which requires effort, or the degree to which an individual commits to achieving a goal, and the position individuals place a goal in their individual goal hierarchy (Locke \& Latham, 2013). 


\subsubsection{Goal Setting Moderating Variables}

In their theory, Locke and Latham (2013) also describe the variables that influence the performance of a specific, difficult goal. The theory of goal setting states the variables knowledge, commitment, social influence, task complexity, situational constraints, and challenge or threat influence the effect of goal setting (Locke \& Latham, 2013).

\section{Knowledge}

Goal setting theory reports that an individual's level of skill or knowledge relative to a set goal will affect their goal performance. If people lack the skill or knowledge required to obtain the specified level of performance, individuals will not be able to achieve the behaviour (Locke \& Latham, 2013). Latham and Seijts (2016) have stated individuals with low knowledge relative to a task need to gain relevant task knowledge, and then concentrate on achieving the task. If an individual concentrates, first on achieving a task, they will typically be distracted from performing well.

\section{Goal Commitment}

Goal commitment affects the relationship between goals and performance outcomes (Locke \& Latham, 2013). Goal commitment refers to an individual's determination or attachment toward achieving a goal (Zetik \& Stuhlmacher, 2002). Difficult goals have been found to produce more positive and significant performance when individuals have high compared to low commitment to a goal (Erez \& Zidon, 1984; Klein, Wesson, Hollenbeck, \& Alge, 1999; Latham \& Seijts, 2016).

\section{Social Influence}

An individual's goal performance can be influenced by peers, social norms, authority and punishment (Earley \& Erez, 1991; Locke \& Latham, 2002; Locke \& Latham, 2013). 
Competition amongst peers, for example, has been found to improve goal performance (Anderson \& O'Reilly, 1981; Latham \& Saari, 1979). Individuals have been found to set significantly higher goals and perform significantly better in a competition condition than those in a control condition (Mueller, 1983).

\section{Task Complexity}

Goal performance is also affected by task complexity (Locke \& Latham, 1990). Individuals vary greatly in their ability to manage and achieve tasks. The effectiveness of goal setting is larger with more straightforward tasks than complex tasks (Locke \& Latham, 2013).

Furthermore, complex tasks are more achievable by a group of individuals, as the abilities of individuals within a group exceed single individuals (Kleingeld, van Mierlo, \& Arends, 2011).

\section{Situational Constraints/Resources and demographics}

Situational and resource constraints affect an individual's ability to perform of a goal. If an individual does not have access to the necessary resources to achieve a goal, goal commitment is more likely to be low (Locke \& Latham, 2006).

\section{Challenge or threat}

Lastly, if a goal is considered a challenge an individual will perform at a higher level than an individual who considers a goal a threat (e.g. to their self-belief) (Locke \& Latham, 2013). This finding has been attributed to the triggered frustration and anxiety that a threat can cause, which can negatively affect an individual's goal achievement strategy and overall goal performance (Latham \& Seijts, 2016).

\subsubsection{Goal Setting and Behaviour Change}

Goal Setting Theory provides a framework for envisaging, explaining, and promoting behaviours. Goal setting is one of the central strategies used in government agencies and 
public bodies, and a main component in assisting individual behaviour management (Epton et al., 2017). Goal setting has been used in many areas, such as targeting education (Bandura \& Schunk, 1981), social behaviours (Madera, King, \& Hebl, 2013) and environmental management (Osbaldiston \& Schott, 2012).

Multiple studies have effectively influenced conservation and natural resource behaviour including solid waste management and recycling (Lingard, Gilbert, \& Graham, 2001; McCaul \& Kopp, 1982), and purchasing behaviour and social norms (Bamberg, 2002; Lindenberg \& Steg, 2007).

Two examples of solid waste management which were influenced by goal setting include Hamad, Bettinger, Cooper, and Semb (1980) and Lingard et al. (2001). Hamad et al. (1980) implemented a paper-recycling programme in an American Primary School. The programme was implemented over an eight-month period, assessing the separate effect of goal setting, feedback, and self-recording. The largest amount of paper was collected during the goal setting condition, and the highest amount of student participation occurred during the selfrecorded condition.

Lingard et al. (2001) implemented solid waste reduction and recycling in a construction site in Australia, using goal setting and posted feedback. To improve the reduction and recycling of concrete and timber, targets and performance goals were set by all personnel from each site. Recycling performance was measured and posted as feedback charts, presented at four on-site lift locations. Results showed that the efficiency of material usage and solid waste that would be sent to landfill was effectively reduced at the source or re-used. However, recycling performance did not significantly improve; it was noted that this might have been influenced by the way construction employees perceived recycling's costs and benefits. 


\subsubsection{Summary}

Goal setting is shown to be an effective tool for promoting behaviour change across a variety of settings. Additionally, research shows goal setting is most effective when goals are specific, and difficult compared to vague easy goals or no goal at all.

These explored findings have located significant gaps in the published literature regarding the application of goal setting. Goal setting has been found to be among the most effective techniques within the domain of pro-environmental behaviour; however it is one of two strategies which have been stated as least studied (Osbaldiston \& Schott, 2012).

Additionally, there are no published goal setting studies which have focused on litter or packaging reduction, few goal setting studies that have worked with young participants, and no studies that have combined the two. There are also few goal setting studies in the environmental domain that have used follow-up assessment and no goal setting studies located within New Zealand.

\subsection{Research Questions}

From the literature review conducted, a series of key questions for this thesis have been identified, detailed below:

i. What are the barriers and benefits for participants and key stakeholders to perform the desired litter and packaging disposal behaviours?

ii. What influence do key stakeholders have on intervention desired litter and packaging disposal behaviours?

iii. Does the use of behaviour change interventions influence the litter and packaging behaviour of intermediate aged school students, and if so, do such behaviours continue in the future? 


\section{Chapter 4 Methodology and Research Design}

\subsection{Introduction}

This chapter describes the methods used to address the aims of this research. An epistemological approach of pragmatism guided this research, with both qualitative and quantitative methods used to collect data. To collect data, semi-structured interviews were conducted with student, parent, and teacher participants. The interviews employed were analysed through thematic analysis, which identifies, analyses, and describes patterns within a data set. In addition, litter and wrapper counts were conducted within Intermediate School grounds. The counts were analysed through the programme SPSS using a statistical paired $t$ test.

\subsection{Epistemological Approach}

The epistemological approach chosen as the guide to this research is pragmatism. Pragmatism accepts there are multiple realities; current truth, knowledge and meaning are ambiguous and continue to change (Onwuegbuzie \& Collins, 2010). The approach of pragmatism is flexible to research design, and it takes into account the context, and aims of a study, so the approach best fits the research questions (Ritchie, Lewis, Nicholls, \& Ormston, 2013).

Pragmatic research is appropriate for methods assessing environmental problems, as it is action-oriented, focussing explicitly on the consequences of research and solving common social and practical problems. The focus on problem-solving promotes the use of context- 
specific methods when exploring research questions, allowing the researcher to best understand the problem in order to provide both practical solutions and theoretical understanding. As such, this allows mixed methods to be employed by drawing on the strengths of both qualitative and quantitative methods of analysis to best answer research questions (Onwuegbuzie \& Collins, 2010; Ritchie et al., 2013).

The use of mixed methods has been challenged in the literature, stating due to epistemological differences mixed method results cannot be combined in a significant way (Bryman, 2004). In contrast, others believe mixed methods can produce the most informative, useful and balanced results compared to research which does not explore the benefits of combining both qualitative and quantitative methods (Creswell, 2014; Onwuegbuzie \& Collins, 2010).

\subsection{Reflexivity}

Reflexivity is a process of self-evaluation throughout the research process, which provides information about the positionality of the researcher, and can affect the collection and analysis of data (Dowling, 2010). In the study of social sciences maintaining reflexivity is crucial for recognising and responding to how the positionality of both the researcher and participants will enhance or inhibit the research interactions and the information collected (Dowling, 2010).

The researchers' positionality within this research is that of a 22-year-old female from a middle-class family, who attended three lower decile ${ }^{2}$ schools in a small rural town in the

\footnotetext{
${ }^{2}$ Deciles measure the socio-economic situation of a school's student community compared to other schools throughout the country (Ministry for Education, 2017).
} 
Western Bay of Plenty of New Zealand. The researcher is Pākehā and university educated in the fields of environmental and biological science.

By maintaining critical reflexivity in this study, transparency is created in the research process, allowing comprehensive and reproducible results to be produced.

\section{Maintaining Positionality}

The aspects of positionality that are of particular importance for this research are societal structures and behaviours, specifically power relations and the researchers' objectivity, subjectivity and intersubjectivity (Teye, 2012).

Societal structures and behaviours act to shape, research, the researcher, and their influence on society. Gathering and interpreting social information involves interactions that can be affected by the expectations of individuals, social norms, and power relations (Dowling, 2010).

Power relations were evident between the researcher and the main participants in this research. This research involved presenting information directly to children and interviewing both children, teachers and parents. As a result of this, the researchers' power relations with these participants differed from one situation to another. Teachers and parents were in a position of influence relative to the researchers' position, and the children were in a lower position of power compared to the researchers' position.

To maintain reflexivity, the researcher attempted to treat those in positions of influence with the same respect as those in positions of less power. For example, during interviews, all participants' perspectives were considered with equal respect. The researcher also made sure to allow those in positions of influence to provide research guidance but was careful not to let 
these participants dictate the research within control. The researcher was also careful not to take advantage of the participants in less powerful positions to gain information.

When considering objective research, for a researcher to maintain objectivity during quantitative data collection, it is stated there can be no interactive relationship between data collection, interpretation and the researcher (Dowling, 2010). However, Dowling (2010) states a researcher's perspective and history makes detached interpretation difficult, if not unattainable.

In this study, objectivity was controlled for during litter and wrapper count data collection. The researcher maintained objectivity in the interpretation of rubbish and wrapper particles by having only the researcher conducting the litter and wrapper counts and using a litter or wrapper identification spreadsheet. In some instances, the interpretation of the data did vary due to contextual variables, making it more subjective. For example, when a storm delayed counts for several days, planted areas had leaves and plant material blown away, revealing old, and dirty pieces of rubbish. Old rubbish was not counted, for it was not new litter.

Within this study subjectivity and inter-subjectivity is described in relation to qualitative research methods. The qualitative methods included child, teacher, and parent interviews. To maintain reflexivity during the interviews, the researcher refrained from making a comment or prompting participants whenever possible.

\subsection{Research Methods}

This study employed mixed methods to quantify and understand the influence of behaviour change interventions on the rate and amount of litter dropped in two intermediate schools and the amount of wrappers in individual's lunch boxes in a single intermediate school. In both 
case studies (Avalon Intermediate (AI) and Raroa Normal Intermediate (RNI)), quantitative methods were used in the form of litter counts before, directly proceeding, and after the behaviour change interventions.

Lunch box wrapper counts were performed at RNI School before, directly proceeding, and after the behaviour change intervention. Qualitative methods were used in both case studies in the form of semi-structured interviews, after the behaviour change interventions, interviewing children, teachers and parents (parents were only interviewed in the RNI case study).

Both quantitative and qualitative data were used to bring together the strengths of both forms of research to compare and confirm results. Quantitative methods were employed to assess the effect of behaviour change interventions on the targeted behaviours, and qualitative methods were used to further understand the causes of the behavioural results. Mixed methods offer a tool for interpreting multifaceted problems in context (Sharan, 2002), assisting a researcher in providing practical solutions and theoretical understanding, fitting with a pragmatist approach.

\subsubsection{Case Studies}

Two case studies were chosen as a method of inquiry to answer the research questions pertinent to this thesis. Case studies produce a snapshot of evolving practices, spaces and places, for a specific period in the case location, produced through the interpretation of the researcher. These snapshots allow the production of context-specific and practical interpretations of real-life practices and environments (Miles, 2015). The use of case studies aligns with a pragmatic approach (Onwuegbuzie \& Collins, 2010).

School settings are frequently used for case studies, as they provide the opportunity to observe school life, and student and teacher life in the school environment (Yin, 2011). This 
is important in exploring how behaviour change interventions influence behaviour decisions in these settings and why. Case studies also assist in understanding how settings influence the behaviour change interventions and behaviour decisions (Baxter \& Jack, 2008). The two case studies chosen for this research are AI situated in Lower Hutt City's Avalon suburb, and RNI situated in Wellington City's Johnsonville suburb, both located in the region of the Greater Wellington, New Zealand.

These two case studies were chosen based on their similarities and differences. Key similarities included their location within the Greater Wellington Region of New Zealand. Both schools indicated a concern with the litter problem within schools grounds. The schools also indicated past failed attempts at addressing the litter problem, which included weekly rubbish pick-ups, and educating children about the severity of the litter problem within their school. RNI School also indicated a past attempt at introducing wrapperless lunches.

These two case studies were also chosen based on their geographical (Figure 3), and perceived economic and social differences. These contextual similarities and differences may have allowed the cases to offer a broader range of results relative to these variables (Baxter $\&$ Jack, 2008). 


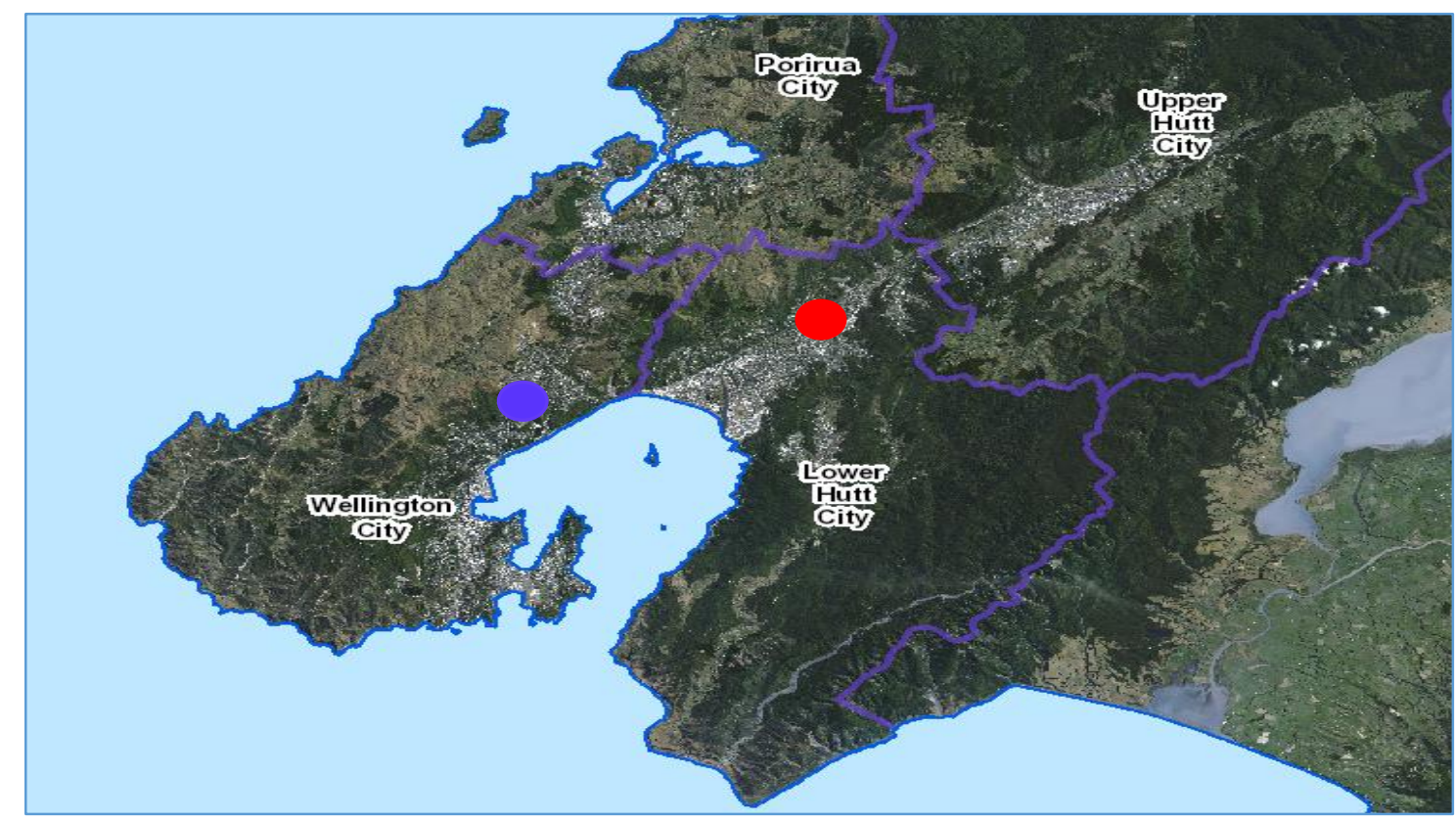

Figure 3 Case study locations in the Greater Wellington Region, New Zealand. AI (red dot) located in Avalon, Lower Hutt City, and RNI (blue dot) located in Johnsonville, Wellington City (GWRC, 2018).

\subsubsection{Research Design}

This study employed a mixed methods research approach, following a mixed methods triangulation design (Figure 4). In this design, both the quantitative and qualitative data were separately collected, with equal weight, and within the same period. Following data collection, the different findings were merged for analysis. This design was chosen to compare mixed method findings, and to connect quantitative results with qualitative findings, in order to determine significant and valid conclusions relevant to the research questions (Creswell \& Plano Clark, 2007).

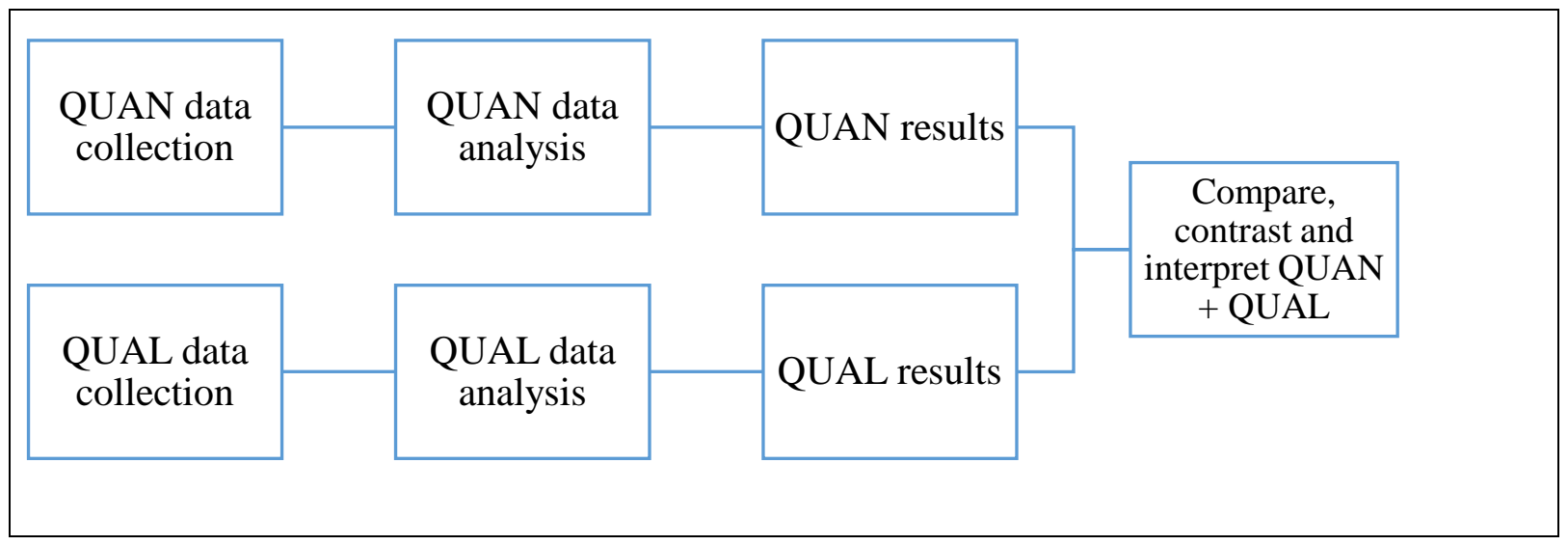

Figure 4 Triangulation Design: Convergence Model (Creswell \& Plano Clark, 2007). 


\subsubsection{Case Study One: Avalon Intermediate School}

This study used both quantitative and qualitative methods to test the hypocrisy paradigm under the theory of cognitive dissonance, which predicts that a public commitment combined with a private acknowledgement of personal past failures will influence an individual's behaviour positively. In this case, for intermediate aged children to drop litter less at AI School (Creswell \& Plano Clark, 2007).

\section{Participants and Setting:}

AI School is situated in the Greater Wellington Region's Lower Hutt City. The school has 195 students and 23 teaching and support staff, with nine main homerooms, and six additional classrooms. Of the 23 staff, nine homeroom teachers participated in the intervention procedure.

Three outdoor observation sites (Figure 5) were chosen as litter count areas due to their proximity to classrooms, seating and bin availability, and the likelihood of students using the area. Site one (Figure 5) is situated outside seven classrooms and includes an extensive seating area and five bins. Site two (Figure 5) is situated outside three classrooms and includes a basketball court and sports turf. This area contains a minimal-medium sized seating area and three bins. Site three is situated outside four classrooms and includes a paved and grassed area, minimal seating and five bins.

Participants in this case study included intermediate aged students who provided litter count and interview data, and teachers who provided interview data. 


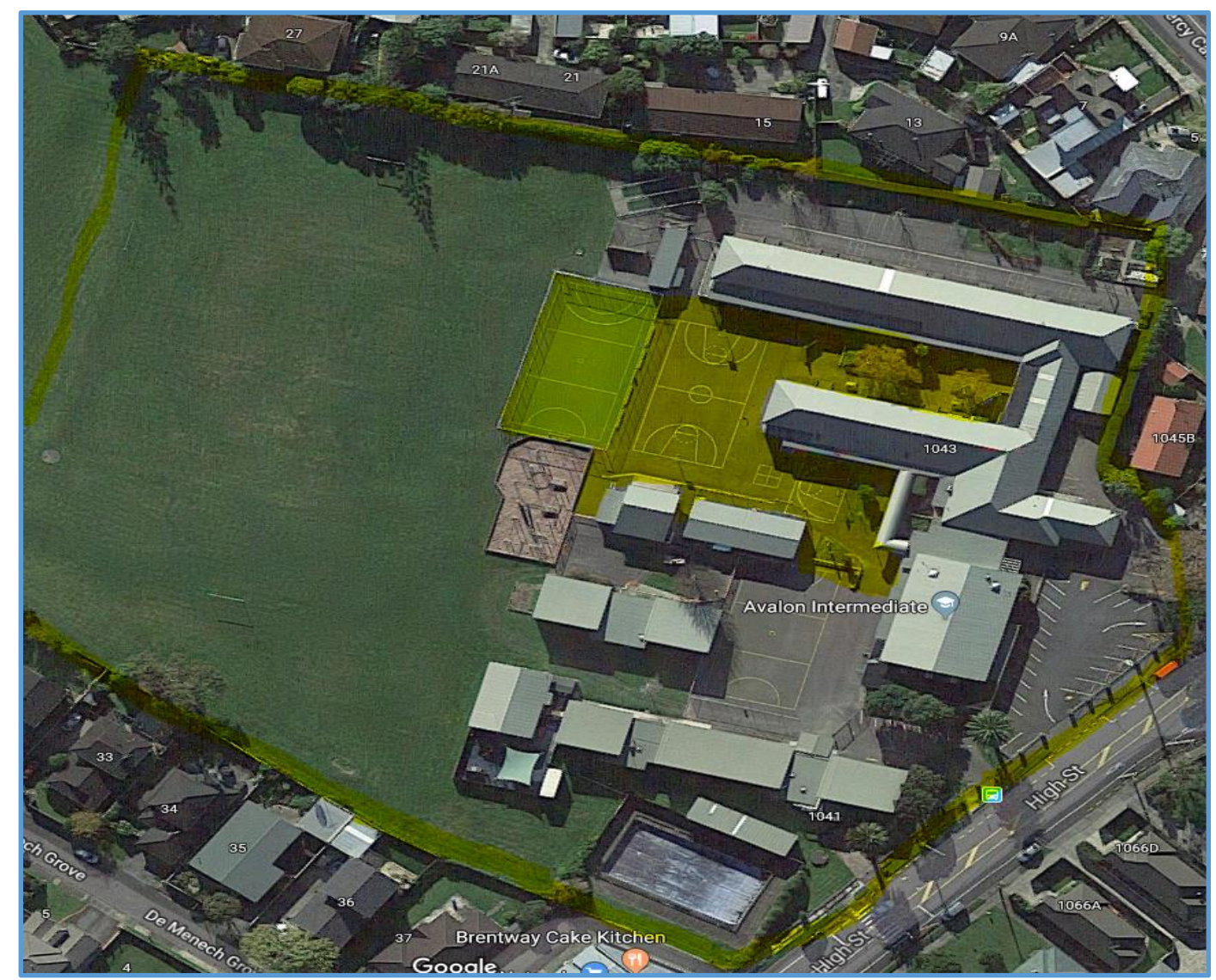

Figure 5 AI School in Lower Hutt City (school boundary and observation sites highlighted in yellow) (Google Maps, 2018a).

\section{Implementation:}

Under the overarching triangulation design, this case study used an $A B A B$ design. $A B A B$ design is a single-case design in which the intervention condition response is compared to baseline responses recorded before the intervention, and with a follow-up response (Christensen, Johnson, Turner, \& Christensen, 2011). The ABAB design used in this study employed the following four phases: (a) baseline, (b) hypocrisy condition, (c) return to baseline, and (d) follow up (Wine, Freeman, \& King, 2015).

Baseline: Prior to implementation, research methods were piloted and adjusted following step four of CBSM, ready to be implemented. Quantitative data was collected using a tabled checklist coding scheme (Table 1) of predetermined categories to assess litter amounts within the three sites in the School. This scheme was chosen as it is efficient, fast and minimises 
recording inaccuracy (Kitchin \& Tate, 2000). Data collection occurred over seven consecutive days (weather dependent). Day one of the counts were discarded from analysis due to the data collected representing both old and new litter. Day two to seven recorded daily litter dropped. Litter counts were performed after school hours so as not to provoke inquiry from the students and to avoid modelling the behaviour of picking up rubbish or promoting a clean environment. This decision was based on two studies, which found modelling the behaviour of litter pickups, and a clean environment positively influences litter reduction (Cialdini et al., 1990; Huffman et al., 1995).

Littered items were assessed and categorised based on the material makeup (plastic, wood, paper, food, metal, and glass) and size of the item (macro $(>1 \mathrm{~cm})$ vs micro $(<1 \mathrm{~cm}))$ (Consulting, 2015). Plastics were characterised into hard and soft categories, paper included cardboard, cotton, clothing and toilet paper and other included wood, glass, crayons and gum. Week two and three of litter counts incorporated counting the percentage of plastic items which were 'wrappers'. These items were categorised into categories torn and whole, representing a torn or whole piece of plastic food wrapping. The differentiation between whole and torn plastic was made based on the assumption that torn plastic is more likely to have been accidentally dropped due to its smaller size versus larger items which are more visible when dropped (accidental or not) (Wever et al., 2010). Littered items considered were items which looked to be discarded for the long term, this did not include such things as clothing, and lunch boxes.

Plastics were the only items categorised into size, as they were the main littered item targeted in the interventions. Micro plastics were identified as being smaller than a thumbnail $(<1 \mathrm{~cm}$ in diameter) and macro plastics larger than $1 \mathrm{~cm}$ and typically $<30 \mathrm{~cm}$. All items were picked up, identified and categorised. During the counts some items (often larger) were marked and 
intentionally left behind, the remaining items were taken from the setting. Marked items were left behind to maintain a similar level of litter in the setting; to avoid influencing littering behaviour.

Table 1 Litter count sheet AI School

\begin{tabular}{|l|l|l|l|l|l|l|l|}
\hline $\begin{array}{l}\text { Week } \\
1\end{array}$ & $\begin{array}{l}\text { Macro } \\
\text { Soft } \\
\text { Plastic } 1 \\
\text { s }\end{array}$ & $\begin{array}{l}\text { Macro } \\
\text { Hard } \\
\text { Plastics }\end{array}$ & Paper/card & Food & Tin/metal & $\begin{array}{l}\text { Micro } \\
\text { Soft } \\
\text { Plastics }\end{array}$ & $\begin{array}{l}\text { Micro } \\
\text { Hard } \\
\text { Plastics }\end{array}$ \\
\hline Area 1 & & & & & & & \\
\hline Area 2 & & & & & & & \\
\hline Area 3 & & & & & & & \\
\hline
\end{tabular}

Procedure: The interventions education and hypocrisy were selected for implementation by the researcher in collaboration with AI stakeholders. These techniques were chosen based on their workability in Avalon's school environment and its positive effect in the literature. The intervention implementation of education and hypocrisy also followed the programme piloting step in CBSM described earlier.

\section{Intervention Pilot}

Due to time and feasibility constraints, a small pilot participant size of intermediate aged children provided feedback on the intervention process. No implementation issues were detected. Feedback provided by participants included further expanding the use of examples and pictures to provoke an empathetic response towards litter pollution. Once the intervention evaluation was complete, both the hypocrisy and education interventions were ready to be implemented.

Intervention Implementation 
Interventions at AI were performed sequentially over a three-day period in week five of the first term of the school year, directly proceeding the baseline data collection. Of the 195 students at AI, $13 \%$ were absent on day one, $8 \%$ on day two, and $6 \%$ on day three of the project implementation. The interventions were performed in one classroom at a time, for approximately an hour and a half, covering three classrooms a day. The school provided the research information sheets and consent forms to the parents one week before the interventions initiation, on behalf of the researcher (Appendix 1). The students were given an information sheet on the day of the intervention (Appendix 2). Although the opportunity was available for withdrawal from the intervention, no students individually or through parental decision opted out of the project.

\section{Presentation}

The intervention began with an educational presentation (Appendix 3) about the effect litter has on the environment. The presentation included education on how littering items affect their local environment, the process of biodegrading versus photodegrading, examples of the impacts of litter on marine life and humans, and the steps that are available to combat the issue of litter pollution specific to intermediate students. After the educational presentation was performed questions and queries from students were answered before moving on to the hypocrisy aspect of the intervention.

\section{Hypocrisy}

To complete the hypocrisy aspect of the intervention, students were first instructed to write a personal commitment to assist in combating the issue of litter pollution. This involved stating what they were going to do to help and why it was important to them to help (e.g. Figure 6). After the students checked their commitment with the researcher or their teacher, they then 
individually read their writing aloud to their class, publicly committing to combat the problem of litter pollution.

To complete the second stage of hypocrisy, the students were instructed to remain quiet and work alone to answer a private survey, to highlight any of their past failures surrounding littering (Appendix 4). After the survey, the researcher asked the teacher to randomly select a student and ask them if they would be happy to be interviewed. The researcher then finished the class by thanking them for their time and promoting that they strive to achieve their commitments to assist in combating litter pollution.

\section{Interviews}

After gaining signed consent from the randomly chosen students from each class, the researcher interviewed these nine individuals using qualitative semi-structured interviews. Interviews were used to gain insight into the participant's perceptions and opinions of the project and litter in general. Interviews will be discussed later in this chapter in the interview section. 


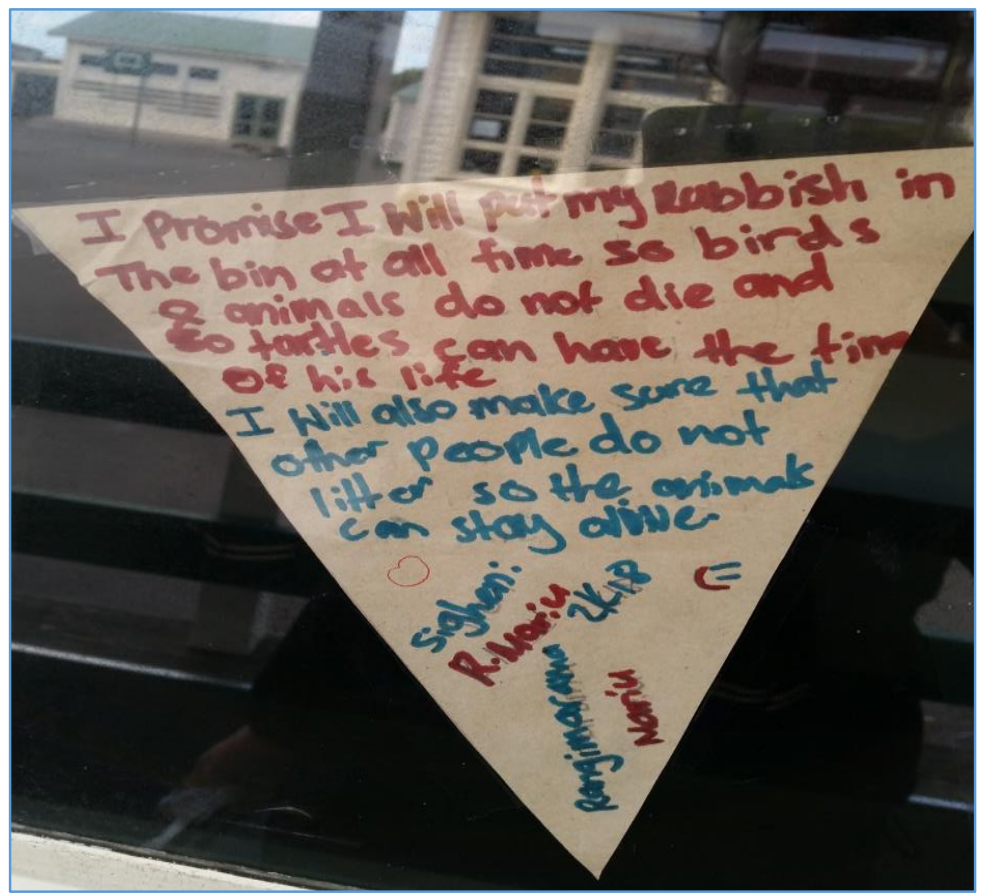

Figure 6 AI Room 6 written personal commitment from a student from the intervention, featured in a classroom window.

Return to Baseline: Quantitative data collection procedures directly proceeding the intervention employed the same process as stated in the baseline. Data was collected using a tabled checklist (Table 1) to assess litter amounts within the three sites within the School. Data collection occurred over seven consecutive days (weather dependent) from 3-5pm. Items were picked up, identified and categorised, some items were marked, and left behind and the remaining items were taken from the setting.

Follow up: Quantitative data collection procedures after the intervention counts involved the same process as those in the baseline and return to baseline.

\section{Interviews:}

Interviews were selected as the qualitative method for this research as participants provide new information through their interpretation of their experience with the project. This allows the researcher to understand and interpret individuals' behaviour and experiences. This is 
highly relevant to understanding participants interpretations of the interventions and how they relate to the success or failure of the interventions (Dunn, 2010; Shopes, 2011).

Qualitative semi-structured interviews were conducted in this case study with student and teacher participants. Students were interviewed during the intervention procedure, while teachers were interviewed during the return to baseline period. Student interviews were used to gain insight into the student's perceptions and opinions of the project and rubbish in general. Teacher interviews were used to gain insight into their perceptions of the project's effectiveness, and children's behaviour towards litter in general and following the intervention.

Semi-structured interviews were used for both students and teachers as they offer a balance between predetermined order and flexibility when producing and constructing the conversation. Utilising this approach, an interview guide was used for both students and teachers (Appendix 5) to focus the interview towards understanding the effectiveness of the intervention, the student's behaviour and their perceived benefits and barriers of littering. Although the interview guide structured the conversation, the nature of semi-structured interviews also allowed the conversation to deviate, with the choice to ask further questions as the researcher gained new ideas (Dunn, 2010).

The interviews were conducted face to face with generally open-ended questions that were recorded via audiotape. Participants had no prior engagement with the interview questions. Students who were interviewed were selected randomly and interviewed for approximately 10 minutes. Prior to the interview students received an information sheet explaining the intentions of the research (Appendix 6) and also signed a consent form stating their approval for their information to be used (anonymously) in this thesis and for their interview to be 
audio-taped (Appendix 7). Anonymity was maintained in this thesis by referring to student participants as Student 1 through to 9.

Teachers and other adult participants interviewed self-volunteered after an email was sent inviting their participation in the interview process. Teachers and other adult participants were interviewed for approximately 25 minutes. Prior to the interview, teachers and other adult participants received an information sheet explaining the intentions of the research (Appendix 8) and were asked to sign a consent form stating their approval for their information to be used (anonymously) in this thesis and for their interview to be audio-taped (Appendix 9). Anonymity was maintained throughout this study by referring to participants as teacher 1 through to 4 and caretaker 1 .

\subsubsection{Case Study Two: Raroa Normal Intermediate School}

This study used both quantitative and qualitative methods to test the theory of goal setting, which predicts that a specific and difficult goal will influence an individual's actions, encourage the formation of strategies; initiating effort on-task, and facilitating task perseverance (Locke \& Latham, 1990). This would influence an individual's behaviour positively, in this case for intermediate aged children to drop litter less and to reduce their lunch box wrappers at RNI School.

\section{Participants and Setting:}

RNI School is situated in Wellington City. The school (Figure 7) has 670 students and 41 teaching and support staff, with 24 main homerooms, and seven additional classrooms. Of the 41 staff, 16 homeroom teachers participated in the intervention procedure. Nine out of the 24 home classrooms were randomly chosen to participate in the lunch box wrapper counts.

Three outdoor observation sites (Figure 7) were chosen as litter count areas due to their proximity to classrooms, seating and bin availability, and the likelihood of students using the 
area. Site one (Figure 7) is situated outside six classrooms and the school gymnasium, it includes a moderate amount of seating in the form of steps and two litter bins. Site two (Figure 7) is situated outside seven classrooms and includes two paved areas and grass areas. This area contains moderate seating in one of the paved areas and four litter bins. Site three (Figure 7) is situated outside four classrooms and includes paved and grassed areas, moderate seating in one of the paved areas and three bins. Participants were intermediate aged students who provided the litter count and interview data and parents and teachers who provided interview data.

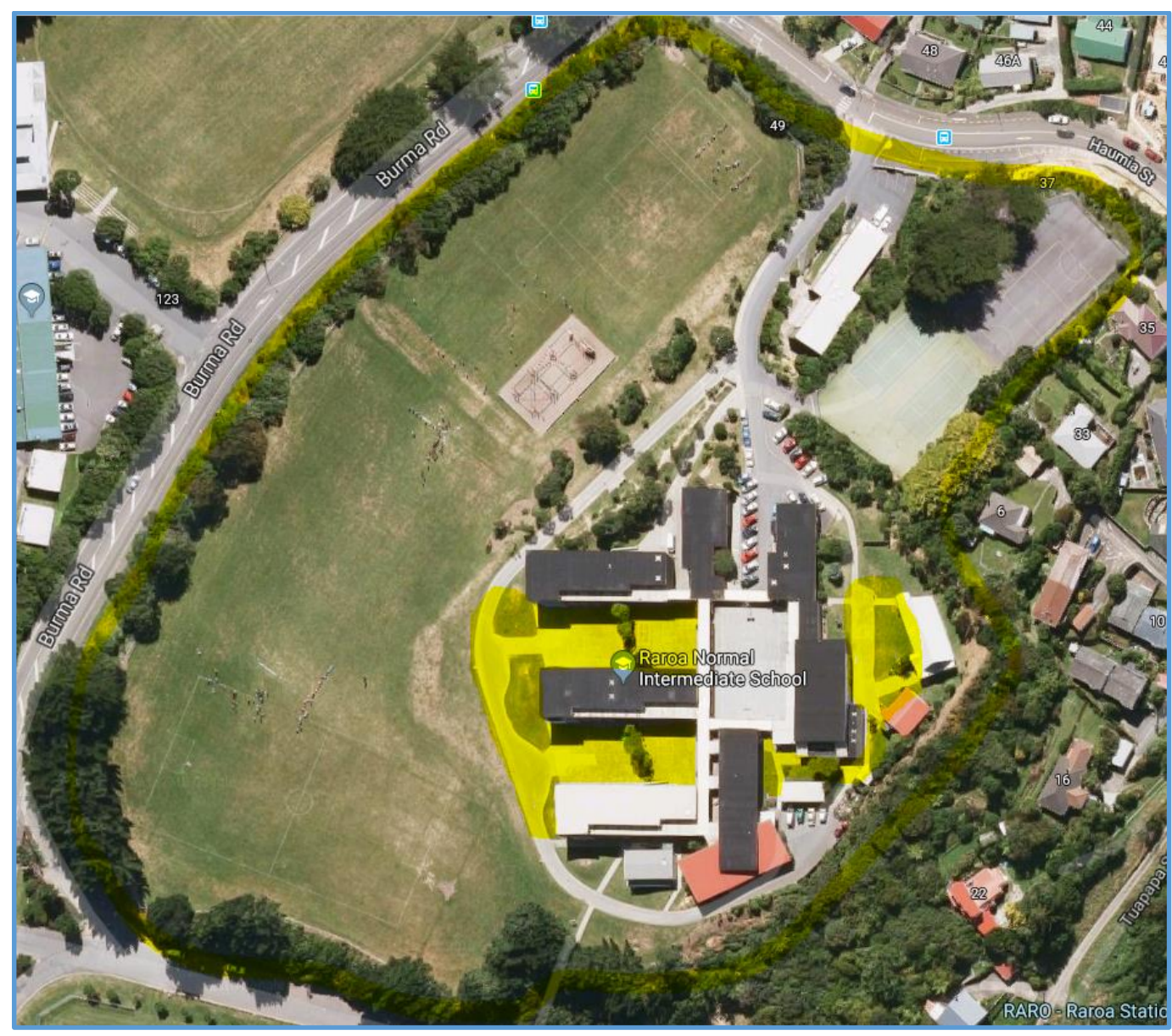

Figure 7 RNI School in Wellington City (school boundary and observation sites highlighted in yellow) (Google Maps, 2018b).

\section{Implementation:}


Following the same $\mathrm{ABAB}$ design as case study one, case study two used the following four phases: (a) baseline, (b) goal setting condition, (c) return to baseline, and (d) follow up (Wine et al., 2015).

Baseline: This section used methods outlined in case study one's baseline section except for also employing quantitative lunch box wrapper counts. Lunch box wrapper counts were collected on site by capturing the lunch boxes data with camera images. Data from the images were then entered into a coding scheme (Table 2) of pre-determined categories to assess wrapper amounts within the student's lunch boxes in the school. The other category encompassed raisin boxes, paper bags, cans and cupcake and muffin papers. Paper towels and fruit stickers were not included in the counts, as these items were not considered wrappers. This scheme was chosen because it is efficient, fast and minimises recording inaccuracy of wrappers (Kitchin \& Tate, 2000). Data collection began before the intervention and occurred over nine consecutive days from 8.40-9am. RNI sent home an information sheet (Appendix 10) in week one of school informing households that RNI is a wrapperless school. Therefore, households may have started reducing wrappers prior to the intervention. Following this the school provided the research information sheets and consent forms to the parents one week before the interventions initiation, on behalf of the researcher (Appendix 12)

Table 2 Lunch box wrapper counts RNI

\begin{tabular}{|l|l|l|l|l|l|l|}
\hline Week 1 & Wrapped & $\begin{array}{l}\text { Glad } \\
\text { bag }\end{array}$ & Tin foil & $\begin{array}{l}\text { Honey } \\
\text { wrap }\end{array}$ & $\begin{array}{l}\text { Cooking } \\
\text { paper }\end{array}$ & $\begin{array}{l}\text { Number } \\
\text { of items }\end{array}$ \\
\hline Day 1: & & & & & & \\
\hline Total: & & & & & & \\
\hline
\end{tabular}


Procedure: The interventions education and goal setting were selected for implementation by the researcher in collaboration with RNI stakeholders. These techniques were chosen based on their workability in Raroa's School environment and their shown effectiveness in the literature. The intervention implementation of education and goal setting also followed the programme piloting step in CBSM described earlier. Feedback was provided and adjusted, ready for the intervention to be implemented.

\section{Intervention Implementation}

RNI School provided the research information sheets and consent forms to the parents on week one of the school term on behalf of the researcher. The students were given their information sheet on the day of the researchers' arrival. Although the opportunity was available for withdrawal from the intervention, no students individually or through parental decision opted out of the project.

The education and goal setting interventions were then performed over a two-day period in week three of term one of the school year. Of the 670 students at RNI, $4 \%$ were absent on day one in the morning and $6 \%$ in the afternoon, $5 \%$ on day two in both the morning and afternoon of the project. The interventions were performed to one group at a time (one group had five classrooms and the remaining groups had four classrooms), for approximately an hour and a half, covering three groups in day one, and two in day two.

\section{Presentation}

The intervention began with the same educational presentation (Appendix 11) as case study one, except for the children were informed of the commitment the school had made to be a wrapperless school in 2018, beginning with the goal of reducing all wrappers by $60 \%$ by the end of term one. After the educational presentation was performed questions and queries from students were answered before moving on to the goal setting aspect of the intervention. 


\section{Goal Setting}

The students were instructed to set a goal of reducing their lunch box wrappers from their lunch box to assist in combating the issue of litter pollution. This was aided by asking the students to plan their usual school lunch around replacing any existing wrappers with alternative options to meet this goal. Examples of wrapperless alternatives were discussed and provided during the presentation, with an emphasis on choosing wrapperless options that were feasible to swap within their household and that they were likely to eat. After the students checked their goal and plan with the researcher or another teacher, the researcher thanked the group for their time and promoted striving to achieve their goals to assist in combating litter pollution. During the goal setting section, the researcher asked the teacher to randomly select a student and ask them if they would be happy to be interviewed.

\section{Interviews}

After providing the students with information sheets and gaining signed consent (Appendix 6 and 7) from the randomly chosen students from the five groups, the researcher interviewed these nine individuals using qualitative semi-structured interviews. Interviews were used to gain insight into the participant's perceptions and opinions of the project and litter in general.

Return to Baseline: Quantitative data collection procedures in the return to baseline intervention counts were performed in the week following the intervention, using the same process as those stated in the baseline.

Follow up: Quantitative data collection procedures were performed six weeks after the return to baseline counts. These follow up counts used the same process as those in the baseline and return to baseline.

\section{Interviews:}


At RNI School, interviews were carried out uses the methods outlined in the interview section of case study one, with the exceptions of interviews employing not only students and teachers but also parents. Parents and teachers were interviewed, during the return to baseline period, using semi-structured interviews. Student interviews were similar to those in case study one, with the exception of also aiming to obtain participant's perceptions and opinions of wrappers in general. Teacher interviews were also modified from case study one's to gain insight into the perceptions of the projects effectiveness, and children's behaviour towards wrappers in general and after the intervention. Parent interviews were used to gain insight into their perceptions of the project's effectiveness, and children's behaviour towards litter and wrappers in general and after the intervention. The interviews were conducted face to face with generally open-ended questions that were recorded via audiotape. Participants had no prior engagement with the interview questions. The two parents who were interviewed self-volunteered after all parents were invited to participate in the interview process via the project information sheet (Appendix 12). Parents were interviewed for approximately 25 minutes. Prior to the interview the parents received an information sheet explaining the intentions of the research (Appendix 13) and signed a consent form stating their approval for their information to be used (anonymously) in this thesis and for their interview to be audiotaped (Appendix 14). Participants anonymity was maintained throughout this study by referring to parent participants as parent 1 and 2, student participants as Student 10 through to 18, teacher participants as teacher 5 through to 9 and caretaker 2 (Creswell, 2014).

\subsubsection{Ethical Standards:}

Ethical approval was gained for both case studies from the Human Ethics Committee, following the ethical outlines set by Victoria University of Wellington. The main ethical considerations in order to gain ethical approval included information and consent forms 
found in the Appendix 1 and 12. The Victoria University of Wellington Human Ethics Committee approved this application on the $13^{\text {th }}$ of December 2017 (Appendix 15).

\subsubsection{Qualitative Analysis}

The qualitative methods of interviews employed in this study were analysed through thematic analysis. Thematic analysis is a qualitative method which allows the researcher to recognise, analyse, and describe patterns (themes) within a data set. The method of thematic analysis acknowledges the interpretations created by the researcher are not independent of the researcher's theoretical and epistemological commitments. Therefore, the analysis is influenced by the researchers understanding of the data. The analysis attempted to identify explicit meanings in the data to provide relevant themes in rich description opposed to covering all data to address the research questions.

Following Braun and Clarke (2006), the analysis was conducted in six steps. This process, began with transcribing the interviews while identifying ideas and linking patterns throughout the data. The next step involved producing codes systematically from the ideas and patterns identified. Codes represent a feature of the researcher's theoretical or analytic interests. Step three involved organising and combining the codes into potential themes. The potential themes were then reviewed for step four, to check all combined information formed a clear pattern and if the chosen themes reflected the whole data set. This was done by constructing a thematic map of the analysis. Step five required further defining and refining the themes and the data within them to produce a succinct analysis. The final step produced a non-repetitive, logical, and succinct, analytical narrative about the research questions. This approach was manually executed across all interview transcripts (students, teachers, and parents). 


\subsubsection{Quantitative Analysis}

Quantitative data sets collected in this study were analysed through the programme SPSS using a statistical paired $t$-test. The paired $t$-test was used to calculate the mean difference between two sets of observations. A paired $t$-test measures a subject or object twice, providing pairs of observations. Used to determine one of two hypotheses: the null or alternative hypothesis. The $t$-test results are determined by looking at the $p$-value $(\leq 0.05)$. The $p$-value provides the probability of detecting the test results under the null hypothesis, and either accepting or rejecting the null hypothesis. The higher the $p$-value, the higher the probability of having weak evidence against the null hypothesis, thus accepting the null hypothesis. The lower the $p$-value, the lower the probability of obtaining a result like the null hypothesis, thus rejecting the null hypothesis (Kazdin, 2016). Cohen's d effect size was also calculated in order to describe the magnitude of the effect (Cohen, 1988). The Cohen's d effect sizes are categorised into small $( \pm 0.2)$, moderate $( \pm 0.5)$, and large $( \pm 0.8)$ these categories explain the strength of the result (Osteen \& Bright, 2010). 


\section{Chapter 5 Results}

\subsection{Introduction}

This chapter describes the qualitative and quantitative results produced by both case studies. This chapter is divided into two sections. The first presents the qualitative semi-structured interview findings and the second the quantitative statistical findings. The qualitative section is broken into ten themes, which were discovered through the thematic analysis. This section focuses explicitly on the influencing factors within the two case studies, which affect the effectiveness of the interventions. The quantitative section is divided into three sections based on each case study's results of litter reduction and wrapper reduction. This section focuses specifically on determining the effectiveness of the interventions in the case studies litter and wrapper counts through statistical $t$-tests. This chapter is organised in line with the thesis research questions:

i. What are the barriers and benefits for participants and key stakeholders to perform the desired litter and packaging disposal behaviours?

ii. What influence do key stakeholders have on intervention desired litter and packaging disposal behaviours?

iii. Does the use of behaviour change interventions influence the litter and packaging behaviour of intermediate aged school students, and if so, do such behaviours continue in the future? 


\subsection{Qualitative semi-structured interview analysis}

Interviews were analysed using a thematic analysis as previously described in chapter 4 . This thematic analysis produced ten key themes which are described in line with addressing the research questions. Themes were identified based on their recurrence in the interviews and the level of emphasis participants placed on the provided information. The themes have been rated as either strong or minor based on their level of occurrence and importance in the interviews. This rating displays the variability of the themes throughout the data set.

\subsubsection{Profiles of the Research Participants}

Table 3 Research participants interviewed for qualitative data collection from case study one and two.

\begin{tabular}{|l|c|c|}
\hline Interview Participants & Case study one & Case study two \\
\hline Student & 9 & 9 \\
\hline Teacher & 4 & 2 \\
\hline Parents & 0 & 1 \\
\hline Caretaker & 1 & 17 \\
\hline Total & 14 & \\
\hline
\end{tabular}

\subsection{Research Question 1}

What are the barriers and benefits for participants and key stakeholders to perform the desired litter and packaging disposal behaviours? 
Table 4 Qualitative thematic analysis: dark blue boxes represent the overarching themes under research question 1 and the light blue boxes represent the sub-themes under the larger themes.

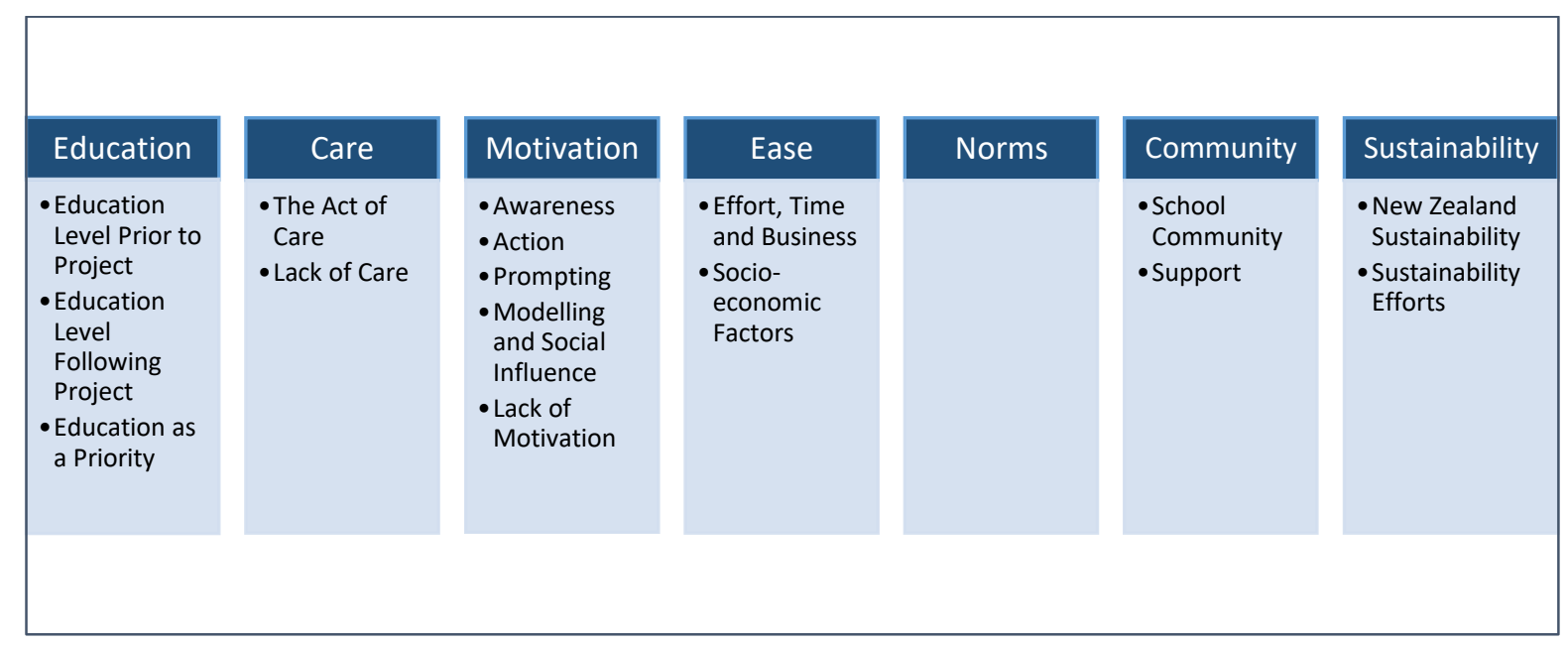

\subsubsection{Education}

Education, was a recurring and apparent theme throughout the case study interviews, forming a strong theme with three sub-themes: education level prior to the project, education level following the project and education as a priority.

\section{Education Level Prior to the Project}

Participants were first asked about their level of education and awareness prior to the projects on the topics of litter pollution, litter in general, and litter specific to their community.

Education levels varied amongst all participants. Adult participants with prior knowledge of the topic stated this knowledge was obtained from past projects in schools, or through their own interest. Although a majority of adults expressed awareness of the topic, some were unaware and unfamiliar with the topic prior to the project. Parents reported a high level of education about the topic prior to the project, however, suggested other parents may not have this same level of knowledge. In particular, parent 2 (who is also a teacher) believed parents might not have the same level of knowledge as a result of not receiving a lot of the information that their children gain at school. Parent 2 illustrated - 
..as a parent, not a lot we'd hear the odd bits and pieces coming back, being a teacher though you do hear about it [...]. As a teacher I do get a lot of education, whether that goes back to my home all the time, I'd [..] say not all the time (Parent 2).

Teachers reported students' level of knowledge on the topic as being mixed. Teacher 3 further explained that "before the project, some [students were] very knowledgeable maybe $10 \%$, maybe $50 \%$ [were] aware of it, and some just didn't know that much, [they] have no idea".

Students self-reported level of knowledge also varied, some students stated they were aware of the topic and the extent of the environmental impacts, with some students acknowledging they had previously gained education on the topic. The remainder of students explained they were unaware of the topic prior to the project. For example, student 4 noted: "I thought they [the rubbish] don't really go anywhere, it'll be fine, they just somehow disappear".

Participants' who had knowledge of the topic gained the majority of it from media sources, such as documentaries, and school inquiries on relevant topics.

\section{Education Level Following the Project}

All participants involved in the project (including parents) expressed a higher awareness and understanding of the topic following the project. Teachers and parents expressed that their increased awareness of the environmental impacts was influencing their behaviour with litter and wrappers. Teachers noted students' education, awareness, and communication on the topic had increased following the project, as well as their enthusiasm towards the topic. This was supported by students, who stated they had gained new information or explained to the interviewer what they had learnt and how they had enjoyed learning about the topic. For example, one student explained: "it's taught me a lot about how we could save the oceans, [..] animals in the sea and how we could help them and the birds" (Student 11). In addition to the 
project, teachers emphasised the continuing effect that a class inquiry into the topic could have in extending the students' knowledge and understanding. Teachers also thought education needed to come from the home environment and as well as education gained at school needing to extend into the home environment.

\section{Education as a Priority}

Teachers described the education provided on the topic of litter and wrapper use as 'huge' and something that 'has to be done', as well as something that needs to be emphasised by teachers. Teachers stated before the project students' underestimated the extent of their effect, and therefore teachers emphasised the importance education played in explaining 'where' students' litter goes and 'why' it is important to be conscious of litter and packaging and their environmental impacts.

\subsubsection{Care for the Environment}

Care was a recurring and apparent theme throughout the case study interviews, forming a strong theme with two sub-themes: the act of care and lack of care. Care encompassed the codes: laziness, encouragement, investment, entitlement, respect, effort, action, and attitudes.

\section{The Act of Care}

Care was described by participants as a recurring action or feeling that influenced and was expressed by individuals, specifically students during the project. When participants were questioned about their general perspective of the environment and litter the main reaction displayed was an emotional response of caring for the environment and the effects litter place on it. Participants highlighted the current state of the environment as negative and recognised the role litter plays in creating that state. Participants also expressed a desire to improve current action towards the environment and protect it. 
In responses to questions, an overlapping commentary about caring for the environment through sustainable practices was noted, with answers referring mainly to the topic of waste (reducing waste, recycling and composting). One participant illustrated this -

..It's [..] sad that all our oceans, they are much dirtier than they were even ten years ago, because people are consuming more and more and more rubbish, and I think it should be people consuming less and less [..] rubbish because some people they [..] think if I put this one piece of rubbish on the floor like nobody will notice and nothing will be different, but if everyone puts one piece of rubbish on the floor in a day everything will be much more dirty (Student 8).

Teachers and parents recognised students displayed care and action (picking up rubbish, bringing wrapperless lunches) after the project. Students also reported caring about littering and wrapper use and how these behaviours affect rivers, oceans, and sea animals. Care displayed and reported by students towards aspects of the intervention varied; this included care towards the counts, education, goal setting, and commitment making. Teachers also recognised students behaviours were influenced by the level of care expressed towards the topic by teachers' and parents'. Some teachers' stated effort and openness adults' displayed encouraged student's behaviour; teacher 5 provided an example of this -

..[teachers] have to practice what they preach and they have to want to do it as well [..], as long as the kids see their teacher actually cares about it, kids want to please teachers, teachers are role models, you want to have the kids looking up to someone that does it as well. If the teacher were like 'Oh who cares if you don't bring wrapperless lunch it doesn't really bother me', then the kids won't bring wrapperless lunches, they don't care, you've got to get the staff on board.

\section{Lack of Care}

A lack of care was also described in the interviews as a recurring action or feeling that was portrayed by participants, and other stakeholders which influenced students during the project. 
Teachers noted the level of care some students showed towards aspects of the intervention was concerning. The students who cared less did not express as much care as others towards the intervention and were thought to be less likely to participate long-term in litter and wrapper reduction. Older students, in particular, were stated as more adverse to participation, as the projects were a new initiative, e.g. "we didn't do it last year so who cares" (Teacher 5). Students also expressed concern about other individual's who lacked care towards the topic. Both teachers' and students' were concerned about the discrepancies between individual's values and action towards the littering and wrapper use. Participants correlated a lack of action with laziness and being bothered. A few participants hypothesised laziness to be dependent on an individual's level of care and entitlement. Teacher 1 described this -

..I feel like [the gap between values and actions] describes what everyone already knows about humans, that humans are lazy. I feel like the one difference to change laziness is empathy, [..] we're all lazy, but the ones that have changed and made a difference are the ones that have empathy. Whereas the ones that don't they still have values, they know it's bad for the environment to litter, but they're lazy they don't have the empathy so they don't care as much, so they don't bother changing their actions because of it (Teacher 1).

Participants also highlighted their concern about the care individuals outside of the intervention (family and friends) would show towards the interventions message. Participants stated other individuals might not want to assist in refusing, reducing, reusing or recycling litter and wrapper, particularly if they have no motivation. One student explained: "I think some of them will respond good and some will respond confused "why would they do that, it's just rubbish' that's what some people say" (Student 14).

\subsubsection{Motivation}

Motivation was a recurring and apparent theme throughout the case study interviews, forming a strong theme with five sub-themes: awareness, action, prompting, modelling and social 
influence, and lack of motivation. Motivation to perform the target behaviours encompassed the codes: encouragement, engagement, visuals and emotions.

\section{Awareness}

Awareness of 'where' litter ends up, 'why' it is harmful (environmental, aesthetic and health effects), and how individual behaviour can influence litter pollution was recognised by multiple interviewees as a motivating factor to perform the targeted behaviours. One student provided an example of this "I [..] only thought about putting rubbish in the bin and picking it up, I didn't think more than that, I didn't think how every day I could have a wrapperless lunch to make a difference, and [it] could really help the world" (Student 11). Although awareness was recognised as important for promoting behaviour performance, teachers stated students responses were variable and time-dependent "they can get all emotional at the time but they can forget" (Teacher 6).

More specifically self-awareness in the world was also identified by teachers as an important motivator, particularly for long-term behaviour performance. Teachers explained the importance of promoting self-awareness in the classroom, promoting 'respect' and "getting them to think about how they can protect their land and what they can do themselves" (Teacher 5). Teachers and students also recognised students displaying the use of selfawareness. Teacher 7 explained -

..in this classroom, a few of them will go around and pick up the rubbish off the floor, they just do that, while others don't know there's rubbish there. They don't see it, they don't think that's their job to pick it up. So it's [..] an awareness of themselves in the world [..]. For the ones that we're connecting with that are getting the message are ready for it somehow, the ones that say 'no it's not my rubbish I don't care', they're not mentally engaged in that way.

\section{Empathy}


Empathy was described by participants to be an important motivator for behaviour change. Participants described that students developed an empathetic response during the presentation segment. The awareness the students gained from the information provided was stated to 'freak them out' and 'shock them'. Many students expressed their concern about the impact of litter on terrestrial and marine organisms, including humans. Others expressed their concern for litters' effects on the environment in general; this included expressing their personal experiences, health concerns, and concern about global warming as motivating factors to take action on the topic. For example, student 13 noted: "I care about the animals, and I saw the pictures, [it was] brutal to see them eat plastic" (Student 13). Creating this response was further explained as 'vital' otherwise the students would not have gained the motivation they needed to change their behaviour -

\footnotetext{
..definitely enforcing it with the education, showing those videos, trying to build the empathy I think is the biggest thing. Anything to educate them to build their empathy, otherwise they're like this person is telling me this they're not going to know why they're doing it (Teacher 1).
}

\section{Action}

Motivation was found to create action and vice versa, as an important influencer of behaviour change. Multiple participants stated that the use of action was effective in motivating the students' behaviour performance, this included counting students' lunch wrappers, setting goals, creating commitments, and advising the students to make their lunches. Teacher 4 explained: "what did help was counting their lunches, them visually seeing oh the teachers going to see them and how we're going, when you [the researcher] came in and [during] DPE [design and production education] doing it [the counts] as well".

\section{Prompting}


The use of prompting in the project was described as a necessary and an important reminder to students to 'keep going' with their behaviours. Many participants stated prompts in the form of positive feedback, competition and visual stimuli, were effective motivating tools. The use of visual stimuli, in particular, was described as an important motivator -

..a lot of [the students] are more visual than they are information based learners, so get them to do something hands-on and it'll stick with them, so the pictures were really really powerful, in the presentation [... the pictures and stories [..] I think that would have been the catalyst more so than the information (Teacher 8).

\section{Modelling and Social Influence}

Most participants stated students would have gained the motivation to perform the targeted behaviours from the influence and modelling displayed by teachers, friends, and family. The importance of key individuals' actions were discussed in regards to their demonstration and engagement with the topic and their effort and performance of the targeted behaviours at school, home and in the community. For example, teacher 7 illustrated "modelling [and] the way rubbish is dealt with at home, if it's just thrown on the floor then why wouldn't [students] do that, if their house and sections are messy then they'd think that was normal”. Modelling and social influence from students was also demonstrated, for example, teacher 2 stated: "I know myself I have to go wrapperless so I don't get pulled up by the kids".

\section{Lack of motivation}

Although motivation in multiple forms was as a recurring theme in the interviews, participant's lack of motivation to perform the targeted behaviours was also highlighted. Participants commented on a lack of motivation as being associated with a lack of care about environmental issues, a lack of understanding and reinforcement of an issue, whether a 
problem 'resonated' with an individual or not, students level of entitlement, and lastly the overwhelming feeling of being helpless against a large worldwide issue e.g. -

..I think they think that big companies are the ones that are ruining it [the environment] so they're like what's the point in me doing it. Sometimes I feel like that too, I go to the supermarket and I see my bags, and I see all these plastic bags, and you think what's the point, it feels like it's too big (Teacher $5)$.

\subsubsection{Ease}

Ease was a recurring theme throughout the case study interviews, forming a strong theme with two sub-themes: effort, time and business and socio-economic factors. Ease of performing the targeted behaviours encompassed the codes: effort required, time, business, convenience, and socio-economics.

\section{Effort, Time and Business}

The majority of the participants discussed the effort required to perform the targeted behaviours. Some participants discussed the behaviours as hard to perform, while others believed they were easily achieved. Participants also discussed how having a lack of time and being busy hindered their capability and willingness to perform the targeted behaviours. Tasks considered to be relevant to the behaviours that were considered hard work, required effort, and were hindered by having a lack of time and being busy included:

- Performing wrapper counts

○ Achieving commitments \& goals

○ Reusing \& recycling at home

- Making wrapper alternatives

○ Purchasing bulk food in a single child household
○ Purchasing wrapperless foods

- Valuing health vs environment

○ Recycling \& composting at school

○ Unlearning convenient habits 


\section{Socio-economic Factors}

Socio-economic factors were discussed in relation to social modelling, and the cost between wrapped goods, unwrapped goods, and the alternatives to plastic packaging. When questioned about how socio-economic factors influence projects implemented in schools, participants discussed that modelling the 'correct' behaviours in the home environment, e.g. picking up rubbish, may be impaired by a household's socio-economic state. For example, teacher 7 illustrated -

..because of the modelling they see in their own community and their families, I know for a fact some of our kids [..] it's hard to imagine that they would, know it's possible to pick up stuff and keep your environment clean, if that's what they see around them and that's what's normal for them (Teacher 7).

Socio-economic factors were also perceived to influence and deter the purchase of wrapperless goods and wrapperless alternatives. Some participants stated that buying in bulk and reducing wrappers was perceived as a benefit as it was cheaper. However, other participants perceived lower socio-economic groups would be less likely to purchase unwrapped goods and wrapperless alternatives due to the low price of wrapped goods and the cost of alternatives.

This was considered particularly important in New Zealand due to the price and accessibility of alternative options. Parent 1 explained: “I think NZ's poorer than people realise, in America, it's easy to have stainless steel, I notice people don't invest in the same things, but it's also two-three times as expensive".

\subsubsection{Normative Influences}

Normative influences were a recurring theme throughout the case study interviews, which formed a minor theme. Normative influences encompassed the codes: child mimicry, peer pressure, and social modelling. 
Schools, families, and peers perspectives on what normal behaviour is relative to the target behaviours (normative influences) was highlighted by participants as having a substantial influence on students' performance of the targeted behaviours. For example, teacher 8 explained -

..what they see, kids are really just copy caters they just mimic what they see, if they see dis-care for our environment from what they see [... then of course that's going to be a really big influence. What thier friends do, peer pressure is always really big, especially in this setting because [..] it's all about where do I fit in, and if the cool thing is to litter, then that's what you're going to follow because it's about fitting in. So I think what they see at home, maybe not parents, it could be big bother, aunty, and what your friends do are the biggest influences (Teacher 8).

The interventions were stated as influencing the social norms and normative messages surrounding the topic in the school community. Participants noted that prior to the interventions the normative message and social norm highlighted was that the school was very dirty and unclean and students needed to take better care of their space. Following the project teachers stated the social norm had changed, teachers 4 and 7 explained: "I've noticed [..] heaps with wrapperless lunches, it's just the way they do it now", and "I've heard kids telling other kids to pick up rubbish sort of thing, more conversations, more awareness" (Teacher 7). One participant described this change as a result of "the fact, so many people were doing it, and we were talking about it every day, and it was something exciting to be a part of" (Teacher 3).

\subsubsection{Community}

Community was a recurring theme throughout the case study interviews, forming a minor theme with two sub-themes: school community and support. Community encompassed the codes: relationships and support. 


\section{School community}

The school community (teachers, parents and students) was discussed as playing an important part in the success of the projects'. When teachers and students were questioned about what they perceived would have made the project successful, many explained that it was the 'school-wide' initiative. The school-wide initiative was thought to be necessary for building the school community and displaying support for the required behaviour change. For instance, student 9 stated: "I like how everyone gets involved". The school community was also stated as affecting the student's behaviour -

..I think it's a lot to do with relationships, feeling like they belong and [if] they feel like it's their place and they can contribute in a positive way. Feeling like they're valued, and people appreciate what they do (Teacher 7).

Teachers described that initially, they believed by promoting community effort alongside the interventions they would receive resistance from the parents. However, teachers reported the majority of parents responded positively to the school-wide initiative. Parent 2 explained: "that's what compelled me to start with, was that this was an initiative that the school was running, so we backed it" (Parent 2).

When questioned about how parents should be involved in future projects, parents and teachers expressed a willingness for greater parent involvement. Unlike case study two, case study one did not involve parental participation which teacher 2 expressed as a failure in the project: "it's unsuccessful in the fact it only gets pushed at school. There's not that whole community thing where they're getting reinforced all the time". Beyond the effort of the school community, one participant noted that the effort of the whole population is required to tackle the problem of litter pollution.

\section{Support}


Support was discussed as an important element when adult participants were questioned about what they believed influenced the student's performance of the targeted behaviours. Support from teachers and parents, in particular, was noted as an important motivating factor. Support for parents in school initiatives was also emphasised, parent 1 suggested parents need to be provided with multiple options when assisting a change applied by the school, e.g. providing recycling options at school alongside wrapperless lunches.

\subsubsection{Sustainability}

Sustainability was a recurring theme throughout the case study interviews, forming a strong theme with two sub-themes: New Zealand sustainability and sustainability efforts.

Sustainability encompassed the codes: environmental issues, New Zealand sustainability, school sustainability, and sustainable practices.

\section{New Zealand sustainability}

Parent, teacher and student perspectives on New Zealand's sustainability varied. New Zealand's past sustainability practices were perceived to be quite different from today's. Participants viewed current practices as better than past practices and continuing to improve. However, one participant expressed concern over the 'improvements' gained through new technology.

Although New Zealand's current sustainability practices were viewed better than the past, participants provided contrasting perspectives on the countries current practices. Individuals highlighted New Zealand's renewable energy practices, recycling systems (including methane recycling) and litter practices as being impressive. However, both teachers and parents discussed the state of the environment as being 'problematic', with participants commenting specifically on New Zealand's waterway health and 'clean green' image as 
problematic. Compared to other countries participants commented on New Zealand's environmental state as comparatively better, with specific reference to the USA.

\section{Sustainability Efforts}

Participants discussed their schools' sustainability, specifically towards waste. Participants noted litter was discussed in assemblies, class, in notices, and as a part of school inquiry. Schools also stated participating in waste management including undertaking rubbish pickups, out of class excursions (beach clean ups, Wellington waste tours), whole school paper recycling and composting (in one school), and staffroom recycling (paper, plastic, and metal). Participants also proposed future practices to be implemented within their schools, including a garden, beehives, (case study one already had these) a worm farm, and recycling (plastic and glass).

Throughout the interviews participants' highlighted sustainable practices they had previously completed, including composting, recycling through public and private services, purchasing plastic alternatives, and supporting the protection of New Zealand's waterways from livestock and litter. Participants, specifically students also expressed their knowledge surrounding sustainability, including sea level rise, global warming, recycling, and landfills. Student 2 provided an example of this: "last year we learnt that when things like plastic and stuff [..] if they're sent to [the] dump, if things like fruits that are natural can naturally biodegrade, well on top of it releases the GHGs which speed up global warming".

\subsection{Research Question 2}

What influence do key stakeholders have on intervention desired litter and packaging disposal behaviours? 
Table 5 Qualitative thematic analysis: dark blue boxes represent the overarching themes under research question 2 and the light blue boxes represent the sub-themes under the larger themes.

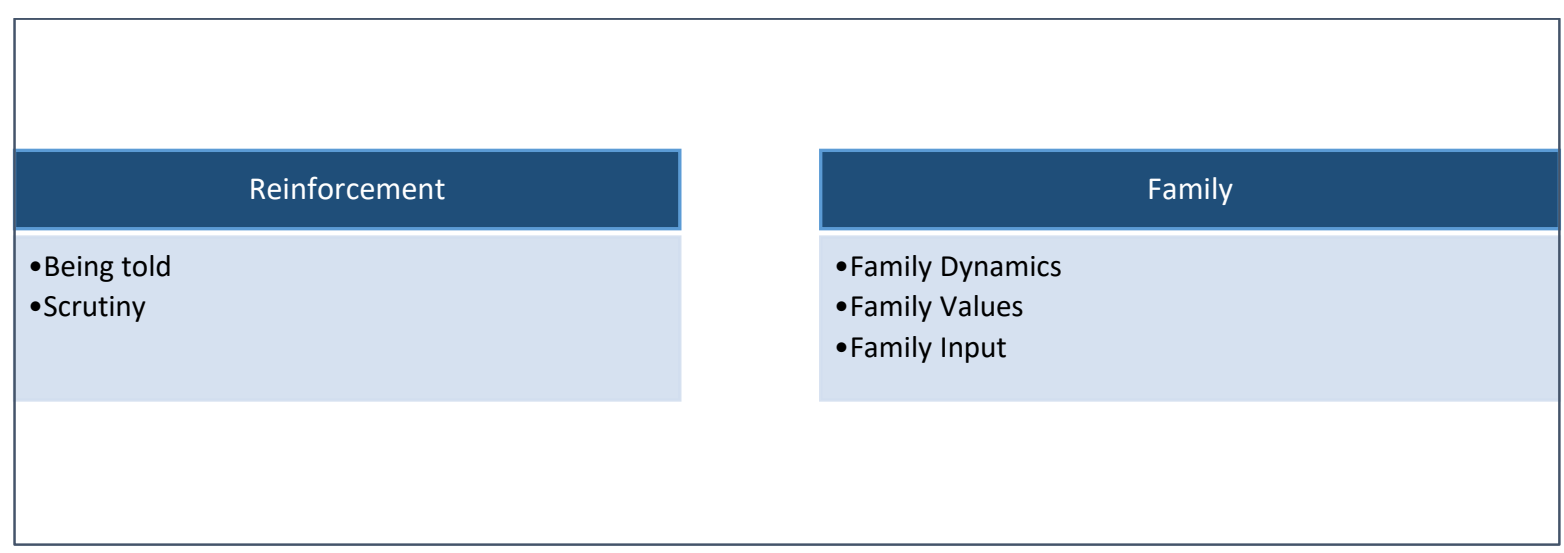

\subsubsection{Reinforcement}

Reinforcement was emphasised in relation to promoting or determining behaviour. The use of reinforcement was a recurring theme throughout the case study interviews, forming a minor theme with two sub-themes: being told and scrutiny.

\section{Being Told}

Reinforcement was described as an effective technique in promoting the targeted behaviours during the project. Teachers described that in the past students' 'being told' to perform a behaviour was problematic. Teachers explained the reinforcement applied as a part of this project was more successful as students were not explicitly told what to do, instead, there was an expectation to perform the behaviours. Teachers described this difference as important in motivating the students' behaviour. Teachers in case study two made an important note of the influence of counting; teachers emphasised reinforcing the counting checks to maintain behaviour change in the future.

\section{Scrutiny}

Although the reinforcement applied in the project was interpreted by teachers as effective in influencing the targeted behaviours, parents interpreted the reinforcement, particularly the 
wrapper counts in case study two, as scrutiny. Interestingly, both parents explained their children only met wrapperless requirements at school. Parent one believed the scrutiny involved in the wrapper counts may have been why, they explained -

...[my child] said "oh we're trying to be wrapperless" but there was no wrapperless experience because there was a wrapper, [the wrapper was left at home]. But she was more worried about the scrutiny of the school. So it was an interesting interpretation of that for her, that it was more about being judged by someone at school than purely being a wrapperless experience".

\subsubsection{Family}

Family was a recurring theme throughout the case study interviews, forming a minor theme with three sub-themes: family dynamics, family values and family input. Family encompassed the codes: family dynamic, values and input.

\section{Family dynamics}

The dynamic within a household was said to play an important role in the success of the projects. Students and teachers were asked to provide their perspectives on how households would respond to the information students had learnt in the intervention. Teachers described students relationships with all 'considered' family members differed and therefore believed household responses would vary. Most students interviewed believed they would receive a supportive reception from their family. Participants noted age could be a determining factor of influence, the age of the student portraying the message and age of the recipients. Student 16 explained: "well my family doesn't listen to me, because I'm not the oldest, it will be a hard job".

\section{Family values}


Family values were described as playing an important role in the success of the projects. Participants described family values towards the topic of litter pollution and reduction as differing between households. This variability was thought to impact individuals' values, resulting in a mixture of students valuing the performance of the targeted behaviours more than others.

Family values were expressed in the interviews with parents and students. Parents thought it was important to be supportive 'to a certain degree' but also found there to be a challenge in juggling multiple family values, e.g. environment vs health vs time. Students reflected on how their families' values fit the topic during the interviews; many students recognised their families already enacted a lot of the practices promoted in the project. One student also realised the impact of litter pollution on their family's practice and value of eating seafood, this student explained: it will be hard for our families and the world if the water does get completely polluted and we have no seafood, because seafood is a weekly dinner for quite a lot of families" (Student 11).

\section{Family input}

Both parents and some students explained their family had invested in changes relevant to the topic as a result of the project, e.g. buying in bulk. Participants stated there are trade-offs when investing in changing behaviour, and some trade-offs may be too great for some families. For example, student 6 explained: "it's kind of hard if you live in a family that sort of works long hours and stuff cause like it's quite hard". 


\subsection{Research Question 3}

\section{Does the use of behaviour change interventions influence the litter and packaging}

behaviour of intermediate aged school students, and if so, do such behaviours continue in the future?

Table 6 Qualitative thematic analysis: dark blue boxes represent the overarching themes under research question 3 and the light blue boxes represent the sub-themes under the larger themes.

\begin{tabular}{|l|l|}
\hline & \multicolumn{1}{c|}{ Project Success } \\
\hline & - Behaviour Change Success \\
& - Student's Response \\
- Success \\
- Improvement \\
- Future Success \\
\hline
\end{tabular}

\subsubsection{Project Success}

Project success was a recurring theme throughout the case study interviews, forming a strong theme with five sub-themes. Project success encompassed the codes: environmental setting, a school-wide approach, and community involvement.

\section{Behaviour Change Success}

Participants' response varied when considering the effectiveness of the project in reducing littering and wrapper use. For example, caretaker 1 explained -

..in some ways I've seen a change for the better, but then there are days when I've seen stuff everywhere. We usually have a huge collection on the far fence, but there hasn't been as much there as there has been in the past. [..] It has been better overall I think (Caretaker 1).

Most participants stated the project had been successful in reducing litter, particularly in comparison with previous years, and specifically those from case study two. Participants from case study one reported less of an obvious difference in litter levels. Participants in case study two who were questioned on the amount of lunch box wrappers present at school after 
the project, stated an improvement had occurred. For example, student 8 explained: "more people from our class $60 \%$ had less than two [wrappers], and $40 \%$ had no wrappers. Despite participants reporting wrapper use had been reduced at school, parent 2 stated even though both of his/her children's lunches were generally wrapperless, it was still not evident that it was decreasing their families weekly rubbish.

\section{Student's Response}

The student's responses to the project were largely positive; students stated 'liking' the project because of the following reasons:

- It was fun

- Gained awareness of the problem

- Learned a lot

- Provided clear content

- The level of detail

- Pictures and videos
- Content with animals

- Commitment making

- Good for people's health, the environment and school

- Provided a good challenge

\section{Success}

Participants provided insight into what they perceived to make the project successful.

Participants discussed the following as influencing the project's success in changing behaviour:

- School-wide approach

- Teacher's cooperation and input

- Shared workload between teachers and parents
- Provision of alternative options

- Educational presentation

- $\quad$ Goal setting

- Commitment making

\section{Improvement}

Although participants found the projects to be positive and mostly successful in changing the targeted behaviours, some improvements were suggested. Improvements included pushing 
the project in a more significant way, and extending the length of the project. More specifically in case study two, improvements suggested were putting more emphasis on the importance of goals set by students, and being more explicit about what a wrapperless lunch entails; in order to avoid students using wrappers and leaving them at home. Case study one participants suggested incorporating families into the project would make it more successful.

\section{Future Success}

Participants provided feedback surrounding what they perceived would continue or enhance the success of the projects in the future. Interviewees suggested maintaining the intervention variables implemented, and extending the length of the project and the project's reach into the community. In addition, participants suggested incorporating hands on activities into the interventions and providing the students with feedback on their performance following the projects. 


\subsection{Quantitative litter and lunch wrapper analysis}

\subsubsection{Observations}

Three observations were completed for case study 1 (before, directly proceeding and follow up) to assess the effectiveness of one outcome variable (litter amount) in AI School grounds. Case study 2 conducted three observations (before, directly proceeding and follow up) to assess the effectiveness of two outcome variables (litter and wrapper amounts).

\subsection{Research Question 3}

Does the use of behaviour change interventions influence the litter and packaging behaviour of intermediate aged school students, and if so, do such behaviours continue in the future?

\subsubsection{Litter Reduction}

\section{Case Study One}

The AI School case study employed the behavioural techniques education and hypocrisy. The effect of these techniques was measured through observations of daily litter amounts dropped in the school grounds within three areas over seven days. Day one of all counts was not used as this represented old (built up litter) and new data (daily dropped litter), as opposed to new data alone.

Week 1 (before the intervention) of the litter counts are visually displayed in Figure 8. The dominant litter found was soft plastic (Figure 8), and of those plastics, 33\% were micro plastics (Table 7). Hard plastics were the second most common litter found (Figure 8) with $31 \%$ of those plastics being micro (Table 7). 


\section{Avalon Intermediate Litter Observation Before Intervention}

- Soft plastic
- Hard plastic
- Tin/metal
- Paper/card
- Food
- Other

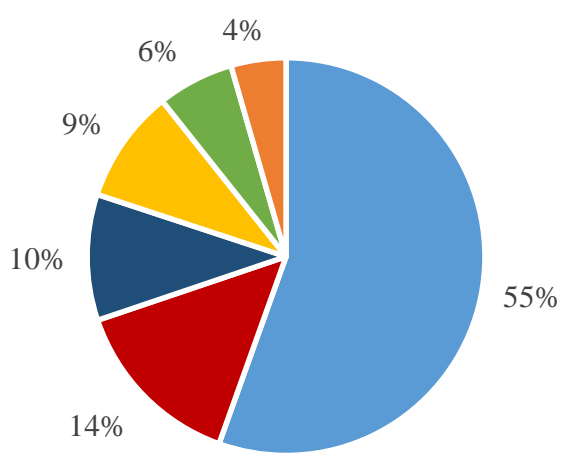

Figure 8 AI litter observation before intervention; percentage of littered items.

Table 7 AI litter observation before intervention daily counts and totals.

\begin{tabular}{|l|r|l|l|r|r|r|l|r|}
\hline $\begin{array}{l}\text { Week } \\
\text { 1 }\end{array}$ & $\begin{array}{l}\text { Macro } \\
\text { plastic } \\
\text { soft }\end{array}$ & $\begin{array}{l}\text { Macro } \\
\text { plastic } \\
\text { hard }\end{array}$ & Paper & Food & Metal & Other & $\begin{array}{l}\text { Micro } \\
\text { Soft }\end{array}$ & $\begin{array}{l}\text { Micro } \\
\text { Hard }\end{array}$ \\
\hline Day 2 & 214 & 61 & 26 & 16 & 37 & 17 & 57 & 14 \\
\hline Day 3 & 139 & 35 & 28 & 18 & 29 & 16 & 62 & 17 \\
\hline Day 4 & 145 & 45 & 30 & 21 & 27 & 5 & 75 & 17 \\
\hline Day 5 & 96 & 21 & 18 & 9 & 29 & 12 & 38 & 4 \\
\hline Day 6 & 132 & 27 & 26 & 14 & 22 & 11 & 49 & 8 \\
\hline Day 7 & 156 & 39 & 19 & 10 & 19 & 10 & 70 & 20 \\
\hline Total & 1167 & 383 & 221 & 118 & 295 & 103 & 393 & 122 \\
\hline
\end{tabular}

Week 2 (directly proceeding the intervention) of the litter counts are visually displayed in

Figure 9. The dominant litter found was soft plastic (Figure 9), with $41 \%$ being micro plastics

(Table 8). Paper/card was the second most common littered item (Figure 9). Of the plastics 
(hard and soft) littered 54\% were identified as torn wrappers (torn), and $24 \%$ as whole wrappers (whole) (Table 8).

\title{
Avalon Intermediate Litter Observation After Intervention
}

\author{
- Soft plastic \\ - Paper/card \\ - Other \\ - Tin/metal \\ - Macro plastic hard \\ - Food
}

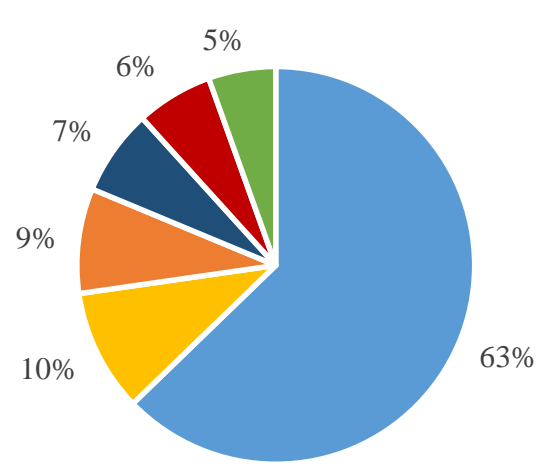

Figure 9 AI litter observation directly proceeding the intervention; percentage of littered items.

Table 8 AI litter observation directly proceeding the intervention daily counts and totals.

\begin{tabular}{|l|r|r|r|r|r|r|l|r|r|r|}
\hline $\begin{array}{l}\text { Week } \\
2\end{array}$ & $\begin{array}{l}\text { Macro } \\
\text { plastic } \\
\text { soft }\end{array}$ & $\begin{array}{l}\text { Macro } \\
\text { plastic } \\
\text { hard }\end{array}$ & Paper & Food & Metal & Other & $\begin{array}{l}\text { Micro } \\
\text { Soft }\end{array}$ & $\begin{array}{l}\text { Micro } \\
\text { Hard }\end{array}$ & Torn & whole \\
\hline Day 2 & 79 & 10 & 15 & 12 & 11 & 1 & 34 & 3 & 51 & 11 \\
\hline Day 3 & 80 & 4 & 15 & 14 & 2 & 6 & 39 & 2 & 43 & 17 \\
\hline Day 4 & 94 & 8 & 16 & 7 & 5 & 2 & 45 & & 68 & 17 \\
\hline Day 5 & 98 & 11 & 12 & 8 & 8 & 7 & 48 & 7 & 66 & 31 \\
\hline Day 6 & 71 & 6 & 12 & 3 & 5 & 6 & 30 & 2 & 37 & 23 \\
\hline Day 7 & 90 & 11 & 9 & 3 & 6 & 2 & 24 & 4 & 44 & 35 \\
\hline Day 8 & 61 & 7 & 12 & 3 & 27 & 4 & 20 & 1 & 35 & 23 \\
\hline Total & 573 & 57 & 91 & 50 & 64 & 28 & 240 & 19 & 344 & 157 \\
\hline
\end{tabular}

Week 3 (follow up from the intervention) of the litter counts are visually displayed in Figure 10. The dominant litter found was soft plastic (Figure 10), this consisted of $28 \%$ micro plastics (Table 9). Hard plastic was the second most common item littered (Figure 10), 
consisting of $20 \%$ of micro plastics (Table 9). Of the plastics (hard and soft) littered $37 \%$ were identified as torn wrappers (torn), and $34 \%$ as whole wrappers whole) (Table 9).

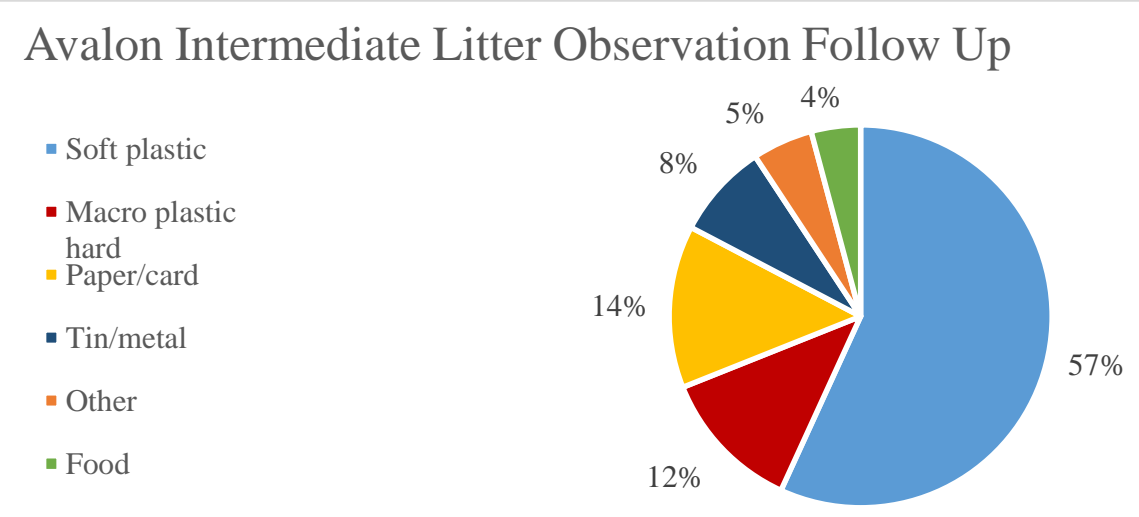

Figure $10 \mathrm{AI}$ litter observation follow up from the intervention; percentage of littered items.

Table 9 AI litter observation follow up from the intervention daily counts and totals.

\begin{tabular}{|l|r|r|r|r|r|r|r|r|r|r|}
\hline $\begin{array}{l}\text { Week } \\
3\end{array}$ & $\begin{array}{l}\text { Macro } \\
\text { plastic } \\
\text { soft }\end{array}$ & $\begin{array}{l}\text { Macro } \\
\text { plastic } \\
\text { hard }\end{array}$ & Paper & Food & Metal & Other & $\begin{array}{l}\text { Micro } \\
\text { Soft }\end{array}$ & $\begin{array}{l}\text { Micro } \\
\text { Hard }\end{array}$ & Torn & whole \\
\hline Day 2 & 53 & 22 & 18 & & 12 & 2 & 13 & 5 & 28 & 28 \\
\hline Day 3 & 66 & 12 & 13 & 3 & 6 & 3 & 14 & 1 & 22 & 30 \\
\hline Day 4 & 90 & 9 & 17 & 9 & 12 & 2 & 38 & 3 & 46 & 25 \\
\hline Day 5 & 57 & 6 & 19 & 6 & 15 & 5 & 24 & 2 & 27 & 18 \\
\hline Day 6 & 59 & 25 & 10 & 1 & 6 & 3 & 18 & 3 & 28 & 28 \\
\hline Day 7 & 64 & 9 & 17 & & 4 & 2 & 5 & 3 & 27 & 35 \\
\hline Total & 389 & 83 & 94 & 19 & 55 & 17 & 112 & 17 & 178 & 164 \\
\hline
\end{tabular}

Across all litter observations, the most commonly littered items included soft and hard plastic and paper/card. Notes were also made across all three weeks identifying the different items counted (Table 10).

Table 10 AI notes made of littered items.

\begin{tabular}{l|l} 
Soft & Wrappers, plasters, cigarette butt, rubber bands, fruit stickers, teared wrappers,
\end{tabular} eraser, synthetic cotton, stickers, yoghurt and noodle lids, hair ties, glad bags, 


\begin{tabular}{|c|c|}
\hline & $\begin{array}{l}\text { juices, styrofoam balls, glad wrap, tape, balloons, masking tape, wristbands, } \\
\text { yoghurt pots, synthetic fabric, lolly wraps, and strapping tape }\end{array}$ \\
\hline Hard & $\begin{array}{l}\text { Straws, lollipop sticks, plastic bottle, googly eye, glitter, lego, pens, forks, ruler, } \\
\text { pencil sharpeners, spoons, juice boxes, board game pieces, counters, beads, a } \\
\text { mouth guard, miscellaneous, and acrylic nails }\end{array}$ \\
\hline Paper & $\begin{array}{l}\text { Paper, toilet paper, cupcake paper, lollipop sticks, cotton, hats, sandpaper, fruit } \\
\text { boxes, wool, cardboard, and clothes }\end{array}$ \\
\hline Food & Fruit, fruit peels, fruit pips, lollies, and sandwiches \\
\hline Metal & $\begin{array}{l}\text { Tin foil, staples, nails, screws, cans, tin wrapped lollies, bobby pins, spring, } \\
\text { paper clip, zip, money, scissors, and an old watch }\end{array}$ \\
\hline Glass & Marbles, glass bottle \\
\hline Wood & Pencils, beads \\
\hline $\begin{array}{l}\text { Not } \\
\text { counted }\end{array}$ & Paint shards, and fruit stickers on fruit \\
\hline
\end{tabular}

\section{$t$-test results}

Two $t$-tests were used to examine whether there were any significant changes in the average litter counts over the course of the study (i.e. before the intervention, directly proceeding the intervention, and six weeks following).

The before counts (average 263.2) and counts directly proceeding (average 123.3) the intervention were found to be significantly different $t(5)=5.28, p=0.0032$, with an effect size of $d=3.71(r=0.88)$ indicating the intervention has significantly changed the students' littering behaviour. The counts directly proceeding the intervention (average 123.3) and following (average 109.5) were found not to be significantly different $t(5)=2.31, p=0.0692$ 
showing the littering behaviour six weeks following the intervention did not significantly change.

\section{Case Study Two}

The RNI case study employed the behavioural techniques education and goal setting. The effect of these techniques were measured through observations of daily litter amounts dropped in the school grounds. Day one of all counts was not used as this represented old (built up litter) and new data (daily dropped litter), as opposed to new data alone.

Week 1 (before the intervention) of the litter counts is visually displayed in Figure 11. The dominant litter found was soft plastic (Figure 11), and of those plastics, $19 \%$ were micro plastics (Table 11). Hard plastics were the second most common litter found (Figure 11) with $37 \%$ of those plastics being micro (Table 11).

\section{Raroa Intermediate Litter Observation Before Intervention}

$$
\begin{aligned}
& \text { - Soft plastic } \\
& \text { - Hard plastic } \\
& \text { - Paper/card } \\
& \text { - Tin/metal } \\
& \text { - Food } \\
& \text { - Other }
\end{aligned}
$$

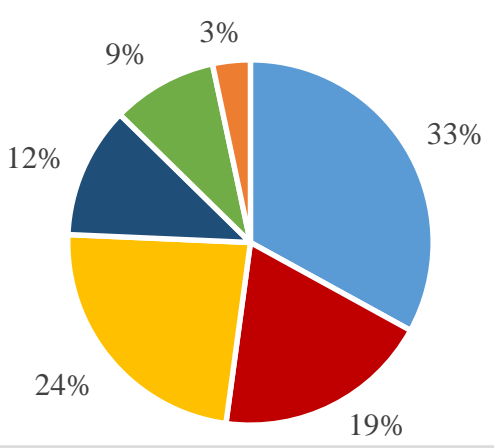

Figure 11 RNI litter observation before the intervention; percentage of littered items.

Table 11 RNI litter observation before intervention daily counts and totals.

\begin{tabular}{|l|l|l|l|l|r|r|r|r|}
\hline Week 1 & $\begin{array}{l}\text { Macro } \\
\text { plastic } \\
\text { soft }\end{array}$ & $\begin{array}{l}\text { Macro } \\
\text { plastic } \\
\text { hard }\end{array}$ & Paper & Food & Metal & Other & $\begin{array}{l}\text { Micro } \\
\text { soft }\end{array}$ & Micro hard \\
\hline Day 2 & 81 & 56 & 66 & 17 & 17 & 10 & 13 & 15 \\
\hline Day 3 & 136 & 87 & 72 & 11 & 28 & 14 & 12 & 17 \\
\hline Day 5 & 116 & 60 & 85 & 24 & 42 & 9 & 33 & 29 \\
\hline Day 6 & 54 & 24 & 18 & 27 & 19 & 3 & 7 & 6 \\
\hline Day 7 & 63 & 38 & 60 & 24 & 45 & 8 & 14 & 18 \\
\hline
\end{tabular}




\begin{tabular}{|l|r|r|r|r|r|r|r|r|}
\hline Day 8 & 74 & 39 & 73 & 45 & 34 & 9 & 22 & 30 \\
\hline Total & 524 & 304 & 374 & 148 & 185 & 53 & 101 & 115 \\
\hline
\end{tabular}

Week 2 (directly proceeding the intervention) of the litter counts are visually displayed in

Figure 12. The dominant litter found was soft plastic (Figure 12), and of those plastics, 13\% were micro plastics (Table 12). Hard plastics were the second most common litter found (Figure 12) with $28 \%$ of those plastics being micro (Table 12). Of the plastics (hard and soft) littered $23 \%$ were identified as torn wrappers (torn), and $32 \%$ as whole wrappers whole (Table 12).

\section{Raroa Intermediate Litter Observation After Intervention}

$$
\begin{aligned}
& \text { - Soft plastic } \\
& \text { - Paper/card } \\
& \text { - Hard plastic } \\
& \text { - Food } \\
& \text { - Tin/metal } \\
& \text { - other }
\end{aligned}
$$

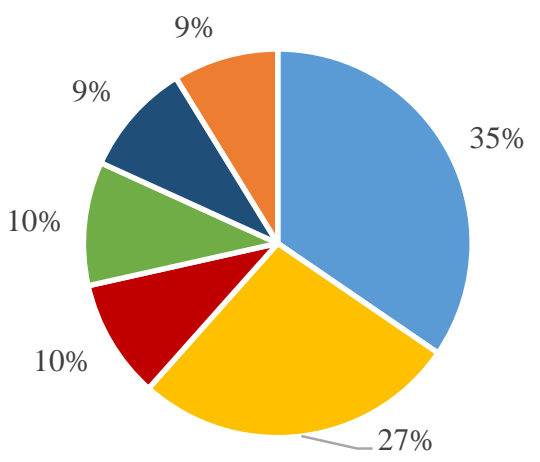

Figure 12 RNI litter observation directly proceeding the intervention; percentage of littered items.

Table 12 RNI litter observation directly proceeding the intervention daily counts and totals.

\begin{tabular}{|l|r|r|r|r|r|r|l|l|r|r|}
\hline $\begin{array}{l}\text { Week } \\
2\end{array}$ & $\begin{array}{l}\text { Macro } \\
\text { plastic } \\
\text { soft }\end{array}$ & $\begin{array}{l}\text { Macro } \\
\text { plastic } \\
\text { hard }\end{array}$ & Paper & $\begin{array}{l}\text { Foo } \\
\text { d }\end{array}$ & Metal & Other & $\begin{array}{l}\text { Micro } \\
\text { Soft }\end{array}$ & $\begin{array}{l}\text { Micro } \\
\text { Hard }\end{array}$ & Torn & Whole \\
\hline Day 2 & 51 & 18 & 35 & 14 & 30 & 6 & 12 & 6 & 20 & 5 \\
\hline Day 3 & 39 & 13 & 35 & 3 & 16 & 7 & 9 & 8 & 10 & 15 \\
\hline Day 4 & 44 & 15 & 28 & 6 & 6 & 2 & 5 & 3 & & 36 \\
\hline Day 5 & 44 & 16 & 52 & 13 & 4 & 7 & 3 & 4 & 19 & 16 \\
\hline Day 6 & 47 & 7 & 28 & 22 & 5 & 11 & 6 & 1 & 16 & 20 \\
\hline Day 7 & 42 & 9 & 28 & 18 & 3 & 3 & 6 & 3 & 12 & 17 \\
\hline Day 8 & 50 & 13 & 30 & 5 & 6 & 10 & 3 & 1 & 18 & 24 \\
\hline Total & 317 & 91 & 236 & 81 & 70 & 46 & 44 & 26 & 95 & 133 \\
\hline
\end{tabular}


Week 3 (follow up from intervention) of the litter counts are visually displayed in Figure 13.

The dominant litter found was soft plastic (Figure 13), which consisted of $11 \%$ micro plastics

(Table 13). Paper/card were found to be the second most common littered item (Figure 13).

Of the plastics (hard and soft) littered $22 \%$ were identified as torn wrappers (torn), and $31 \%$ as whole wrappers whole (Table 13).

\section{Raroa Intermediate Litter Observation Follow Up}
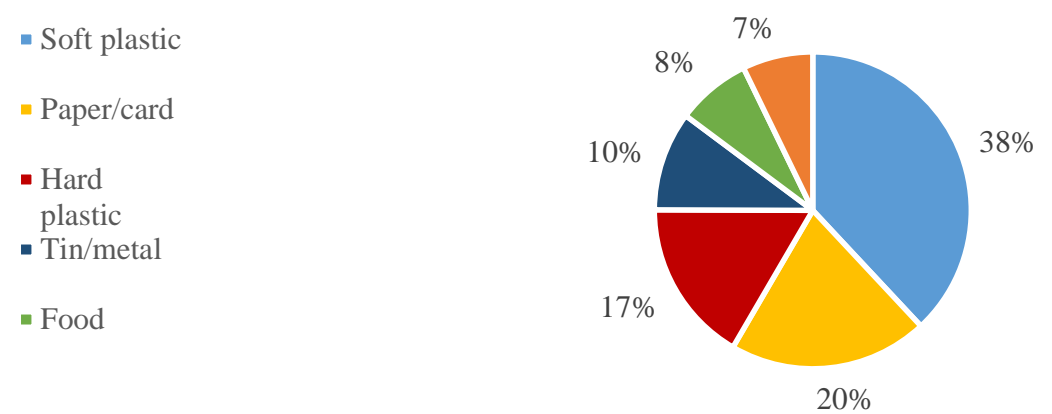

Figure 13 RNI litter observation follow up from the intervention; percentage of littered items.

Table 13 RNI litter observation follow up from the intervention daily counts and totals.

\begin{tabular}{|l|r|r|r|r|r|r|r|r|r|r|}
\hline $\begin{array}{l}\text { Week } \\
3\end{array}$ & $\begin{array}{l}\text { Macro } \\
\text { plastic } \\
\text { soft }\end{array}$ & $\begin{array}{l}\text { Macro } \\
\text { plastic } \\
\text { hard }\end{array}$ & Paper & \multicolumn{1}{l}{ Food } & Metal & Other & $\begin{array}{l}\text { Micro } \\
\text { Soft }\end{array}$ & $\begin{array}{l}\text { Micro } \\
\text { Hard }\end{array}$ & Torn & Whole \\
\hline Day 2 & 68 & 24 & 36 & 11 & 4 & 7 & 7 & 4 & 30 & 19 \\
\hline Day 3 & 60 & 23 & 17 & 8 & 10 & 7 & 8 & 4 & 16 & 27 \\
\hline Day 4 & 51 & 32 & 30 & 12 & 26 & 8 & 4 & 12 & 15 & 21 \\
\hline Day 5 & 46 & 20 & 38 & 9 & 12 & 11 & 5 & 3 & 15 & 23 \\
\hline Day 6 & 36 & 14 & 20 & 13 & 7 & 7 & 5 & & 9 & 20 \\
\hline Day 7 & 36 & 17 & 18 & 3 & 7 & 3 & 4 & 7 & 12 & 25 \\
\hline Total & 297 & 130 & 159 & 56 & 66 & 43 & 33 & 30 & 97 & 135 \\
\hline
\end{tabular}


Across all litter observations, the most commonly littered items included soft and hard plastic and paper/card. Notes made across all three weeks identified the different items counted (Table 14).

Table 14 RNI notes made of littered items.

\begin{tabular}{|l|l|}
\hline Soft & $\begin{array}{l}\text { Wrappers, plasters, cigarette butt, rubber bands, fruit stickers, teared wrappers, } \\
\text { eraser, synthetic cotton, hair ties, glad bags, styrofoam balls, glad wrap, tape, } \\
\text { balloons, masking tape, yoghurt pot, synthetic fabric, lolly wrap, strapping tape, } \\
\text { sponge, shoelaces, synthetic soft earplug, headphones, polystyrene, art sponge, } \\
\text { juices, lunch box liner, earpiece, and miscellaneous }\end{array}$ \\
\hline Hard & $\begin{array}{l}\text { Straws, lollipop sticks, plastic bottle, pens, ruler, pencil sharpeners, juice box, } \\
\text { yoghurt pot, bottle cap, pins, googly eye, beads, cable tie, sunscreen, highlighter, } \\
\text { tennis ball part, synthetic mesh, acrylic nail, sushi fish, miscellaneous, fake } \\
\text { feather, cupcake tray, bread holder, peg, forks, tennis ball part, glue stick, cotton } \\
\text { bud, and milk bottle }\end{array}$ \\
\hline Paper & $\begin{array}{l}\text { Cupcake paper, lollipop sticks, cotton, sandpaper, fruit box, wool, clothes, sticky } \\
\text { notes, newspaper tissue, togs, matches, cooking paper, cotton paper clip, and } \\
\text { cardboard }\end{array}$ \\
\hline Food & $\begin{array}{l}\text { Fruit, fruit peels, fruit pips, lollies, and sandwiches } \\
\text { counted }\end{array}$ \\
\hline Metal & $\begin{array}{l}\text { Tin foil, staples, nails, screws, bobby pins, paper clip, pins, screws, safety pin, } \\
\text { cans, razor, bolt, pencil sharpener, and scissors }\end{array}$ \\
\hline Mood & $\begin{array}{l}\text { Pencils, paintbrush, popsicle sticks } \\
\text { Miscellaneous }\end{array}$ \\
\hline
\end{tabular}

\section{$t$-test results}


Two $t$-tests were used to examine whether there were any significant changes in the average litter counts over the course of the study (i.e. before the intervention, directly proceeding the intervention, and six weeks following).

The before counts (264.7) and counts directly proceeding (120.1) the intervention were found to be significantly different $t(5)=3.99, p=0.0104$, with an effect size of $d=7.67(r=0.97)$ indicating that the intervention significantly reduced the students' littering behaviour. The counts directly proceeding (120.1) and following (125.2) the intervention were found not to be significantly different $t(5)=0.33, p=0.7524$ showing the littering behaviour six weeks following the intervention did not significantly change.

\subsubsection{Lunch box wrappers}

\section{Case study two}

The RNI School case study employed the behavioural techniques education and goal setting. The effect of these techniques were measured through the observation of daily wrapper amounts.

Results from Week 1 (before the intervention) of the wrapper counts is visually displayed in Figure 14. The dominant lunch item counted was found to be wrapperless (Figure 14), with $12 \%$ of the wrapperless items recorded falling into one of the other five categories (Table 15). 


\section{Raroa Intermediate Lunch Box Observation Before Intervention}

- Wrapperless

Wrapped

- Wrapped

Wrapperless

Figure 14 RNI wrapperless lunch observation before the intervention; percentage of items.

Table 15 RNI lunch observation before the intervention daily counts and totals.

\begin{tabular}{|l|r|r|r|r|r|r|r|}
\hline Week 1 & Wrapperless & Wrapped & Glad bag & Other & Honey wrap & Cooking paper & Tin foil \\
\hline Day 1 & 87 & 34 & 6 & 1 & 1 & 2 & 1 \\
\hline Day 2 & 102 & 13 & 7 & 2 & 8 & 4 & 8 \\
\hline Day 3 & 96 & 16 & 5 & & & & \\
\hline Day 4 & 87 & 28 & 11 & 2 & 1 & 2 & 1 \\
\hline Day 5 & 104 & 7 & 6 & 1 & & & \\
\hline Day 6 & 97 & 26 & 4 & 5 & & & \\
\hline Day 7 & 87 & 17 & 6 & 4 & 1 & & 2 \\
\hline Day 8 & 96 & 9 & 1 & & 1 & & \\
\hline Day 9 & 81 & 18 & 10 & 3 & & & \\
\hline Total & 837 & 168 & 56 & 18 & 12 & & 12 \\
\hline
\end{tabular}

Week 2 (directly proceeding the intervention) of the wrapper counts are visually displayed in

Figure 15. The dominant lunch item counted was found to be wrapperless (Figure 15), with $12 \%$ of the wrapperless items recorded falling into one of the other five categories (Table 16). 


\section{Raroa Intermediate Lunch Box Observation After Intervention}

- Wrapperless

Wrapped $16 \%$

- Wrapped

Wrapperless

Figure 15 RNI wrapperless lunch observation directly proceeding the intervention; percentage of items.

Table 16 RNI lunch observation directly proceeding the intervention daily counts and totals.

\begin{tabular}{|l|r|r|r|r|r|r|r|}
\hline Week 2 & Wrapperless & Wrapped & Glad bag & Other & Honey wrap & Cooking paper & Tin foil \\
\hline Day 1 & 88 & 10 & 5 & 2 & 1 & & \\
\hline Day 2 & 95 & 13 & 11 & 2 & & 3 & 2 \\
\hline Day 3 & 95 & 13 & 5 & & 1 & & \\
\hline Day 4 & 97 & 7 & 5 & 3 & & & \\
\hline Day 5 & 78 & 27 & 6 & & 1 & 1 & \\
\hline Day 6 & 89 & 24 & 4 & 1 & & 1 & \\
\hline Day 7 & 112 & 17 & 7 & 1 & 5 & 5 & 2 \\
\hline Day 8 & 91 & 20 & 6 & 8 & 1 & & \\
\hline Day 9 & 83 & 26 & 6 & & 3 & 1 & 1 \\
\hline Total & 828 & 157 & 55 & 17 & 12 & 11 & 5 \\
\hline
\end{tabular}

Week 3 (follow up from the intervention) of the wrapper counts are visually displayed in

Figure 16. The dominant lunch item counted was found to be wrapperless (Figure 16), with $12 \%$ of the wrapperless items recorded falling into one of the other five categories (Table 17). 


\section{Raroa Intermediate Lunch Box Observation Follow Up from Intervention}

- Wrapperless

Wrapped

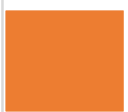

$21 \%$

- Wrapped

Wrapperless

Figure 16 RNI wrapperless lunch observation follow up from the intervention; percentage of items.

Table 17 RNI lunch observation follow up from the intervention daily counts and totals.

\begin{tabular}{|l|r|r|r|r|r|r|r|}
\hline Week 3 & Wrapperless & Wrapped & $\begin{array}{l}\text { Glad } \\
\text { bag }\end{array}$ & Other & $\begin{array}{l}\text { Honey } \\
\text { wrap }\end{array}$ & $\begin{array}{l}\text { Cooking } \\
\text { paper }\end{array}$ & Tin foil \\
\hline Day 1 & 86 & 17 & 9 & & 1 & 1 & \\
\hline Day 2 & 89 & 16 & 14 & 4 & & & \\
\hline Day3 & 71 & 17 & 4 & 2 & & & 2 \\
\hline Day 4 & 69 & 26 & & 1 & 2 & 1 & \\
\hline Day 5 & 52 & 15 & & 2 & 3 & & \\
\hline Day 6 & 65 & 26 & 1 & 1 & 1 & 2 & 2 \\
\hline Day 7 & 86 & 21 & 6 & & 1 & 2 & 2 \\
\hline Day 8 & 72 & 18 & 11 & & 1 & 3 & \\
\hline Day 9 & 90 & 29 & 6 & & & 1 & \\
\hline Total & 680 & 185 & 51 & 10 & 9 & 10 & 6 \\
\hline
\end{tabular}

\section{$t$-test results}

Two $t$-tests were used to examine whether there were any significant changes in the average wrapper counts over the course of the study (i.e. before the intervention, directly proceeding the intervention, and six weeks following).

The before counts (35.1) and counts directly proceeding the intervention (32.2) were found to be significantly different $t(8)=2.51, p=0.0363$, with an effect size of $d=1.00(r=0.45)$ 
indicating that the intervention significantly changed the level of wrappers presented in students' lunch boxes. The counts directly proceeding (32.2) and following the intervention (35) were found not to be significantly different $t(8)=0.14, p=0.8944$ showing the amount of wrapper presented in the students' lunch boxes did not significantly change six weeks following the intervention. 


\section{Chapter 6 Discussion and Conclusion}

\subsection{Introduction}

The reduction of littering has been targeted in the literature, utilising a range of behaviour change techniques. The behaviour change techniques education, the hypocrisy paradigm and goal setting have not been assessed in relation to litter reduction in a school setting however. To better understand the effectiveness of these techniques, this study applied these techniques in an attempt to reduce littering in two New Zealand intermediate schools. This chapter discusses the results of this study, aiming to answer the three research questions posed in this study. Under these research questions, this section provides an understanding of what barriers and benefits preclude and promote the behaviour of littering and packaging use, how key stakeholders influenced the interventions' results, and how effective the chosen techniques were at influencing the targeted behaviours in a New Zealand intermediate school setting. This chapter concludes by summarising the research findings, limitations of the research, and the relevance of this research for decision makers.

\subsection{Research Question 1}

What are the barriers and benefits for participants and key stakeholders to perform the desired litter and packaging disposal behaviours?

The barriers and benefits of littering influence the behaviour in a meaningful way. This study identified variables in the research that acted as barriers to and influenced the perceived benefits of performing the targeted behaviours. 


\subsubsection{Cognitive variables}

\section{Education}

During the qualitative data collection process, awareness (due to education) was described by participants as a benefit that promoted the targeted litter and wrapper behaviours. Teachers reported that the awareness students gained from the education provided was a necessary step in the intervention and will also be an important ongoing investment the school can make to maintain the targeted behaviours. Support for the use of education was displayed by the students who provided positive feedback about the educational section of the intervention. More specifically, teachers placed a large emphasis on the importance of educating the students about 'where' their litter goes and 'why' it is important to be conscious of littering, wrapper use and the environmental and health effects associated with these behaviours.

Many researchers argue that only a small fraction of pro-environmental behaviour can be connected directly to environmental awareness and knowledge. Despite these findings, litter concern and awareness often positively influence the behaviour of littering (Khawaja \& Shah, 2013). The findings of this research align with the use of education to influence the behaviour of littering.

When interpreting why the use of education may have been beneficial in promoting litter reduction two key variables can be examined. First, the environmental content used explained the desirable and undesirable behaviours, providing rationales for, and suggestions and alternatives about to how to perform the targeted behaviours. Secondly, the education was tailored to engage the target audience, focussing on areas perceived to be of interest to the audience demographic (the marine and terrestrial animals), aligning the education with their beliefs, as well as drawing on their community for examples. By highlighting the issue of littering in a way that resonated with the participants' beliefs, an emotional connection was 
developed where participants displayed care and empathy for terrestrial and marine organisms.

\section{Motivation}

Participants described the benefits of education as triggering motivation to act towards the problem. Participants gained motivation from their awareness of the problem, and their empathy and care towards the issue.

These findings are supported in the literature, where the importance of an individual's awareness of an environmental problem and its causes, as well as knowing how to act to reduce relevant environmental impact, have been shown to promote pro-environmental behaviour (Kollmuss \& Agyeman, 2002). In addition, individuals' expressions of empathy and care for the environment have been observed in similar studies, with conclusions of motives for empathy and care being comparable to that observed here (Ballantyne \& Packer, 2002; Kollmuss \& Agyeman, 2002; Steg \& Vlek, 2009).

Furthermore, participants stated that the motivation produced by awareness, empathy and care could also act as a barrier that could negatively influence the targeted behaviours. Awareness of an environmental problem can promote pro-environmental behaviour (Kollmuss \& Agyeman, 2002). But conversely, if people are unaware of negative consequences related to littering, they are more likely to litter than those who have gained an understanding that there are consequences (Heberlein, 1972).

Moreover, care and emotion can promote pro-environmental behaviour. A study by Khawaja and Shah (2013) which focused on the determinants of littering behaviours, found that individuals who have low altruism (care) are more likely to litter. Emotional distress however, can prevent an individual from performing a pro-environmental behaviour. Individuals instead can produce defence mechanisms towards an emotion they are feeling. 
These defence mechanisms include denial of the problem, delegation of emotion, apathy, and deliberate distancing from that emotion (Kollmuss \& Agyeman, 2002).

These studies support the view found in this study that if individuals are not aware, or do not show care or empathy in regard for the presented issue, the target behaviours are less likely to be performed. In particular, it is suggested that when promoting empathy to encourage behaviour change, the behaviour should be achievable. Strong feelings towards an issue, combined with a sense of helplessness, will not promote action (Kollmuss \& Agyeman, 2002). In this study, the motivators of awareness, care, and empathy are shown to be key in driving behaviour change.

\subsubsection{Situational variables}

\section{Normative Influences}

Situational variables influence the behaviour of littering (Cialdini, 2003; Cialdini et al., 1990). In the qualitative component of this study, participants noted that normative influence was both a barrier and benefit. Normative influence from family, peers, and the schools were noted as the main influencing norms in both case studies. This influence included the way stakeholders involved with the schools spoke about and treated their surrounding environment, and whether the student's friends were performing or promoting the targeted behaviours.

The normative influences of school, family, and peers have been found to influence attitudes which influence action. Kollmuss and Agyeman (2002) found social norms, family customs, and cultural traditions shape and influence individuals' attitudes and actions towards the environment. For example, if an individual's main cultural influence promotes an unsustainable lifestyle, the individual is less likely to perform pro-environmental behaviours. 
This study, along with others (Cialdini, 2003) suggest the normative influences presented in this study may have acted as a barrier to or benefit of performing the targeted behaviours.

\section{Descriptive Norms}

Participants reported the descriptive norms used about littering at school prior to the projects (individuals littered a lot) acted as a barrier to behaviour performance. Following the projects, participants explained that the descriptive norms used had changed for the majority of individuals and families, and litter was talked about in a positive light (individuals were littering less). After the implementation of the projects descriptive norms related more closely with the injunctive norms expressed by both schools.

Highlighting descriptive norms is likely to be counterproductive when an environmentally harmful behaviour is prevalent (Cialdini, 2003). For example, messages designed to deter a certain behaviour may have the opposite effect of encouraging that behaviour where they describe a large number of people who engage in the environmentally destructive behaviour. Descriptive norms are effective when the predominant behaviour is environmentally beneficial (Cialdini, 2003). Based on this finding, the change reported in the schools' descriptive norms about littering may have assisted in both the litter and wrapper reduction found in both schools.

\subsubsection{Personal and situational variables}

\section{Motivation}

\section{Benefits}

Motivation can promote the performance of pro-environmental behaviours (Pelletier et al., 1998). Awareness was described by the participants in this study as a central component of students' motivation to perform the targeted behaviours. More specifically, teachers 
described students' self-awareness in the world as a motivating influence to perform the desired behaviours. When an individual's values lay beyond their own immediate wellbeing including biospheric and prosocial values, they have been found to be more likely to perform a pro-environmental behaviour (Steg \& Vlek, 2009).

In this research, teachers believed self-awareness increased with age (maturity) and that only certain individuals in this research possessed this quality. The level of knowledge an individual acquires increases as they grow older, because education positively influences an individual's awareness (Kollmuss \& Agyeman, 2002).

\section{Visuals}

Motivation driven by empathy came from the images displayed in the projects. Participants described that they were shocked by and felt empathy towards organisms and the environment displayed in the images which showed animal injury and unclean environments caused by litter pollution. Kollmuss and Agyeman (2002) have found emotional engagement from images is important for gaining support for campaigns, leading to projects which aim to protect large mammals gaining a large amount of public support. Imagery has often been used in the environmental field to translate environmental damage into understandable, perceivable information. Images are often found to provide increased understanding but not necessarily an emotional connection to engage people (Kollmuss \& Agyeman, 2002).

Contrary to the literature's general findings, the use of images provoked shock and empathy which created an emotional connection in this study.

\section{Social Modelling and Influence}

The influence of others (social modelling) can motivate an individual's response to littering (Cialdini, 2003). Participants described the influence of others (social modelling and 
influence from teachers, parents and peers) to have motivated students to perform the targeted behaviours. Social modelling and influence provide cues about what is socially accepted or is the right thing to do, and has been suggested as being highly relevant in school playgrounds where littering can be prominent (Long et al., 2014). In addition, effort and action from teachers, parents and peers have been found to play a part in influencing an individual's attitudes, motivations and behavioural outcomes (Long et al., 2014). Based on these studies, as well as the support and reliance students had on the key stakeholders in this research (particularly in case study two) it is thought the influence of others may have assisted in the litter and especially the wrapper reduction found in both schools.

\section{Prompting}

Participants noted the effort to perform the target behaviours at times appeared unachievable and therefore believed the use of prompts would promote the behaviours. Prompting or cueing a behaviour has been found to promote pro-environmental behaviour, specifically litter reduction (Geller et al., 1977). It is likely that prompts used in this research would have assisted in the performance of the targeted behaviours.

\section{Barriers}

Alongside beneficial motivators were motivators which were considered barriers to performing the targeted behaviours.

\section{Lack of Reinforcement}

The lack of reinforcement of the behaviour (only one session of intervention engagement) was thought to hinder the students' engagement. This was mentioned mostly in regard to case study one, as case study two had continued interaction and reinforcement from lunch box 
counting. Projects working with young individuals are argued by Zelezny (1999) to be more likely to produce significant results when projects last longer than 10 hours.

\section{Entitlement}

Participants believed some students lacked the motivation to perform the target behaviours, due to feelings of entitlement and a lack of responsibility. Feelings of entitlement creating a barrier to performing pro-environmental actions are reported in the literature (Miller, Rathouse, Scarles, Holmes, \& Tribe, 2010). Research studying English tourists' behaviour towards the environment found tourists were resistant to changing their behaviours and expressed entitlement to consume the resources available (Miller et al., 2010). Children expressing entitlement is often associated with parental influence (Segrin, Woszidlo, Givertz, Bauer, \& Taylor Murphy, 2012). In the future, parental involvement in the projects could be increased to provide the opportunity to increase parents' awareness of the project as well as how their child is performing the target behaviours. Increasing parental involvement may positively affect the influence parents have on their children in association with the targeted behaviours.

\section{Helplessness}

Despite participants having the opportunity to create change through the targeted behaviours, some experienced feeling helpless against the worldwide issue of litter pollution. This feeling has been explained by Kollmuss and Agyeman (2002) as being reliant on an individual's 'locus of control', which represents a person's perception of whether they can or cannot bring about change through their own actions. Individuals with an external locus of control believe their actions are inconsequential and believe only powerful others can bring about change, which was the case for some individuals in this research. Alternatively, individuals with a strong locus of control feel that their behaviour will create change. Although participants had 
the opportunity to create change through the targeted behaviours, they may not have felt as though their behaviours were significant. Providing feedback to individuals about the achievement of the project may have helped resolve a part of this issue.

\section{Ease}

During the qualitative interviews, an individual's sense of ease towards performing the targeted behaviours was found to be both a benefit and a barrier to behaviour performance. The perception of behaviour being easy or difficult can relate directly to an individual's performance of that behaviour. People are more likely to perform environmental behaviours which are perceived to be easy compared to behaviours which are perceived to be difficult (Green-Demers, Pelletier, \& Ménard, 1997).

\section{Effort, Time, and Business}

Participants stated that effort was required when performing certain behaviours, as well as remembering and being bothered to perform behaviours. Regarding recycling, obtaining support from supermarkets, purchasing bulk foods, and using or obtaining specific plastic alternatives, participants explained that effort was required due to the lack of convenience and ease associated with these actions, creating a barrier to performing the targeted behaviour. Interestingly, while some participants reported effort was required to perform these behaviours, others stated these behaviours as easy.

These perceptions of ease may have been influenced by an individual's level of access to services. Individuals with greater access to 'greener' options such as recycling schemes and 'green' products are more likely to be pro-environmental and use them (Barr, 2003).

Therefore, the poorer the services, the less likely individuals are to use them (Kollmuss \& Agyeman, 2002). 
Goal setting and commitment making were also stated by participants to be both easy and difficult to perform; this is likely due to the subjectivity individuals have when perceiving goals and commitments. Whether an individual perceives a goal or commitment as easy or hard is dependent on their experience and ability relative to the goal or commitment. However, Locke and Latham (2013) state that, as long as an individual has an acceptable commitment and ability to achieve a goal, the more difficult the goal, the better an individual's performance. Therefore, to promote the effective use of goals and commitments, alongside gaining commitment, understanding an individual's ability to achieve a goal or commitment, as well as providing the opportunity to increase their ability to perform the behaviour may be an important step in inducing performance.

Participants stated how busy they were and how much time they had as barriers to performing the targeted behaviours. Being busy and having time to perform a task relates directly to people's priorities. It has been hypothesised that an individual's more immediate needs and motives (e.g. saving time and money, being comfortable) are often prioritised over motives such as social values and altruism. In addition, an individual's knowledge and values can also be overridden by one's habits and feelings of responsibility. If an individual does not value the result of a behaviour or it does not align with their personal priorities, they are less likely to perform the behaviour (Kollmuss \& Agyeman, 2002). Participants stated being busy was a barrier which resulted in the favouring of convenience foods over wrapper free alternatives, acting lazy, and failing to achieve commitments and goals. In addition, participants stated that having a lack of time created a barrier to invest in behaviour change and to create new habits. Based on the findings in the literature, it is likely that the target behaviours, as well as the tasks involved to achieve them, were not prioritised or valued by all participants.

\section{Socio-economics}


During the interview process, socio-economic factors were stated by participants as both a barrier and benefit to behaviour performance. Participants believed socio-economics influenced what type of modelling was displayed relevant to the target behaviours in students' home environments. Socio-economic factors and particularly economic factors, were also perceived to influence the purchase or deter the purchase of wrapperless goods and wrapperless alternatives. Factors such as monthly income, education level, and type of residence have been found to affect littering behaviour (Khawaja \& Shah, 2013). More specifically, people's decisions and behaviour have been shown to be strongly influenced by economic factors (Kollmuss \& Agyeman, 2002). These studies support the findings of this research that socio-economic factors may have directly or indirectly influenced the performance of the target behaviours.

\section{Sustainability}

Participants' understanding of sustainability was perceived to be both a benefit and a barrier to performing the targeted behaviours.

Participants discussed contrasting perspectives concerning New Zealand's current and past sustainability practices and the school's sustainability practices. The perceptions of participants highlight the barriers and benefits individuals perceive when considering sustainability. Country and community-specific factors can influence pro-environmental behaviour, such as social influences, environmental legislation, and the availability of 'green' goods and services (Cordano et al., 2010; Diamantopoulos et al., 2003). Because the sustainable practices within a community and country can differ, participants' differences in opinion presented towards sustainability may highlight the difference in practices or the availability of services the participants have experienced or have available. This differentiation may have influenced participants' performance of the targeted behaviours. 


\section{Project Success}

During the qualitative data collection participants provided advice on what needs to be improved to maintain future success.

Suggestions regarding what needs to be improved to maintain future success were aimed at the projects themselves and making them more comprehensive. Suggestions to influence the project's future success in changing behaviour included the provision of hands-on activities. Compared to directly experiencing an environmental problem, learning about it is much less likely to influence people's behaviour (Kollmuss \& Agyeman, 2002). The use of hands-on activities suggested in this research supports the findings in the literature.

The provision of feedback was also suggested by a participant in case study two following the implementation of the project. The provision of feedback is a part of the theory of goal setting, which was implemented in case study two. Due to time constraints and a lack of consensus in the literature about the use of feedback when promoting task performance in combination with goal setting; feedback was not included in case study two's intervention. However, some studies have provided evidence that goals promote task performance better when feedback is provided compared to when it is not (McEwan et al., 2015).

\subsection{Research Question 2}

\section{What influence do key stakeholders have on intervention desired litter and packaging}

\section{disposal behaviours?}

The behaviour change literature suggests that parents, teachers, and peers all play a role in influencing attitudes, motivations and behavioural outcomes (Long et al., 2014). As mentioned in the literature review, there is growing evidence that a bi-directional approach 
between children and parents can influence both children's and parents' pro-environmental attitudes and behaviours (Öllerer, 2015; Payne, 2005). Additionally, in line with the overarching framework of CBSM, effective environmental programmes should target the entire community (Pooley \& O’Connor, 2000).

The qualitative results reported in this study support that of the literature, with interviewees stating that the influence of family dynamic, family values, and family input, school community, and teacher, parent, and community support all play or played an important role in the success of the projects through both direct and indirect influence of the participants.

Participants reported mixed views on the effect of punishments and reinforcement from key stakeholders during the projects. Participants stated that reinforcement before the intervention was ineffective due to the disinclination associated with being told what to do. However, participants noted that reinforcement relevant to the projects, specifically in case study two was effective in influencing the students and teachers behaviours. This was suggested by participants to be a result of introducing the behaviour and projects as an expectation, as well as the scrutiny and reminder associated with assessing the wrapperless behaviour in case study two. Punishments and reinforcement have been found in the literature to affect an individual's personal response to littering (Long et al., 2014) and have also been found to be effective in the behaviour change literature (Timlett \& Williams, 2008). Based on these studies, the use of reinforcement and punishment used in this research may have influenced the target behaviours.

\subsection{Research Question 3}

Does the use of behaviour change interventions influence the litter and packaging behaviour of intermediate aged school students, and if so, do such behaviours continue in the future? 


\section{Littering Behaviour}

The quantitative results produced in both case studies provide evidence in support of behaviour change interventions hypocrisy and goal setting in combination with education as effective methods to reduce the behaviour of littering in an outdoor Intermediate School setting. Both case studies significantly reduced litter by over $50 \%$ when comparing before intervention litter counts with counts directly proceeding the intervention, and both case study effect sizes were large. Additionally, both case studies maintained reduced litter levels six weeks following the intervention, with results showing that follow-up counts did not significantly increase or decrease from the counts directly proceeding the intervention.

The success of the quantitative findings is supported by the qualitative results; with most participants stating the project had been successful in reducing litter in the school grounds. This was particularly true for participants from case study two (especially in comparison with previous years). In contrast, participants from case study one reported that litter levels varied, with some participants reporting litter reduction success while others were unsure about litter reduction success.

\section{Wrapper Use Behaviour}

Quantitative data also provided evidence in support of goal setting as an effective intervention in reducing lunch box wrapper use in case study two. Lunch box wrappers were found to be significantly reduced by $6.6 \%$ when comparing before intervention wrapper counts with counts directly proceeding the intervention, and the effect size was moderate.

Reduced wrapper levels were maintained six weeks following the intervention, with results showing that follow-up counts did not significantly increase or decrease. The quantitative 
results found were reemphasised in the qualitative data, with interview participants stating that the amount of lunch box wrappers present at school had decreased after the intervention.

\section{Case Study Effect Sizes}

The litter reduction effect for case study one $(d=0.88)$ was not easily compared with the existing literature, because other hypocrisy studies did not use Cohen's d effect sizes. However, the hypocrisy intervention in case study one was found to be significantly effective, comparable to multiple hypocrisy interventions, as described in a review by Stone and Fernandez (2008) on the use of hypocrisy to motivate behaviour change. It is important to note, however, that all studies used in Stone and Fernandez (2008) used a two-group comparison whereas this study used the same group. Also, Stone and Fernandez (2008) did not analyse any hypocrisy interventions related to litter reduction.

The litter reduction effect size for case study two $(d=0.97)$ exceeded the average effect size of goal setting displayed in the literature, demonstrating a large effect size. The wrapper reduction effect size $(d=0.45)$ result correlated closely with the literature's average effect size. For comparison, a meta-analysis by Epton et al. (2017), which analysed the effects of goal setting on behaviour change reported an average significant effect size from across 384 studies $(N=16,523)$ of $d=0.34$. In case study two, participants were incentivised to employ wrapperless lunches two and a half weeks prior to the intervention; this may have resulted in reduced wrapper and litter amounts in case study two prior to the before intervention counts. Additionally, many studies use a two-group comparison whereas this study used the same group; therefore the effect size comparison made in this research is not directly comparable. Furthermore, the meta-analysis by Epton et al. (2017) did not analyse any goal setting interventions related to litter reduction.

\section{Littered Items}


Litter counts across both case studies found soft plastic, hard plastic, and paper to be the top three littered items. Soft plastics were identified consistently as the item most littered, and hard plastic and paper were interchangeably the second and third items most littered. These results correspond with national and international litter survey results. For example, a study by Waste Not Consulting (2015) found that in eight urban areas in New Zealand, the top three littered items in ascending order were: paper, snack food packaging, and unclassified packaging. Internationally, these results correspond with a study by Beck (2007) who surveyed the litter of twelve American states; results found that in five out of ten states the two most common pieces of litter were paper and plastic.

Plastic littered items were categorised into micro and macro. Of all plastics observed in case study one, an average of $33 \%$ micro plastics were found, and in case study two an average of $19 \%$ micro plastics were found. Compared to published literature, the prevalence of micro plastics measured in this study is lower than expected. The national survey by Waste Not Consulting (2015) found that small littered items (up to $6 \mathrm{~cm}$ in diameter) represented $96.5 \%$ of all litter surveyed. However, it is important to note this research only collected micro data for plastic littered items, whereas Waste Not Consulting (2015) collected micro data for cigarette butts, chewing gum, and small littered glass, plastic, metal, tyres, and paper.

\section{Wrappers}

Initial litter counts (i.e. before the intervention) conducted for this research did not categorise plastic items into being whole or torn; this was only done during the following two counts (directly proceeding the interventions and after). However, the counts directly proceeding the intervention and following did provide insight into the percentage of lunch box based items that made up the plastic counts. Across both studies, the average of whole wrappers was $30 \%$, and torn pieces were $34 \%$. The differentiation between whole and torn plastic was made 
based on the assumption that torn plastic is more likely to have been accidentally dropped due to its smaller size versus larger items which are more visible when dropped (accidental or not). This was based on the literature which states the frequency of littering and resistance to change is influenced by the characteristics of an item being littered (Wever et al., 2010).

These results provide an insight into the percentage of plastic rubbish from students' lunch box packaging that was potentially dropped by students, compared to the remaining other plastic items counted which may or may not have been dropped by students. This is important to note, as the educational presentation that was provided to the students targeted lunch box wrappers and home plastics as the items to attempt to 'refuse, reduce, reuse and recycle'.

It stated in the literature that the characteristics of an item influence the behaviour of the individual littering (Wever et al., 2010). Interestingly, in the notes made for items littered in this research, both case studies had many reusable as well as single-use items littered. This could suggest that some items may have been passively littered (active vs passive littering ${ }^{3}$ ) or that the students were uninfluenced by the characteristics of the items. The wrapperless lunch counts in case study two showed $11 \%$ of the overall counts consisted of glad bags, cooking paper, tin foil, and other items. These items are identified as reusable, and although students, teachers and parents stated these items were used again, all the listed items were found more than once during the litter counts.

\section{Behaviour Change Interventions}

\section{Hypocrisy and Goal Setting}

\footnotetext{
3 Active littering occurs when litter is kept in an individual's hand while they occupy an area, when leaving the area the litter is deposited in the area; and passive littering is when an individual deposits litter in an area and when leaving the area the litter is left behind (Sibley \& Liu, 2003).
} 
The results from both behaviour change interventions relating to hypocrisy and goal setting indicated a reduction in littering and packaging use. Most participants believed the projects were successful in changing the targeted behaviours, and participants highlighted the importance and influence of the interventions in the project's success. Although participants from case study two highlighted the importance of the interventions, some also mentioned their uncertainty around the direct effect of the interventions on the targeted behaviours. When questioned about what participants perceived to influence the project's success participants (unbeknownst to them) highlighted many of the attributes and moderating variables of both intervention theories discussed in Chapter Two. Both theories attributes' and moderating variables described in Chapter Two were highlighted as influences on the projects. The variables highlighted included commitment making, social influence, normative messages, goal setting, knowledge, and contextual influence.

Both theories, for example, highlighted social support and influence as variables which can influence the effect of the interventions. Research on the hypocrisy intervention describes that social support and pressure can influence an individual's engagement in advocating for a behaviour and accepting personal responsibility for a past behaviour (McKimmie et al., 2003). Social support and influence were described in interviews as key influences in the projects. They were not linked with moderating the success of the interventions themselves, but with project success as a whole (as described above). In addition, some moderating variables were not addressed during the implementation of the project. However, they were highlighted by participants in the interviews as influencing project effectiveness. For example, adult participants stated that some students perceived the goal of reducing wrappers in their lunches not as a challenge (as described in the goal setting moderating variables), but as a threat, causing anxiety and worry. Adult participants stated the importance of remedying this response in future projects, so the children do not associate stress with achieving a goal, 
so as not to impair their mental wellbeing and achievements. This matter fits with the findings in the literature that when individuals perceive a goal as a threat, this can negatively affect their goal performance (Locke \& Latham, 2013).

\section{Education}

Alongside both behaviour change interventions, education was found to be an essential prerequisite for the success of the interventions. The influence of education was stated to be an important part of the intervention during the interviews. Prior to the intervention, participants reported that students possessed varying levels of education. Research indicates that individuals have relatively low levels of marine education. Walter and Lien (1985) reported Canadian students' knowledge levels about the marine environment as being surprisingly low. Following the intervention in the current study, participants reported that students' level of education, as well as their awareness and communication surrounding the topic, had improved. Although it is difficult to determine the effect of education in this study (because it was combined with other interventions), this observation does fit with the finding that environmental education improves environmental knowledge (Leisher et al., 2012; McGuire, 2015). Teachers from case study one also stated taking up new, related behaviour changes following the presentation (teachers did not partake in goal setting or hypocrisy). This self-reported behavioural change is consistent with a smaller sample of the literature suggesting education can promote behaviour change (Zelezny, 1999).

\section{CBSM}

The findings of this study suggest that community based social marketing, when used in conjunction with environment engagement, can be used to better manage an individual's environmental behaviour. These findings, in line with Kennedy (2010) show that behaviours can be effectively influenced using a comprehensive approach; focusing on identifying and 
overcoming barriers to change, promoting benefits to act, utilising behaviour change interventions, and evaluating the results.

\subsection{Conclusion}

Recognising the part which domestic littering plays in the growing global litter problem, the main objective of this research was to test and understand the effect of behaviour change interventions on littering in a New Zealand school setting. Guided by the CBSM framework this research posed three questions to address the research objective. These questions explored the barriers and benefits of littering and packaging use, the influence of key stakeholders in reducing the rate of littering and wrapper use, and the influence of behaviour change interventions on litter and packaging behaviours in New Zealand schools. This research used a mixed methods approach, informed by a pragmatic epistemology. Data collection consisted of quantitative litter and wrapper counts and semi-structured interviews with teachers, parents, and students.

The key conclusions of this study are summarised as follows. Multiple barriers and benefits of performing the targeted behaviours were identified during the interview process. These barriers and benefits, for the most part, matched with those found in the literature. Barriers to and benefits of performing the targeted behaviours included cognitive, situational, and personal variables. From these variables, the main influencing factors observed were education, care for the environment, motivation, ease, normative influences, community and sustainability. The identification of these variables is critical for understanding factors that have influenced the project's effectiveness in inducing behaviour change, as well as barriers to consider for future projects. 
Regarding the influence of key stakeholders in reducing the rate of littering and wrapper use, family and teachers were identified during the interview process as key influencers impacting students' performance of the targeted behaviours. These results aligned with those in the literature. A major impact on the students' performance of the target behaviours was identified as the influence of family dynamic, values, and input, school community, and teacher, parent, and community support. These findings provide support for future projects to consider the influence of key stakeholders and integrate further community involvement into future projects.

Lastly, the behaviour change interventions of hypocrisy and goal setting in combination with education resulted in a significant reduction of litter and packaging behaviours in two New Zealand schools. Both case studies resulted in reduced litter and wrapper levels six weeks following the intervention. These results largely match results of intervention studies observed in the literature. Based on litter counts in both case studies, it was found that soft plastic, hard plastic, and paper were the top three littered items; these findings also match those in the literature. In both studies, (the average of) whole wrappers and torn pieces made up approximately a third of all litter.

A majority of participants identified the projects as successful in changing the targeted behaviours. Participants highlighted the attributes and moderating variables of both intervention theories (e.g. social support and influence) as influencing the project's success. These results provide support for the use of behaviour change interventions of hypocrisy and goal setting in combination with education for targeting litter and packaging behaviours in a New Zealand school context. 


\subsection{Research Limitations}

Four main limitations of this research were recognised. Firstly, each case study within this research implemented two techniques (goal setting and education, and hypocrisy and education), leading to difficulty in separating the sole effects of the individual techniques. A more extended study would be needed to determine the unique effects of either goal setting, hypocrisy, or education.

Another limitation of the present study was the identification of the barriers and benefits of littering. Following the CBSM framework, this research would ideally have identified the barriers and benefits of littering in a number of steps. Firstly, by reviewing the relevant literature on littering, secondly by performing observations of people refusing to litter, or putting litter in the bin as well as observing people littering. Thirdly, by conducting focus groups to investigate the target audiences' attitudes and behaviours to refusing to litter or putting litter in a bin; and lastly, surveying the target audience to increase the understanding of individuals' barriers and benefits to performing the target behaviour. Due to the time and resource constraints imposed by a master's thesis, this research conducted step one alone, i.e. reviewing the literature relevant to littering.

The study was also limited in terms of the recruitment of parent participants. Two parents were recruited for case study two, while it was not possible to recruit any parents for case study one. Although attempts to recruit parents were made, the researcher was only able to communicate via the school, inhibiting direct contact with the parents. As a result, it is not known how the project may have affected the whole household for the AI School study (e.g., children talking about the litter problem with their parents). Additionally, qualitative interviews relied on individuals' self-reported behaviour and their interpretation of other people's behaviour. Self-reported data may be more subjective, and susceptible to under and over reporting compared to objective observations (Bernard, 2017). 
Lastly, the quantitative litter and wrapper counts used for determining the behavioural effect of the interventions were subjective, relying upon the researcher's interpretation. In some instances, decisions had to be made about what should or should not be included in the counts. For example, on days when the lawns were mown, the mower would scatter one item of litter into multiple pieces. In those instances, these pieces were identified as coming from one item, and only one item was counted. The justification for this was based on assessing the behaviour of littering, not what happened to the litter after it had been discarded.

\subsection{Research Contributions and Recommendations}

\subsubsection{Research contributions}

The primary contribution of this research to the field of environmental studies is the development of effective resources and empirical examples to modify behaviour with the goal of reducing marine and terrestrial litter pollution. The resources developed are suitable for use by programme designers, researchers and policymakers, providing valuable insight into the process and achievement of behaviour change. With increased national and international focus on sources of marine and terrestrial pollution, this thesis provides direction on best practice for effective litter reduction.

The findings of this thesis also present an academic contribution in the field of behaviour change, in further investigating effective intervention strategies and developing a deeper understanding of barriers and benefits to littering. This provides an opportunity to better understand the effect of behaviour change techniques in diverse contexts, as well as the factors that may moderate the effect of an intervention.

Additional contributions of this thesis include further research guided by the CBSM framework, producing statistically significant results in reducing the rate of littering and 
packaging use, in a New Zealand context. This thesis also provides further exploration of mixed methods research design, specifically contributing to an understanding of quantitative litter detection, and qualitative variables moderating behaviour.

\subsubsection{Recommendations for additional research}

The findings of this thesis provide a number of opportunities for additional research, to continue in developing resources and strategies to effectively induce behaviour change. Key recommendations/opportunities include:

1. Application of behaviour change resources developed in this thesis across a broader range of primary and tertiary institutions, as well as elsewhere in a community. The success of this thesis in reducing littering and packaging use provides an opportunity to examine the wider scale effectiveness of behaviour change strategies by applying them to a wider audience and monitoring the effect.

2. Implementation of ongoing quantitative and qualitative monitoring over a longer timescale. This may include implementing a survey to further identify and understand moderating variables (e.g. empathy) behind student participants' behaviour. The success of this thesis in providing a short-term reduction in littering and packaging use provides an opportunity to explore a longer-term effect of the interventions. It also provides an opportunity to deepen the understanding of the influencing drivers for behaviour change identified in this research.

3. Employment of multiple reinforcing visits that allow development after an initial intervention, providing further development of rapport, individual knowledge and understanding, and the prompt and maintenance of the behaviour change techniques. The successful results produced from this thesis, by providing one visit as a part of the project, demonstrates an opportunity to explore a hypothesis that more time spent 
implementing an intervention could positively increase the proportion of behaviour changed.

4. Further investigating the influence of empathy in litter reduction case studies. Results from this thesis highlighting the importance of empathy in promoting proenvironmental behaviour provides a foundation for testing the correlation between participants' empathy levels and their willingness to act pro-environmentally or towards the specified target behaviours.

\subsection{Concluding Statement}

This research presented findings on the effect of the hypocrisy and goal setting behaviour change interventions, used in combination with education to monitor littering and packaging use in New Zealand schools. Results demonstrate that interventions positively induced behaviour change in two Wellington Intermediate Schools. In conjunction with behaviour change interventions, the findings show the barriers and benefits of littering and packaging use, and the influence of key stakeholders presented in both case studies had a considerable effect on the outcome of the projects. Overall, this thesis provides programme designers, researchers and policymakers with a resource to understand the process and achievement of litter and packaging reduction. With increased marine and terrestrial pollution, this study can be used to increase awareness and concern, highlight the ease and significance of changing individual behaviours, and ultimately increase the practice of environmental protection. By protecting the environment from litter pollution a more sustainable and prosperous society is achievable and can be maintained for future generations to come. 


\section{Chapter 7 References}

Aivazidis, C., Lazaridou, M., \& Hellden, G. F. (2006). A comparison between a traditional and an online environmental educational program. The Journal of Environmental Education, 37(4), 45-54.

Allsopp, M., Walters, A., Santillo, D., \& Johnsto, P. (2006). Plastic debris in the world's oceans. Amsterdam, Netherlands: Greenpeace.

Anderson, J. C., \& O'Reilly, C. A. (1981). Effects of an organizational control system on managerial satisfaction and performance. Human Relations, 34(6), 491-501.

Anderson, M. C. (1982). Litter reduction in an urban park using behvaiour modification techniques $(\mathrm{PhD})$, New York University, New York.

Aronson, E. (1968). Dissonance theory: Progress and problems. Chicago: Rand McNally.

Aronson, E. (1992). The return of the repressed: Dissonance theory makes a comeback. Psychological Inquiry, 3(4), 303-311. doi: 10.1207/s15327965pli0304_1

Aronson, E. (1999). Dissonance, hypocrisy, and the self-concept. In E. H.-J. J. Mills (Ed.), Cognitive dissonance: Progress on a pivotal theory in social psychology (pp. 103-126). Washington, DC: American Psychological Association.

Aronson, E. (1999). The power of self-persuasion. American Psychologist, 54(11), 875-884.

Aronson, E., Fried, C., \& Stone, J. (1991). Overcoming denial and increasing the intention to use condoms through the induction of hypocrisy. American Journal of Public Health, 81(12), 1636-1638.

Aronson, E., \& O’Leary, M. (1982). The relative effectiveness of models and prompts on energy conservation: A field experiment in a shower room. Journal of Environmental Systems, 12(3), 219-224.

Asch, J., \& Shore, B. M. (1975). Conservation behavior as the outcome of environmental education. The Journal of Environmental Education, 6(4), 25-33.

Ballantyne, R., \& Packer, J. (2002). Nature-based excursions: School students' perceptions of learning in natural environments. International Research in Geographical and Environmental Education, 11(3), 218-236.

Bamberg, S. (2002). Effects of implementation intentions on the actual performance of new environmentally friendly behaviours - results of two field experiments. Journal of Environmental Psychology, 22(4), 399-411. 
Bandura, A., \& Schunk, D. H. (1981). Cultivating competence, self-efficacy, and intrinsic interest through proximal self-motivation. Journal of Personality and Social Psychology, 41(3), 586598.

Barr, S. (2003). Strategies for sustainability: Citizens and responsible environmental behaviour. Area, $35(3), 227-240$.

Baxter, P., \& Jack, S. (2008). Qualitative case study methodology: Study design and implementation for novice researchers. The Qualitative Report, 13(4), 544-559.

Beck, R. (2007). Literature review_litter: A review of litter studies, attitude surveys and other litterrelated literature Consultant's Report on file with Keep America Beautiful. McLean Virginia.

Bernard, H. R. (2017). Research methods in anthropology: Qualitative and quantitative approaches. New York: Rowman \& Littlefield.

Boren, L. J., Morrissey, M., Muller, C. G., \& Gemmell, N. J. (2006). Entanglement of New Zealand fur seals in man-made debris at Kaikoura, New Zealand. Marine Pollution Bulletin, 52(4), 442-446. doi: 10.1016/j.marpolbul.2005.12.003

Braun, V., \& Clarke, V. (2006). Using thematic analysis in psychology. Qualitative Research in Psychology, 3(2), 77-101.

Britain, S., Webster, R., \& Vetter, O. (2017). Littering Interventions: A review of interventions aimed at fostering behaviour change to reduce litter in New Zealand. Unpublished Report. Wellington, New Zealand: Sustainable Coastlines.

Brown, T. J., Ham, S. H., \& Hughes, M. (2010). Picking up litter: An application of theory-based communication to influence tourist behaviour in protected areas. Journal of Sustainable Tourism, 18(7), 879-900.

Bryman, A. (2004). Social research methods (2 ed.). Oxford: Oxford University Press.

Christchurch City Council. (2016). All about litter. Retrieved August 1st 2017, from http://resources.ccc.govt.nz/files/LitterAbatement-loveyourrubbish.pdf

Christensen, L. B., Johnson, B., Turner, L. A., \& Christensen, L. B. (2011). Research methods, design, and analysis (12 ed.). Essex, United Kingdom: Pearson Education Limited.

Christensen, N. A., \& Cole, D. N. (2000, 23 May). Leave no trace practices: Behaviors and preferences of wilderness visitors regarding use of cookstoves and camping away from lakes. Paper presented at the Proceedings-Wilderness Science in a Time of Change conference.

Cialdini, R. B. (2003). Crafting normative messages to protect the environment. Current Directions in Psychological Science, 12(4), 105-109.

Cialdini, R. B., Reno, R. R., \& Kallgren, C. A. (1990). A focus theory of normative conduct: Recycling the concept of norms to reduce littering in public places. Journal of Personality and Social Psychology, 58(6), 1015. 
Ciccia, A., Step, M., \& Turkstra, L. (2003). Show me what you mean: Nonverbal communication theory and clinical application. The ASHA Leader, 8(22), 4-34.

Clayton, S., Litchfield, C., \& Geller, E. S. (2013). Psychological science, conservation, and environmental sustainability. Frontiers in Ecology and the Environment, 11(7), 377-382.

Cochrane, W., \& Maré, D. (2018). Urban influence and population change in New Zealand. Policy Quarterly, 13, 61-71.

Cohen, J. (1988). Statistical power analysis for the behavioral sciences (2nd ed.). New York: Academic Press.

Cone, J. D., \& Hayes, S. C. (1980). Environmental problems/behavioral solutions. Cambridge, United Kingdom: Cambridge University Press.

Confer, J. J., Mowen, A. J., Graefe, A. R., \& Absher, J. D. (2000). Magazines as wilderness information sources: Assessing users' general wilderness knowledge and specific Leave No Trace knowledge. Paper presented at the Proceedings from the National Wilderness Science conference: A time of change, Missoula, Montana.

Consulting, W. N. (2015). National litter survey. from https://www.recycling.kiwi.nz/files/3914/3201/1821/National Litter_Survey 1415 e.pdf

Cooper, J., \& Fazio, R. H. (1984). A new look at dissonance theory Advances in experimental social psychology (Vol. 17, pp. 229-266). New York: Elsevier.

Cordano, M., Welcomer, S., Scherer, R., Pradenas, L., \& Parada, V. (2010). Understanding cultural differences in the antecedents of pro-environmental behavior: A comparative analysis of business students in the United States and Chile. The Journal of Environmental Education, 41(4), 224-238.

Creswell, J. W. (2014). Research design : Qualitative, quantitative, and mixed methods approaches (4th ed. ed.). Thousand Oaks: SAGE Publications.

Creswell, J. W., \& Plano Clark, V. L. (2007). Designing and conducting mixed methods research Thousand Oaks, California: Sage

Damerell, P., Howe, C., \& Milner-Gulland, E. (2013). Child-orientated environmental education influences adult knowledge and household behaviour. Environmental Research Letters, 8(1), $15-16$.

De Young, R., Duncan, A., Frank, J., Gill, N., Rothman, S., Shenot, J., . . Zweizig, M. (1993). Promoting source reduction behavior: The role of motivational information. Environment and Behavior, 25(1), 70-85.

Denne, T., \& Wright, L. (2016). Evaluating the costs and benefits of introducing a container deposit system for New Zealand. Retrieved August 2nd 2017, from https://www.recycling.kiwi.nz/files/3014/6101/9990/CDS_report_2016.pdf

Derraik, J. G. (2002). The pollution of the marine environment by plastic debris: A review. Marine Pollution Bulletin, 44(9), 842-852. 
Diamantopoulos, A., Schlegelmilch, B. B., Sinkovics, R. R., \& Bohlen, G. M. (2003). Can sociodemographics still play a role in profiling green consumers? A review of the evidence and an empirical investigation. Journal of Business research, 56(6), 465-480.

Dickerson, C. A., Thibodeau, R., Aronson, E., \& Miller, D. (1992). Using cognitive dissonance to encourage water conservation. Journal of Applied Social Psychology, 22(11), 841-854.

Dodge, M. C. (1972). Modification of littering behavior an exploratory study. (PhD), Utah State University, Utah, U.S.A.

Doucette, J. E., \& Cole, D. N. (1993). Wilderness visitor education: Information about alternative techniques Forest service general technical report. Ogten, Utah: Forest Service.

Dowling, R. (2010). Power, subjectivity, and ethics in qualitative research In I. Hay (Ed.), Qualitative Research Methods in Human Geography (Three ed.). New York: Oxford University Press

Dresner, M., \& Gill, M. (1994). Environmental education at summer nature camp. The Journal of Environmental Education, 25(3), 35-41.

Duncan, A. P. (1997). Source reduction in context: A conceptual framework and field study of waste prevention behavior. $(\mathrm{PhD})$, University of Michigan, Michigan.

Dunn, K. (2010). 'Doing' qualitative research in human geography In I. Hay (Ed.), Qualitative Research Methods in Human Geography (Three ed.). Canada: Oxford University Press

Earley, P. C., \& Erez, M. (1991). Time-dependency effects of goals and norms: The role of cognitive processing on motivational models. Journal of Applied Psychology, 76(5), 717.

Emmel, J. M. (1995). The effect of home learning activities as a part of an educational unit in solid waste management education on fifth-grade sutdent and parent knowledge, attitudes, and behaviors. (PhD), New Mexico State University, Las Cruces, New Mexico.

Epton, T., Currie, S., \& Armitage, C. J. (2017). Unique effects of setting goals on behavior change: Systematic review and meta-analysis. Journal of Consulting and Clinical Psychology, 85(12), 1182-1198. doi: 10.1037/ccp0000260

Erez, M., \& Zidon, I. (1984). Effect of goal acceptance on the relationship of goal difficulty to performance. Journal of Applied Psychology, 69(1), 69-78.

Eriksen, M., Lebreton, L. C., Carson, H. S., Thiel, M., Moore, C. J., Borerro, J. C., , . Reisser, J. (2014). Plastic pollution in the world's oceans: More than 5 trillion plastic pieces weighing over 250,000 tons afloat at sea. PloS One, 9(12), 111-119.

Festinger, L. (1957). A theory of cognitive dissonance. London, United Kingdom: Tavistock.

Festinger, L., \& Carlsmith, J. M. (1959). Cognitive consequences of forced compliance. The Journal of Abnormal and Social Psychology, 58(2), 203.

Fien, J. (2001). The learning for a sustainable environment project: A case study of an action network for teacher education. Australian Journal of Environmental Education, 17, 77-86.

Finnie, W. C. (1973). Field experiments in litter control. Environment and Behavior, 5(2), 123-144. 
Frantz, C. M., Flynn, B., Atwood, S., Mostow, D., Xu, C., \& Kahl, S. (2016). Changing energy behavior through community based social marketing: Springer.

Gall, S., \& Thompson, R. (2015). The impact of debris on marine life. Marine pollution bulletin, 92(1), 170-179.

Gardner, G. T., \& Stern, P. C. (1996). Environmental problems and human behavior. Boston, U.S.A: Allyn \& Bacon.

Geller, E. S. (2002). The challenge of increasing proenvironment behavior. Handbook of Environmental Psychology, 2, 525-540.

Geller, E. S., Winett, R. A., \& Everett, P. B. (1982). Preserving the environment: New strategies for behavior change (Vol. 102). New York: Pergamon Press.

Geller, E. S., Witmer, J. F., \& Tuso, M. A. (1977). Environmental interventions for litter control. Journal of Applied Psychology, 62(3), 344-351.

Goldstein, N. J., Griskevicius, V., \& Cialdini, R. B. (2007). Invoking social norms: A social psychology perspective on improving hotels' linen-reuse programs. Cornell Hotel and Restaurant Administration Quarterly, 48(2), 145-150.

Google Maps. (2018a). Avalon Intermediate from https://www.google.com/maps/place/Avalon+Intermediate/@_ 41.1889232,174.9485271,17z/data=!3m1!4b1!4m5!3m4!1s0x6d47555d4ab901f3:0xd616de1 $37 \mathrm{ad} 07 \mathrm{c} 8 \mathrm{~d} ! 8 \mathrm{~m} 2 ! 3 \mathrm{~d}-41.1889232 ! 4 \mathrm{~d} 174.9507158$

Google Maps. (2018b). Raroa Normal Intermediate.

Gramann, J. H., \& Vander Stoep, G. A. (1986). Reducing depreciative behavior at Shiloh National Military Park. Texas: Department of Recreation and Parks, Texas Agricultural Experiment Station, Texas A \& M University.

Green-Demers, I., Pelletier, L. G., \& Ménard, S. (1997). The Impact of behavioural difficulty on the saliency of the association between self-determined motivation and environmental behaviours. Canadian Journal of Behavioural Science, 29(3), 157-166. doi: 10.1037/0008400X.29.3.157

Gregory, G. (1974). Environment and change: A social studies unit (PhD), Carnegie-Mellon University, Michigan.

Gregory, M. R. (2009). Environmental implications of plastic debris in marine settingsentanglement, ingestion, smothering, hangers-on, hitch-hiking and alien invasions. Philosophical Transactions of the Royal Society of London B: Biological Sciences, 364(1526), 2013-2025.

GWRC. (2018). GWRC web map viewer. from http://mapping.gw.govt.nz/GW/GWpublicMap_Mobile/?webmap=d4e8a3b2241045e68fd8fc $\underline{\text { 9f91973b10 }}$ 
Ham, S. H., \& Krumpe, E. E. (1996). Identifying audiences and messages for nonformal environmental education: A theoretical framework for interpreters. Journal of Interpretation Research, 1(1), 11-23.

Hamad, C. D., Bettinger, R., Cooper, D., \& Semb, G. (1980). Using behavioral procedures to establish an elementary school paper recycling program. Journal of Environmental Systems, 10(2), 149-156.

Harré, N. (2011). Psychology for a better world : Strategies to inspire sustainability. Auckland, N.Z.: Dept. of Psychology, University of Auckland.

Heberlein, T. A. (1972). Moral norms, threatened sanctions, and littering behavior. Dissertation Abstracts International, 32, 72-98.

Hemmert, A. (2004). Waste-free lunches: A lesson in environmental stewardship. Green Teacher(74), $18-23$.

Horsley, A. D. (1977). The effects of a social learning experiment on attitudes and behavior toward environmental conservation. Environment and Behavior, 9(3), 349-384.

Huffman, K. T., Grossnickle, W. F., Cope, J. G., \& Huffman, K. P. (1995). Litter reduction: A review and integration of the literature. Environment and Behavior, 27(2), 153-183.

Jordan, J. R., Hungerford, H. R., \& Tomera, A. N. (1986). Effects of two residential environmental workshops on high school students. The Journal of Environmental Education, 18(1), 15-22.

Kamp, M. E. V., Johnson, D. R., \& Swearingen, T. C. (1994). Deterring minor acts of noncompliance: A literature review. Washington D.C.: Cooperative Park Studies Unit, College of Forest Resources, University of Washington.

Kantola, S. J., Syme, G. J., \& Campbell, N. A. (1984). Cognitive dissonance and energy conservation. Journal of Applied Psychology, 69(3), 416-421.

Kāpiti Coast District Council. (2018). Zero waste education - Free to Kāpiti schools. Retrieved June 22nd 2018, from https://www.kapiticoast.govt.nz/services/A---Z-Council-Services-andFacilities/Rubbish-and-Recycling/waste-reduction--education/zero-waste-education--free-tokpiti-schools/

Kazdin, A. E. (Ed.). (2016). Methodological issues and strategies in clinical research (4th edition. ed.). Washington, D.C: American Psychological Association.

Keep New Zealand Beautiful. (2018). Litter hub. Retrieved from https://www.litter.org.nz/.

Keizer, K., Lindenberg, S., \& Steg, L. (2008). The spreading of disorder. Science, 322(5908), 16811685 .

Kennedy, A. L. (2010). Using community-based social marketing techniques to enhance environmental regulation. Sustainability, 2(4), 1138-1160.

Khawaja, F., \& Shah, A. (2013). Determinants of littering: An experimental analysis. Pakistan Development Review, 52(2), 157-168. 
Kitchin, R., \& Tate, J. N. (2000). Conducting research in human geography Harlow, United Kingdom: Prentice Hall.

Klein, H. J., Wesson, M. J., Hollenbeck, J. R., \& Alge, B. J. (1999). Goal commitment and the goalsetting process: Conceptual clarification and empirical synthesis. Journal of Applied Psychology, 84(6), 885-896.

Kleingeld, A., van Mierlo, H., \& Arends, L. (2011). The effect of goal setting on group performance: a meta-analysis. Journal of Applied Psychology, 96(6), 1289-1304.

Kollmuss, A., \& Agyeman, J. (2002). Mind the gap: Why do people act environmentally and what are the barriers to pro-environmental behavior? Environmental Education Research, 8(3), 239260.

Latham, G. P., \& Locke, E. A. (1991). Self-regulation through goal setting. Organizational Behavior and Human Decision Processes, 50(2), 212-247.

Latham, G. P., \& Saari, L. M. (1979). Application of social-learning theory to training supervisors through behavioral modeling. Journal of Applied Psychology, 64(3), 239-246.

Latham, G. P., \& Seijts, G. H. (2016). Distinguished scholar invited essay: Similarities and differences among performance, behavioral, and learning goals. Journal of Leadership \& Organizational Studies, 23(3), 225-233.

Lee, M. (2016). Development and evaluation of a hypocrisy induction intervention for exercise (PhD), University of South Florida, Tampa, Florida.

Leisher, C., Mangubhai, S., Hess, S., Widodo, H., Soekirman, T., Tjoe, S., . . Halim, A. (2012). Measuring the benefits and costs of community education and outreach in marine protected areas. Marine Policy, 36(5), 1005-1011.

Levin, E. (2006). Effective litter reduction. (M.A.), University of Pennsylvania, Kutztown, Pennsylvania.

Lindenberg, S., \& Steg, L. (2007). Normative, gain and hedonic goal frames guiding environmental behavior. Journal of Social Issues, 63(1), 117-137.

Lingard, H., Gilbert, G., \& Graham, P. (2001). Improving solid waste reduction and recycling performance using goal setting and feedback. Construction Management \& Economics, 19(8), 809-817.

Liu, J. H., \& Sibley, C. G. (2004). Attitudes and behavior in social space: Public good interventions based on shared representations and environmental influences. Journal of Environmental Psychology, 24(3), 373-384.

Locke, E. A., \& Latham, G. P. (1990). A theory of goal setting \& task performance. Englewood Cliffs, New Jersey: Prentice-Hall, Inc.

Locke, E. A., \& Latham, G. P. (2002). Building a practically useful theory of goal setting and task motivation. American Psychologist, 57(9), 705-717. doi: 10.1037/0003-066X.57.9.705 
Locke, E. A., \& Latham, G. P. (2006). New directions in goal-setting theory. Current Directions in Psychological Science, 15(5), 265-268.

Locke, E. A., \& Latham, G. P. (Eds.). (2013). New developments in goal setting and task performance (Vol. 68). New York: Blackwell Pub.

Locke, E. A., Shaw, K. N., Saari, L. M., \& Latham, G. P. (1981). Goal setting and task performance: 1969-1980. Psychological Bulletin, 90(1), 125-152.

Long, J., Harré, N., \& Atkinson, Q. D. (2014). Understanding change in recycling and littering behavior across a school social network. American Journal of Community Psychology, 53(34), 462-474.

Loughland, T., Reid, A., Walker, K., \& Petocz, P. (2003). Factors influencing young people's conceptions of environment. Environmental Education Research, 9(1), 3-19.

Madera, J. M., King, E. B., \& Hebl, M. R. (2013). Enhancing the effects of sexual orientation diversity training: The effects of setting goals and training mentors on attitudes and behaviors. Journal of Business and Psychology, 28(1), 79-91.

Manning, R. (2003). Emerging principles for using information/education in wilderness management. International Journal of Wilderness, 9(1), 20-27.

Marion, J. L., \& Reid, S. E. (2007). Minimising visitor impacts to protected areas: The efficacy of low impact education programmes. Journal of Sustainable Tourism, 15(1), 5-27.

McAvoy, L. (1984). Hamborg, r.(1984) Wilderness visitor knowledge of regulations: A comparison of visitor contact methods. Journal of Interpretation, 9(1), 1-10.

McCaul, K. D., \& Kopp, J. T. (1982). Effects of goal setting and commitment on increasing metal recycling. Journal of Applied Psychology, 67(3), 377-379. doi: 10.1037/0021-9010.67.3.377

McEwan, D., Harden, S. M., Zumbo, B. D., Sylvester, B. D., Kaulius, M., Ruissen, G. R., . . . Beauchamp, M. R. (2015). The effectiveness of multi-component goal setting interventions for changing physical activity behaviour: A systematic review and meta-analysis. Health psychology review, 10(1), 67-88.

McGuire, N. M. (2015). Environmental education and behavioral change: An identity-based environmental education model. International Journal of Environmental and Science Education, 10(5), 695-715.

McKenzie-Mohr, D. (2011). Fostering sustainable behavior: An introduction to community-based social marketing. Gabriola Island, Canada: New Society Publishers.

McKenzie-Mohr, D. (2000). New ways to promote proenvironmental behavior: Promoting sustainable behavior: An introduction to community-based social marketing. Journal of Social Issues, 56(3), 543-554. doi: 10.1111/0022-4537.00183

McKimmie, B. M., Terry, D. J., Hogg, M. A., Manstead, A. S., Spears, R., \& Doosje, B. (2003). I'm a hypocrite, but so is everyone else: Group support and the reduction of cognitive dissonance. Group Dynamics: Theory, Research, and Practice, 7(3), 214-239. 
Miles, R. (2015). Complexity, representation and practice: Case study as method and methodology. Issues in Educational Research, 25(3), 309-318.

Miller, G., Rathouse, K., Scarles, C., Holmes, K., \& Tribe, J. (2010). Public understanding of sustainable tourism. Annals of Tourism Research, 37(3), 627-645.

Ministry for Education. (2017). School deciles. from https://www.education.govt.nz/school/running-aschool/resourcing/operational-funding/school-decile-ratings/

Ministry for the Environment. (2016). What you can do to reduce marine pollution. from http://www.mfe.govt.nz/marine/marine-pages-kids/how-you-can-reduce-marine-pollution

MSW Consultants. (2009). National visible litter study. New Market, MD.

Mueller, M. (1983). The effects of goal setting and competition on performance: A laboratory study. (M.Sc), University of Minnesota, Minneapolis, Minnesota.

Oliver, S. S., Roggenbuck, J. W., \& Watson, A. E. (1985). Education to reduce impacts in forest campgrounds. Journal of Forestry, 83(4), 234-236.

Öllerer, K. (2015). Environmental education-the bumpy road from childhood foraging to literacy and active responsibility. Journal of Integrative Environmental Sciences, 12(3), 205-216.

Onwuegbuzie, A. J., \& Collins, K. M. (2010). A call for mixed analysis among stress and coping researchers: Deconstructing separatist qualitative and quantitative analysis in mixed research Toward a Broader Understanding of Stress and Coping: Mixed Methods Approaches (pp. 105-143). Houston, Texas: San Houston State University.

Osbaldiston, R. (2003). Meta-analysis of the responsible environmental behavior literature. Unpublished doctoral dissertation. University of Missorui. Columbia, Missouri.

Osbaldiston, R., \& Schott, J. P. (2012). Environmental sustainability and behavioral science: Metaanalysis of proenvironmental behavior experiments. Environment and Behavior, 44(2), 257299.

Oskamp, S., Harrington, M. J., Edwards, T. C., Sherwood, D. L., Okuda, S. M., \& Swanson, D. C. (1991). Factors influencing household recycling behavior. Environment and Behavior, 23(4), 494-519.

Osteen, P., \& Bright, C. (2010, January). Effect sizes and intervention research. Paper presented at the Society for Social Work and Research Conference. San Francisco, CA, San Francisco, CA.

Pandey, J. (1990). The environment, culture, and behavior. In R. Brislin (Ed.), Applied cross-cultural psychology (pp. 254-277). Thousand Oaks, CA: SAGE.

Payne, P. G. (2005). Families, homes and environmental education. Australian Journal of Environmental Education, 21, 81-95.

Pelletier, L. G., Tuson, K. M., Green-Demers, I., Noels, K., \& Beaton, A. M. (1998). Why are you doing things for the environment? The motivation toward the environment scale (MTES). Journal of Applied Social Psychology, 28(5), 437-468. 
Pooley, J. A., \& O'Connor, M. (2000). Environmental education and attitudes: Emotions and beliefs are what is needed. Environment and Behavior, 32(5), 711-723.

Public Opinion Surveys, I. (1968). Who litters and why? Princeton, New Jersey: Keep America Beautiful, Inc. .

Reiter, S. M., \& Samuel, W. (1980). Littering as a function of prior litter and the presence or absence of prohibitive signs. Journal of Applied Social Psychology, 10(1), 45-55.

Richter, T., Rendigs, A., \& Maminirina, C. P. (2015). Conservation messages in speech bubblesEvaluation of an environmental education comic distributed in elementary schools in Madagascar. Sustainability, 7(7), 8855-8880.

Ritchie, J., Lewis, J., Nicholls, C. M., \& Ormston, R. (2013). Qualitative research practice: A guide for social science students and researchers. London, United Kingdom: Sage.

Robinson, S. N. (1976). Littering behavior in public places. Environment and Behavior, 8(3), 363 384.

Roggenbuck, J. W. (1992). Use of persuasion to reduce resource impacts and visitor conflicts. Influencing Human Behavior, 149-208.

Roggenbuck, J. W., \& Berrier, D. L. (1981). Communications to disperse wilderness campers. Journal of Forestry, 79(5), 295-297.

Schultz, P. W. (2014). Strategies for promoting proenvironmental behavior. European Psychologist, 19, 107-117.

Schultz, P. W., Bator, R. J., Large, L. B., Bruni, C. M., \& Tabanico, J. J. (2013). Littering in context: Personal and environmental predictors of littering behavior. Environment and Behavior, 45(1), 35-59.

Segrin, C., Woszidlo, A., Givertz, M., Bauer, A., \& Taylor Murphy, M. (2012). The association between overparenting, parent-child communication, and entitlement and adaptive traits in adult children. Family Relations, 61(2), 237-252.

Sharan, B. (2002). Qualitative research in practice: Examples for discussion and analysis. California, San Francisco: Jossey-Bass.

Shopes, L. (2011). Oral history. Thousand Oaks, California: Sage.

Sibley, C. G., \& Liu, J. H. (2003). Differentiating active and passive littering: A two-stage process model of littering behavior in public spaces. Environment and Behavior, 35(3), 415-433.

Skogan, W. (2012). Disorder and crime. In B. Welsh \& D. Farrington (Eds.), The oxford handbook of crime prevention (pp. 173-188). Oxford, England Oxford University Press.

Slavin, C., Grage, A., \& Campbell, M. L. (2012). Linking social drivers of marine debris with actual marine debris on beaches. Marine pollution bulletin, 64(8), 1580-1588.

Stark, S., \& Torrance, H. (2005). Case Study. In B. Somekh \& C. Lewin (Eds.), Research methods in the social sciences (pp. 33-40). London: SAGE publications 
StatsNZ. (2018). Subnational population estimates: At 30 june 2017. Retrieved from https://www.stats.govt.nz/information-releases/subnational-population-estimates-at-30-june2017-provisional

Steg, L., \& Vlek, C. (2009). Encouraging pro-environmental behaviour: An integrative review and research agenda. Journal of Environmental Psychology, 29(3), 309-317.

Stern, P. C. (1999). Information, incentives, and proenvironmental consumer behavior. Journal of Consumer Policy, 22(4), 461-478.

Stone, J., Aronson, E., Crain, A. L., Winslow, M. P., \& Fried, C. B. (1994). Inducing hypocrisy as a means of encouraging young adults to use condoms. Personality and Social Psychology Bulletin, 20(1), 116-128.

Stone, J., \& Fernandez, N. C. (2008). To practice what we preach: The use of hypocrisy and cognitive dissonance to motivate behavior change. Social and Personality Psychology Compass, 2(2), 1024-1051.

Stone, J., Wiegand, A. W., Cooper, J., \& Aronson, E. (1997). When exemplification fails: Hypocrisy and the motive for self-integrity. Journal of Personality and Social Psychology, 72(1), 54-65.

Tauranga City Council. (2018). Litter and stream clean ups. from https://www.tauranga.govt.nz/living/rubbish-and-recycling/minimising-waste/communitywaste-programmes/litter-and-stream-clean-ups

Tavris, C., \& Aronson, E. (2008). Mistakes were made (but not by me): Why we justify foolish beliefs, bad decisions, and hurtful acts. Boston, New York: Houghton Mifflin Harcourt.

Teye, J. K. (2012). Benefits, challenges, and dynamism of positionalities associated with mixed methods research in developing countries: Evidence from Ghana. Journal of Mixed Methods Research, 6(4), 379-391.

Thomas, R. (2017). Review of litter reduction interventions. Wellington, New Zealand.

Timlett, R. E., \& Williams, I. D. (2008). Public participation and recycling performance in England: A comparison of tools for behaviour change. Resources, Conservation and Recycling, 52(4), 622-634.

Vlek, C. (2000). Essential psychology for environmental policy making. International Journal of Psychology, 35(2), 153-167.

Walter, H., \& Lien, J. (1985). Attitudes of Canadian students and teachers toward the marine environment and marine education (pp. 0-17). Ottawa, Canada: Institute of Education Sciences.

Waste Not Consulting. (2015). National Litter Survey. from https://www.recycling.kiwi.nz/files/3914/3201/1821/National Litter_Survey 1415 e.pdf

Wever, R., Van Onselen, L., Silvester, S., \& Boks, C. (2010). Influence of packaging design on littering and waste behaviour. Packaging Technology and Science, 23(5), 239-252. 
Williams, C. (1996). Combatting marine pollution from land-based activities: Australian initiatives. Ocean \& Coastal Management, 33(1), 87-112.

Williams, E., Curnow, R., \& Streker, P. (1997). Understanding littering behaviour in Australia. Pyrmont, New South Wales: Beverage Industry Environment Council.

Wine, B., Freeman, T. R., \& King, A. (2015). Withdrawal versus reversal: A necessary distinction? Behavioral Interventions, 30(1), 87-93.

Yates, S. (2018). National Litter Behaviour Research. from https://www.litter.org.nz/assets/Uploads/Behaviour-Study/6414f5b4d5/KNZB-Litterbehaviour-report-DRAFT-0.3-Released-3.4.18.pdf

Yin, R. K. (2011). Applications of case study research. Thousand Oaks, California: Sage Publications. Zelezny, L. C. (1999). Educational interventions that improve environmental behaviors: A metaanalysis. The Journal of Environmental Education, 31(1), 5-14.

Zetik, D. C., \& Stuhlmacher, A. F. (2002). Goal setting and negotiation performance: A metaanalysis. Group Processes \& Intergroup Relations, 5(1), 35-52. 


\title{
Appendices
}

Appendix 1. Information sheet and consent form AI School

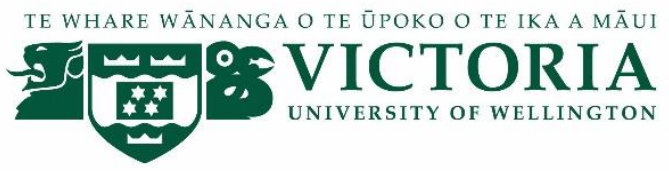

\section{Environmental Engagement: Using behaviour change tools to influence litter reduction in intermediate aged schools}

\author{
INFORMATION SHEET FOR PARENTS OR LEGAL GUARDIAN OF STUDENT \\ Researcher: Rachel Thomas, School of Geography, Environment and Earth Sciences, \\ Victoria University of Wellington
}

\begin{abstract}
About this project
I am a Masters student in Environmental Studies at Victoria University of Wellington. As part of this degree, I am undertaking a research project leading to a thesis. This project aims to assess the effectiveness of behaviour change tools in reducing rubbish amounts in Avalon Intermediate school grounds. This study may be published, and or presented at conferences.
\end{abstract}

This research project has received approval from the Avalon Intermediate School board and principal, and Victoria University Human Ethics Committee, Ethics Approval: 0000025377.

\section{What is involved?}

I am working alongside Avalon Intermediate, inviting child participants, aged 9-12, as well as selected teachers and parents to take part in this research. As part of this research project the children will participate in a presentation highlighting the effects of rubbish on our environment and their community, they will also participate in a commit making activity and a survey to highlight their past behaviours all taking approximately 1 hour to complete. This 
research will be supplemented by conversations with child participants, teachers, and parents to offer perspective and opinion on the project. Your child will be giving their consent by completing the project and answering questions. Surveys and audio recorded conversations will be kept in a locked computer and filling cabinet, and will be destroyed one month after completion.

\section{How can you help?}

If you would like to be a part of this study you can participate in a conversation to offer your opinion and home experience of the rubbish reduction project. I will interview you at your child's school, a public place, or a setting in which you feel comfortable. I will ask you questions about your experience and perceptions of the Rubbish Reduction Project. The interview will take approximately 30 minutes. If you are willing to participate or would like to know more please send an email to Rachel Thomas to organise a time and location.

\section{If you have any questions or problems, who can you contact?}

If you have any questions, either now or in the future, please feel free to contact either:

\section{Student:}

Name: Rachel Thomas

University email address:

thomasrach2@myvuw.ac.nz

\section{Supervisor:}

Name: Dr. Wokje Abrahamse

Role: Senior Lecturer

School: Geography, Environment and Earth Sciences

Phone: 044635217

wokje.abrahamse@vuw.ac.nz

\section{Human Ethics Committee information}

If you have any concerns about the ethical conduct of the research you may contact the Victoria University HEC Convenor: Associate Professor Susan Corbett. Email susan.corbett@vuw.ac.nz or telephone +64-4-463 5480.

\section{Avalon Deputy Principal:}

Name: Ariana Te Whetu

Avalon Intermediate email address: 


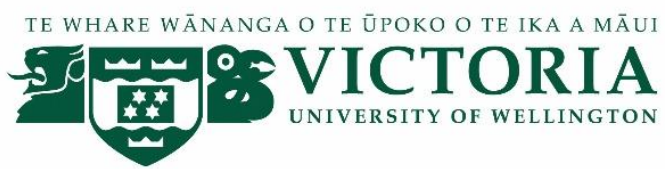

\title{
Environmental Engagement: Using behaviour change tools to influence litter reduction in intermediate aged schools
}

\author{
PROJECT FORM FOR PARENTS OR LEGAL GUARDIAN OF STUDENT
}

Researcher: Rachel Thomas, School of Geography, Environment and Earth Sciences, Victoria University of Wellington

Avalon Intermediate is including this project into their curriculum to engage the children in environmental awareness. If you would like any of the information explained further or have additional questions, please contact the researcher or the deputy principal.

Any information your child provides will be kept confidential to the researcher, and the supervisor. This study may be published, and or presented at conferences. The published results will not use your child's name, and the results of the study will not be attributed to them in any way that will identify them. The primary material such as the surveys and recorded conversations will be kept safe, locked in a filing cabinet and a computer and wiped from the recording device.

Please tick this box if you would like an anonymised summary of the results. If you have indicated that you would like to be sent this document, please provide your contact details below and have your child return this slip to the school. If you do not have an email address or would prefer a posted copy, please input your postal address instead.

Email/Postal address:

If after having the opportunity to ask questions and have them answered to your satisfaction you wish for your son or daughter to be withdrawn from participating in the project and or interview, please contact the researcher or the deputy principal. 
Nga mihi,

Rachel Thomas

Appendix 2. Information sheet for student AI School

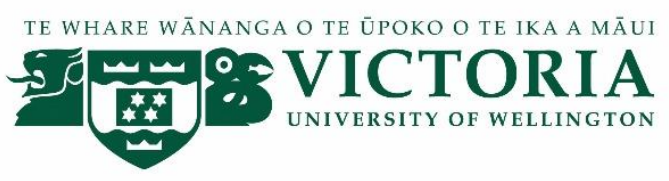

\section{Rubbish Reduction \\ PROJECT INFORMATION SHEET FOR STUDENT}

You are invited to take part in my University research. Please read this information.

\section{Who am I?}

My name is Rachel Thomas and I am a Masters student in Environmental Studies at Victoria University of Wellington.

\section{What am I doing?}

I will provide you with a presentation about rubbish and why it is bad for our environment and community. I will also ask you to participate in an activity and survey.

\section{What does participating mean?}

By participating in this project, you will be giving your consent. I won't record your name. For this reason, it will not be possible to connect you with this study. This study may be published, and or presented at conferences.

\section{Further Questions?}

If you would like to ask me any questions at all then please have your parents email me anytime. There is more information about this study in the 'Parent or legal guardian information sheet'. If they have not received a paper copy of this from your teacher, I will happily send you one in the mail.

Rachel Thomas - Victoria University of Wellington

Email: thomasrach2@myvuw.ac.nz 
Appendix 3. Education presentation for AI School

Slide 1 \& 2

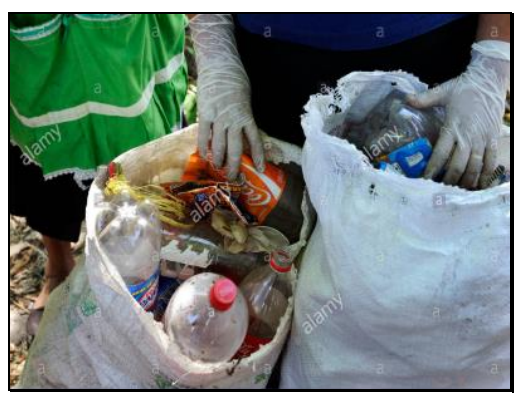

Slide $3 \& 4$

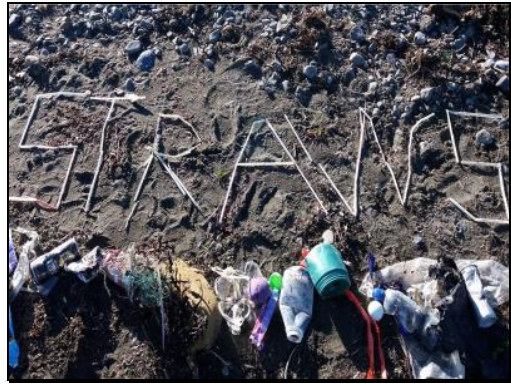

Slide 5 \& 6

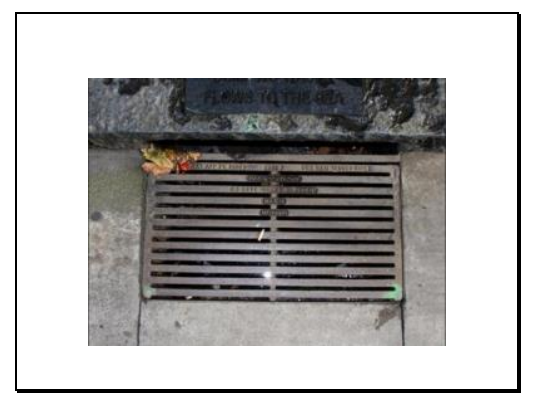

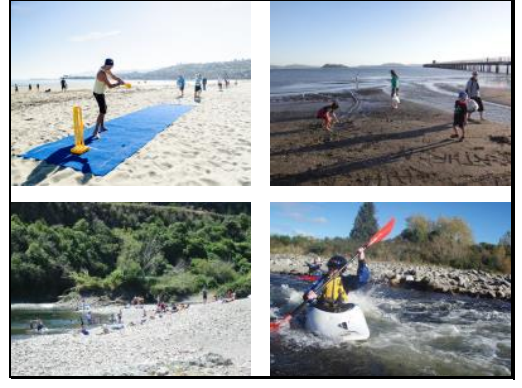
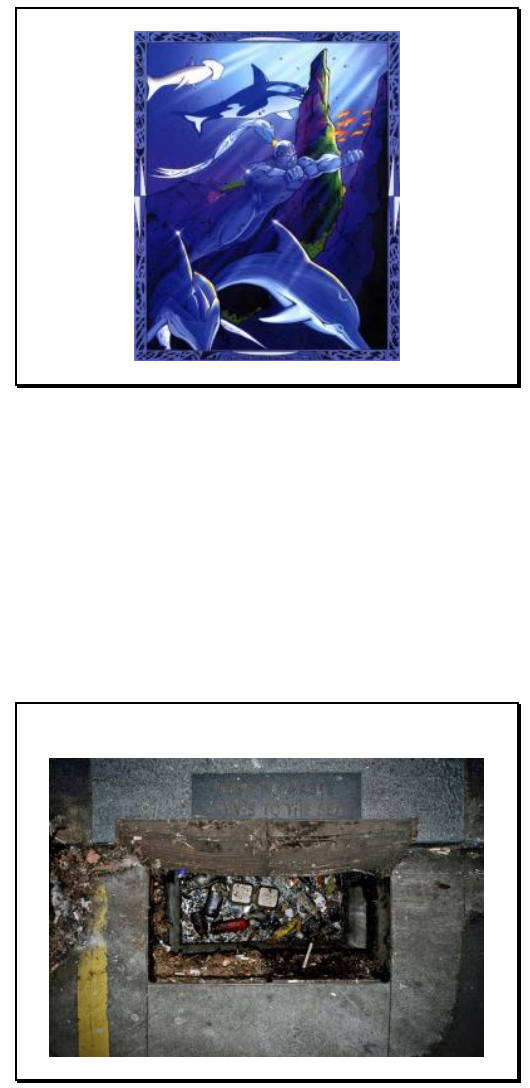
Slide $7 \& 8$

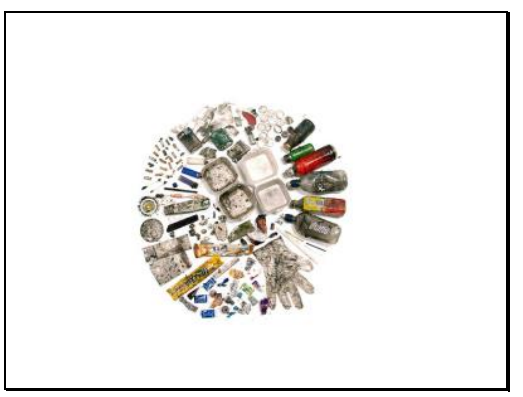

Slide 9 \&

10
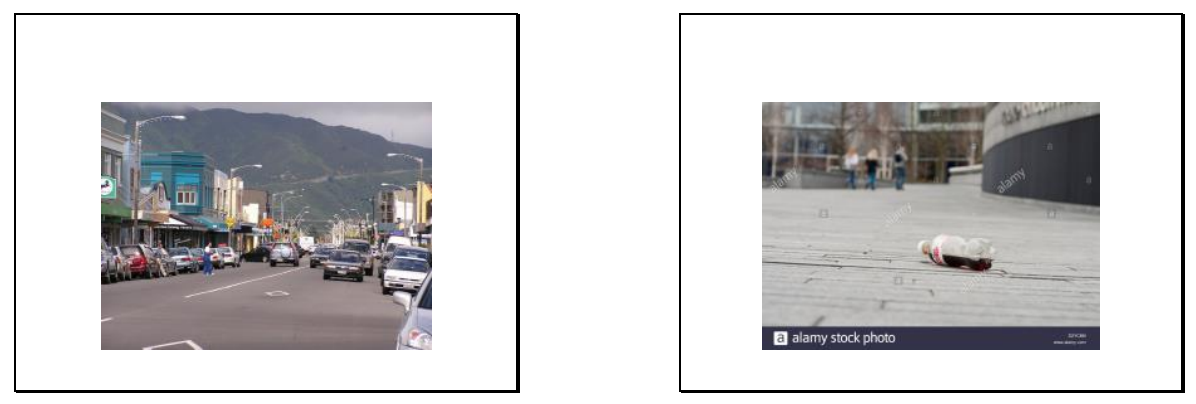

Slide 11 \&

12

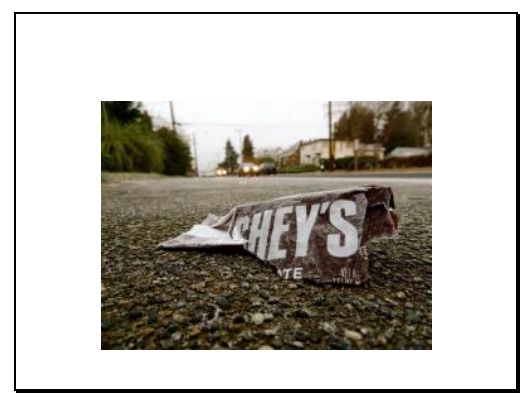

- https://www.youtube.com/watch?v=1zUuEA8 $\underline{\text { s9qE\&feature }=\text { youtu.be }}$ 
Slide 13 \& 14

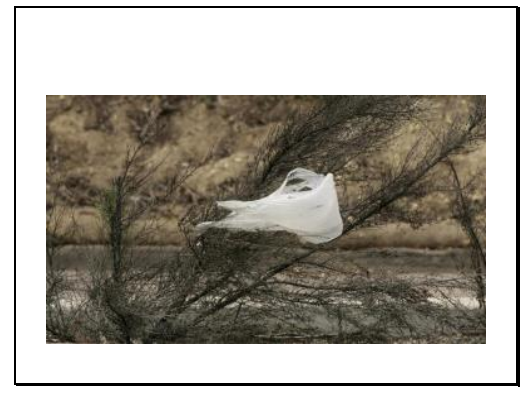

Slide 15 \& 16

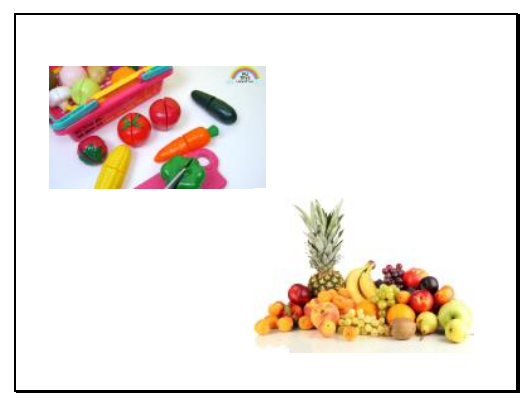

Slide 17 \& 18

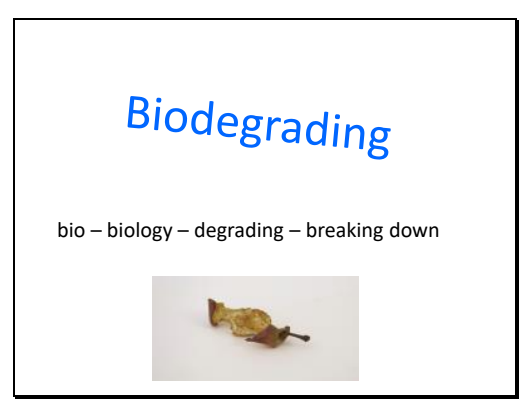

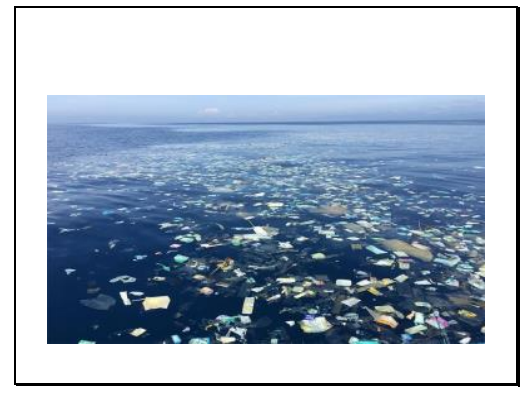
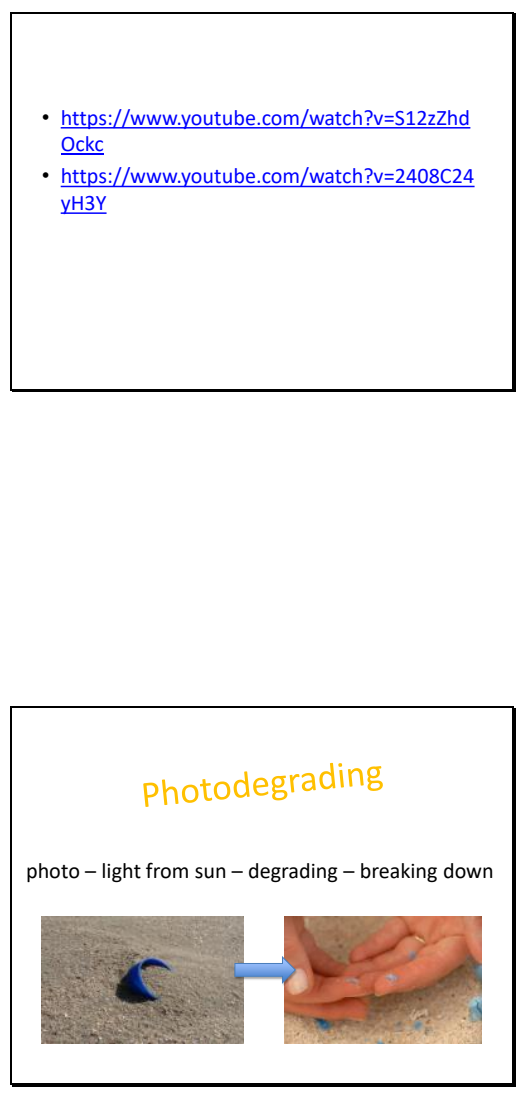
Slide 19 \& 20

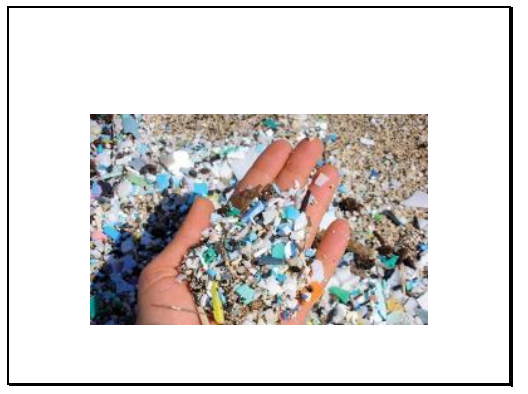

Slide $21 \&$

22

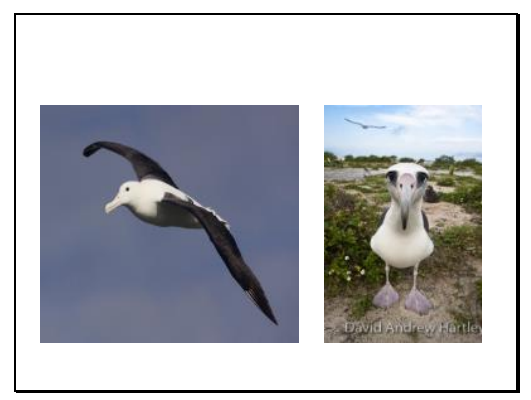

Slide 23 \& 24

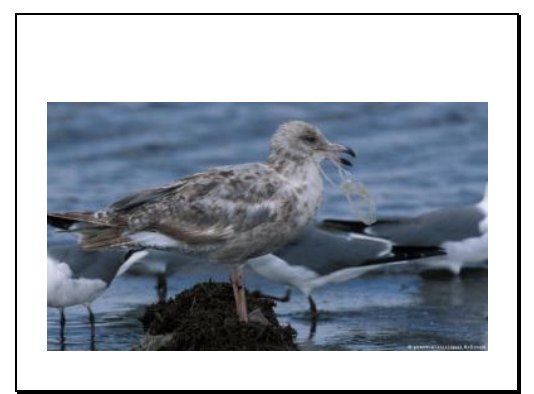

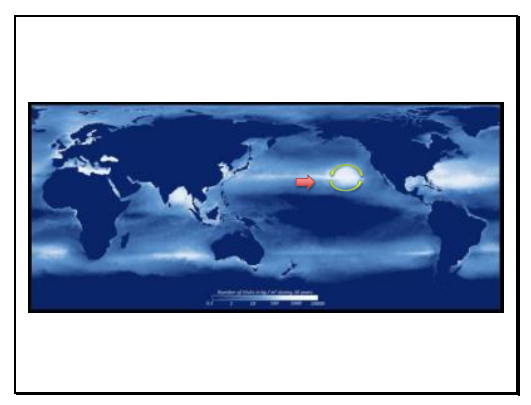
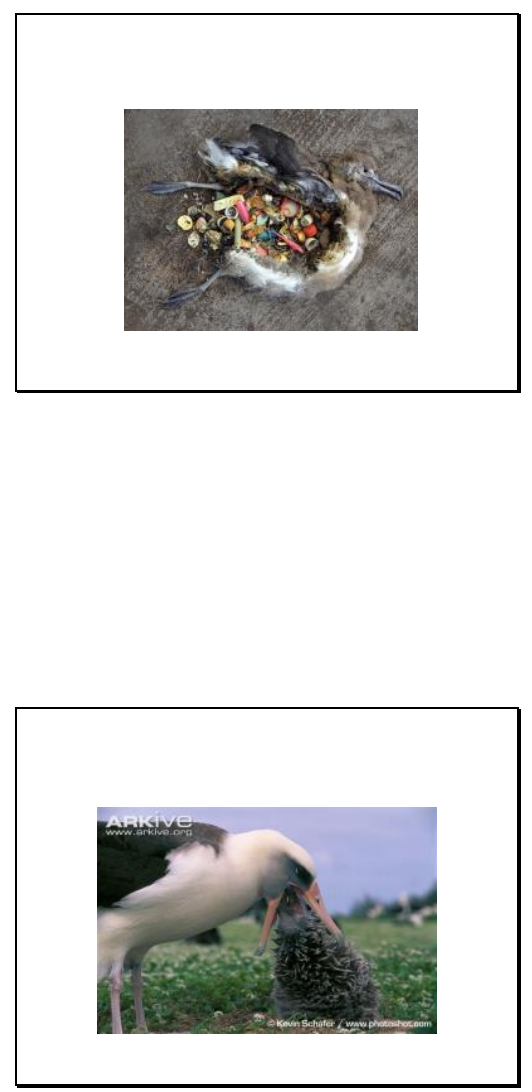
Slide 25 \& 26

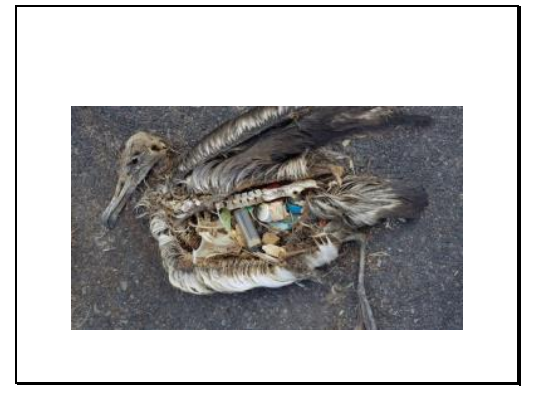

Slide 27 \& 28

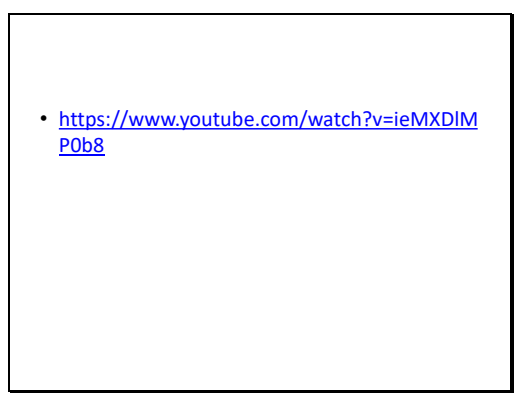

Slide 29

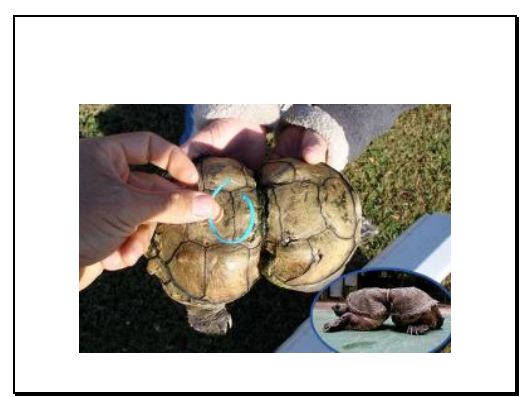

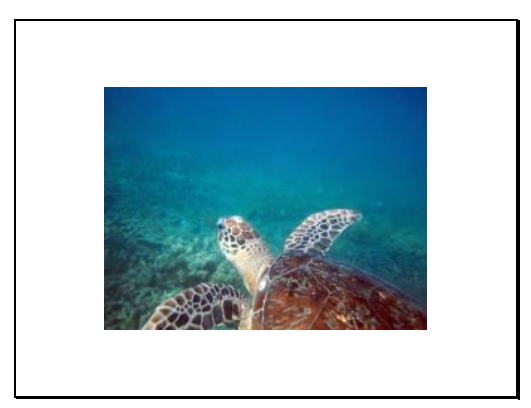

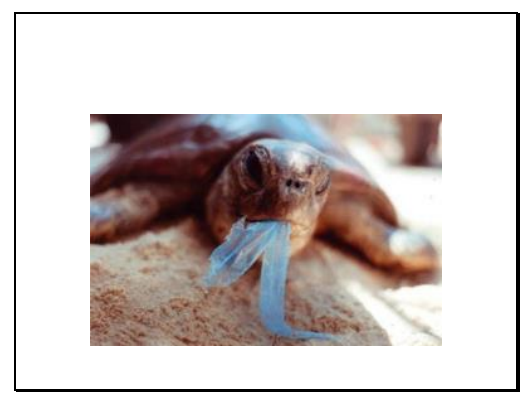

- https://www.youtube.com/watch?v=AODP-rTUEE 
Slide 31 \& 32

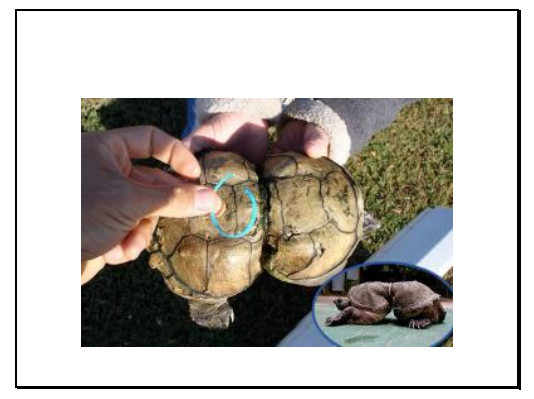

Slide 33 \& 34

Slide 35 \& 36

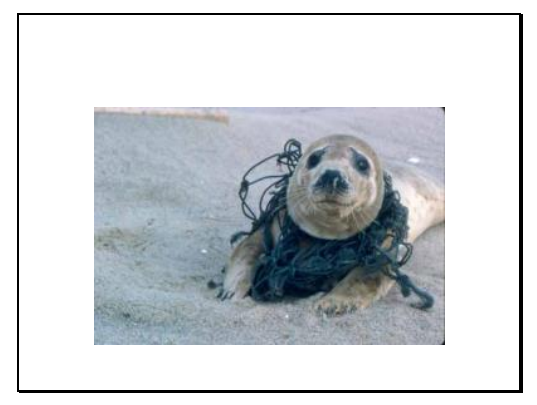

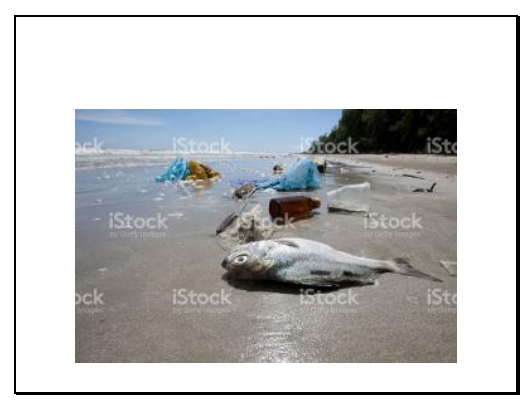

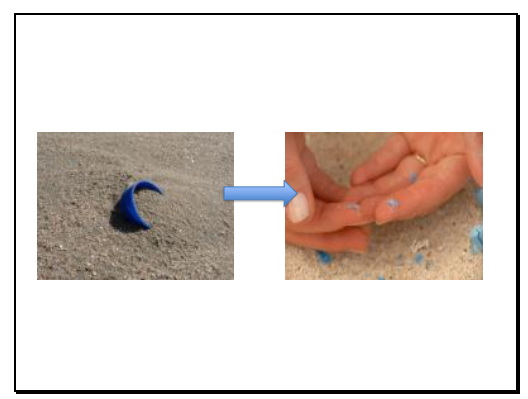


Slide 37 \& 38

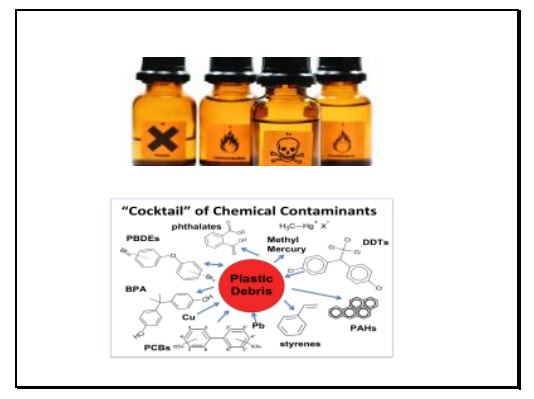

Slide 39 \& 40

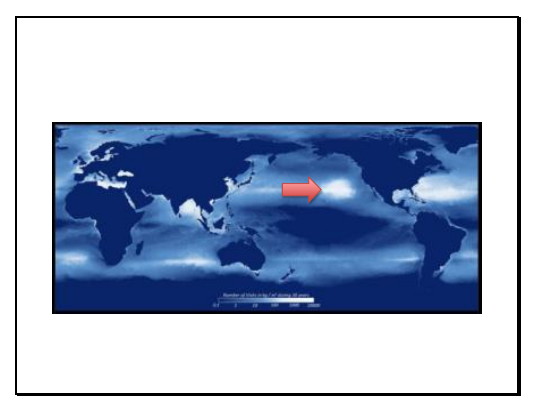

Slide 41 \& 42

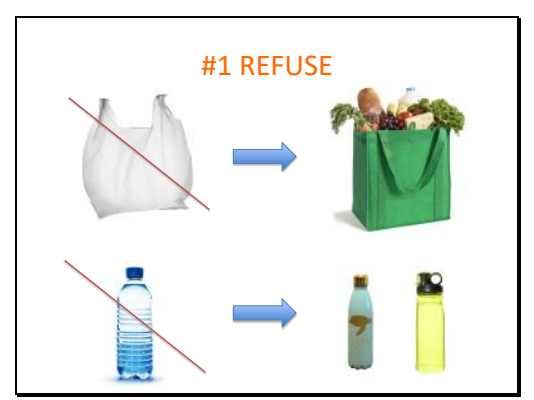

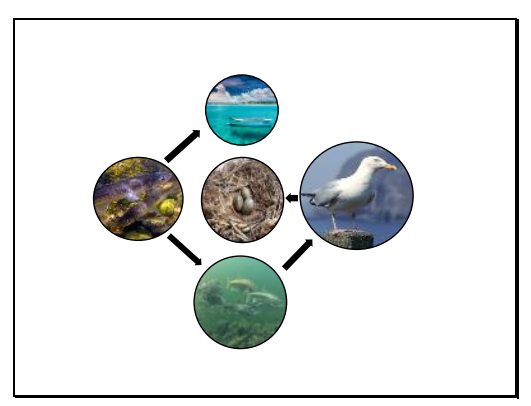
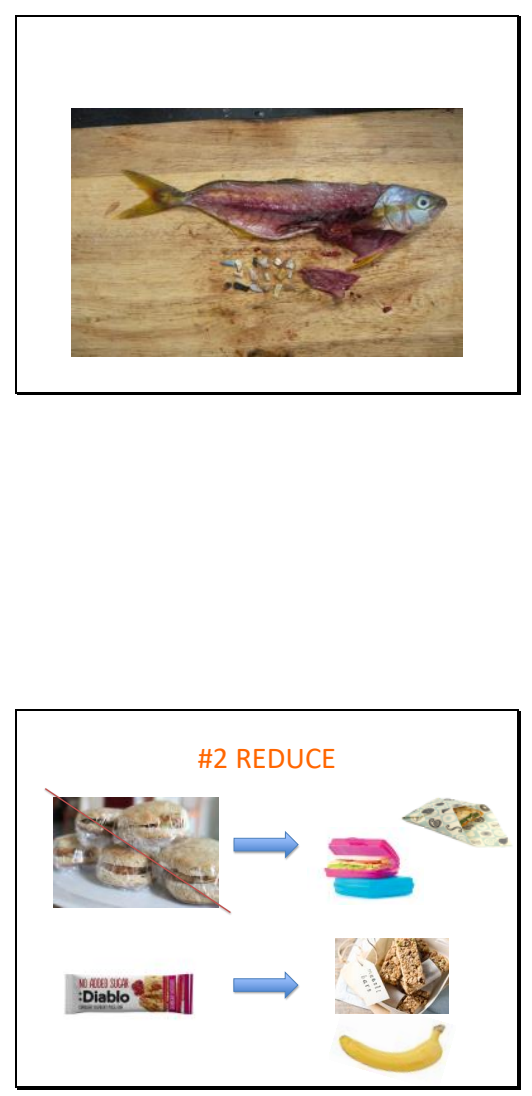
Slide 43 \& 44

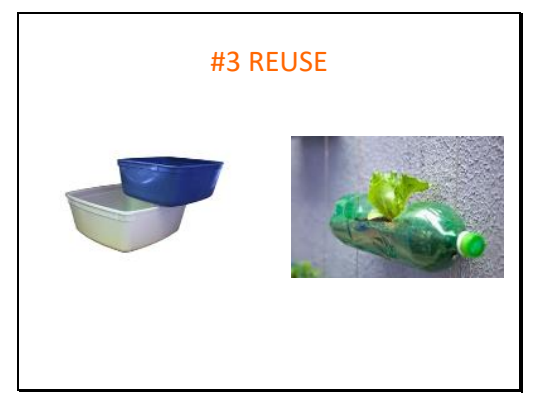

Slide 45 \& 46

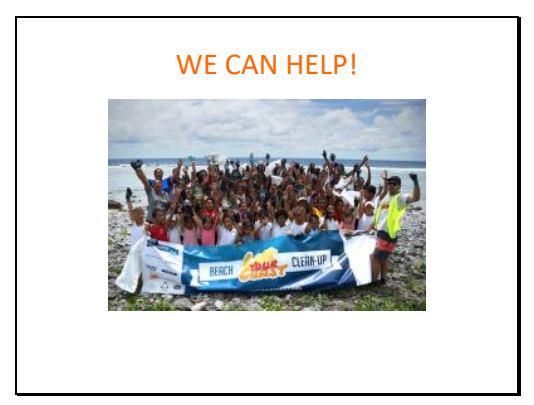

Slide 47 \& 48

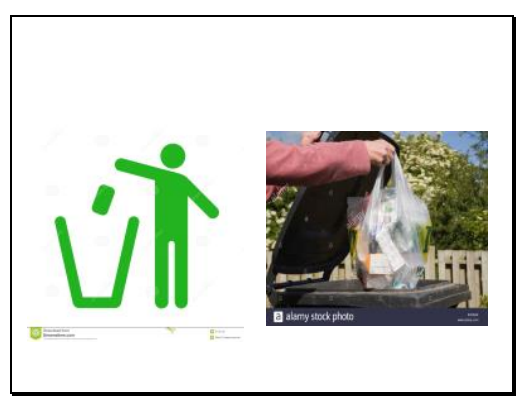

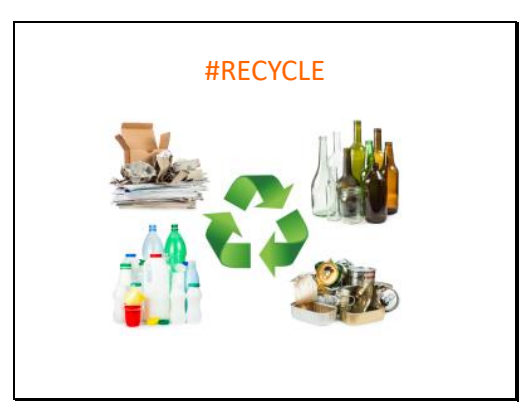
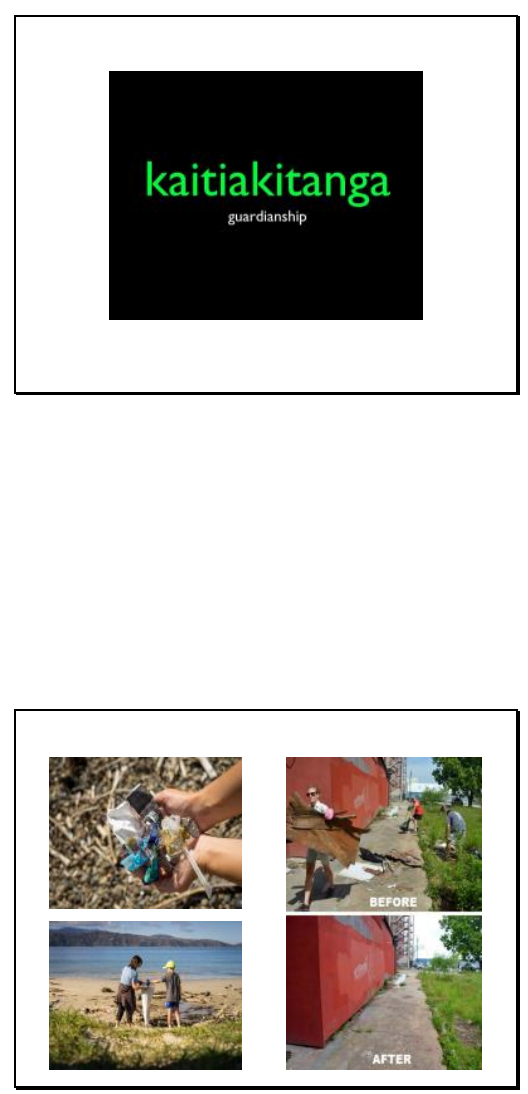
Slide 49 \& 50
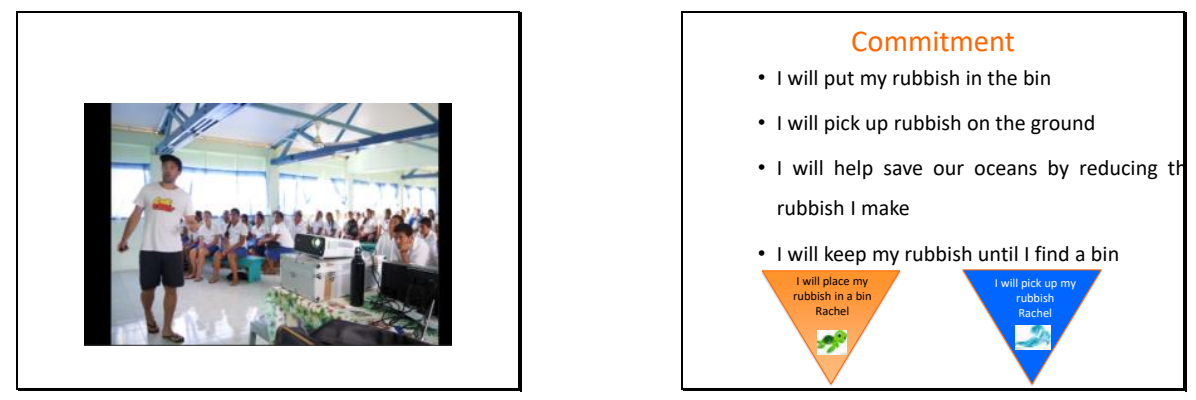

Slide 51

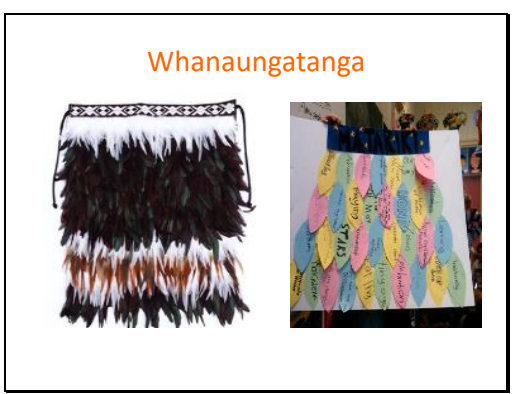




\section{Appendix 4. Survey for hypocrisy condition AI School}

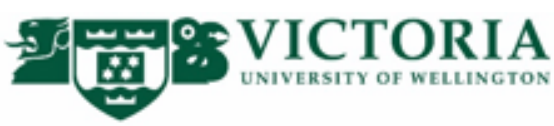

\section{Rubbish Reduction}

\section{SURVEY FOR PARTICIPANTS}

When you have used or eaten something, that makes rubbish, what do you do most?

\begin{tabular}{|c|c|c|c|}
\hline $\begin{array}{c}\text { Put in } \\
\text { bin }\end{array}$ & $\begin{array}{c}\text { Put in bin } \\
\text { sometimes }\end{array}$ & $\begin{array}{c}\text { Leave } \\
\text { behind }\end{array}$ & $\begin{array}{c}\text { Leave } \\
\text { behind } \\
\text { sometimes }\end{array}$ \\
\hline & & & \\
\hline
\end{tabular}

(You can tick more than one)

\begin{tabular}{|c|c|c|c|c|}
\hline $\begin{array}{c}\text { More than } \\
\text { once a } \\
\text { day }\end{array}$ & $\begin{array}{c}\text { Once a } \\
\text { day }\end{array}$ & $\begin{array}{c}1-2 \\
\text { times } \\
\mathrm{a} \\
\text { week }\end{array}$ & $\begin{array}{c}\text { Once a } \\
\text { month }\end{array}$ & Never \\
\hline 1 & 2 & 3 & 4 & 5 \\
\hline
\end{tabular}
Circle One

Please rank how often in the last 1-2 months you have picked up rubbish?

|

Please rank how often in the last 1-2 months you have left your rubbish behind (even if it was an accident)?

Do you think you should always be responsible for your own rubbish, even when there are no rubbish bins around?

\begin{tabular}{|c|c|c|c|c|}
\hline $\begin{array}{c}\text { More than } \\
\text { once a } \\
\text { day }\end{array}$ & $\begin{array}{c}\text { Once a } \\
\text { day }\end{array}$ & $\begin{array}{c}1-2 \\
\text { times } \\
\text { a } \\
\text { week }\end{array}$ & $\begin{array}{c}\text { Once a } \\
\text { month }\end{array}$ & Never \\
\hline 1 & 2 & 3 & 4 & 5 \\
\hline
\end{tabular}

\begin{tabular}{|l|c|c|}
\hline Yes & No & Don't know \\
\hline & & \\
\hline
\end{tabular}

If there are no bins around what do you do with your rubbish?

Please say why you did not put rubbish in the bin in the past (answer only if you did not put rubbish in the bin): 
In the future how often will you put your rubbish in the bin?

\begin{tabular}{|l|c|c|c|c|}
\hline Never & Sometimes & $\begin{array}{c}\text { Most } \\
\text { times }\end{array}$ & $\begin{array}{c}\text { Almost } \\
\text { every } \\
\text { time }\end{array}$ & $\begin{array}{c}\text { Every } \\
\text { time }\end{array}$ \\
\hline 1 & 2 & 3 & 4 & 5 \\
\hline
\end{tabular}

In the future how often will you pick up rubbish to put in a bin?

\begin{tabular}{|l|c|c|c|c|}
\hline Never & Sometimes & $\begin{array}{c}\text { Most } \\
\text { times }\end{array}$ & $\begin{array}{c}\text { Almost } \\
\text { every } \\
\text { time }\end{array}$ & $\begin{array}{c}\text { Every } \\
\text { time }\end{array}$ \\
\hline 1 & 2 & 3 & 4 & 5 \\
\hline
\end{tabular}

In the future if there is no bin around what will you do with your rubbish?

\begin{tabular}{|l|c|}
\hline $\begin{array}{c}\text { Leave it } \\
\text { behind }\end{array}$ & $\begin{array}{c}\text { Take it } \\
\text { with me }\end{array}$ \\
\hline & \\
\hline Tick one
\end{tabular}

Why do you think it may be important to put your rubbish in the bin and to pick up rubbish in the future?

\section{Appendix 5. Semi-structured interview guide AI School}

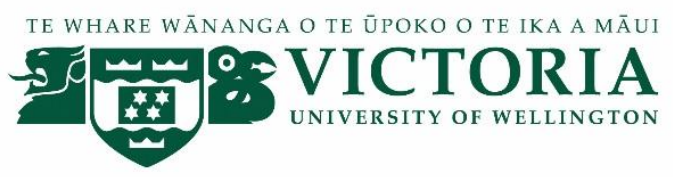

\section{Rubbish Reduction}

INTERVIEW GUIDE FOR PARTCIPANTS

- The project

- Litter 
- Achieving commitments and goals

- Friends and family

- Motives

- Education

- Litter practice

- Future success

- Students behaviour

- Households

\section{Appendix 6. Information sheet for student interviews}

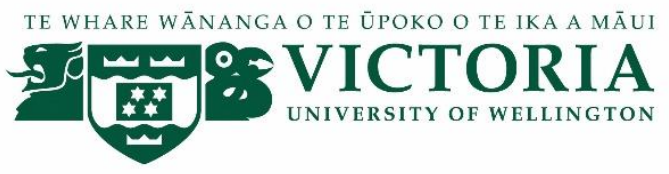

\section{Rubbish Reduction \\ INTERVIEW INFORMATION SHEET FOR PARTICIPANTS}

You are invited to take part in my University research. Please read this information before deciding whether or not to take part. If you decide to participate, thank you. If you decide not to participate, thank you for considering this request.

\section{Who am I?}

My name is Rachel Thomas and I am a Masters student in Environmental Studies at Victoria University of Wellington.

\section{What am I doing?}

I have provided your school with a rubbish reduction project, and I would like to hear about what you thought of it?

\section{How can you help?}

If you agree to take part, I will ask you questions about your experience with the Rubbish Reduction Project. The interview will take 5-10 minutes. You can stop the interview at any time, without a given reason.

\section{What does participating mean?}

By participating in this interview, you will be giving your consent. Your interview will be kept private, even from your teachers. I won't record your name. For these reasons, it will not 
be possible to connect you with this study. This study may be published, and or presented at conferences.

\section{Further Questions?}

If you would like to ask me any questions at all then please have your parents email me anytime. There is more information about this study in the 'Parent or legal guardian information sheet'. If they have not received a paper copy of this from your teacher, I will happily send you one in the mail.

Thank you for reading this. I look forward to seeing you soon at school.

Rachel Thomas - Victoria University of Wellington

Email: thomasrach2@myvuw.ac.nz

\section{Appendix 7. Consent form for student interviews}

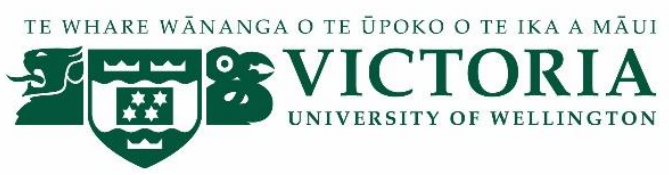

\section{Environmental Engagement: Using behaviour change tools to influence litter reduction in intermediate aged schools CONSENT TO CONVERSATION FOR STUDENT}

This consent form will be held for 1 year.

Researcher: Rachel Thomas, School of Geography, Environment and Earth Sciences, Victoria University of Wellington.

- I have read the Information Sheet and the project has been explained to me. My questions have been answered to my satisfaction. I understand that I can ask further questions at any time.

- I agree to take part in an audio recorded conversation.

I understand that:

- I may withdraw from this study at any point before March $30^{\text {th }} 2018$, and any information that I have provided will be returned to me or destroyed.

- $\quad$ The identifiable information I have provided will be destroyed on August $18^{\text {th }} 2018$. 
- $\quad$ Any information I provide will be kept confidential to the researcher.

- I understand that the results will be used for a Masters report and a summary of the results may be used in academic reports and/or presented at conferences.

- I would like a copy of the recording of my conversation: $\quad$ Yes No

- I would like a copy of the transcript of my conversation: $\quad$ Yes No

Signature of participant:

Name of participant:

Date:

Contact details:

Appendix 8. Information sheet for adult interviews AI School

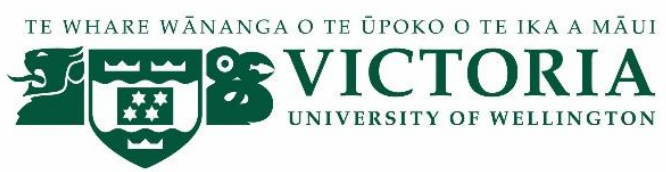

\section{Environmental Engagement: Using behaviour change tools to influence litter reduction in intermediate aged schools}

\section{INFORMATION SHEET FOR ADULT}

You are invited to take part in this research. Please read this information before deciding whether or not to take part. If you decide to participate, thank you. If you decide not to participate, thank you for considering this request.

\section{Who am I?}

My name is Rachel Thomas and I am a Masters student in Environmental Studies at Victoria University of Wellington. This research project is working towards my thesis.

\section{What is the aim of the project?}

This project aims to assess the effectiveness of the behaviour change tools cognitive dissonance (when an individual holds two psychologically inconsistent thoughts, for example when an individual says or does something which runs counter to their own beliefs, they will automatically change, dismiss, or add thoughts to try to bring these thoughts into greater 
harmony to reduce their 'psychological tension') and education, through the observation of litter amounts in Avalon Intermediate school grounds.

This research project has received approval from the Avalon Intermediate School board and principal, and Victoria University Human Ethics Committee, Ethics Approval: 0000025377.

\section{How can you help?}

If you agree to take part, I will interview you at your school. I will ask you questions about your experience and perceptions of the Rubbish Reduction Project. The interview will take approximately 30 minutes. I will record the interview and write it up later. You can stop the interview at any time, without a given reason. You can withdraw from the study by contacting me at any point before the March $30^{\text {th }} 2018$. If you withdraw, the information you provided will be destroyed or returned to you.

\section{What will happen to the information you give?}

This research is confidential. You will not be named in the final report. Only my supervisors and I will read the notes or transcript of the interview. The interview transcripts, summaries and any recordings will be kept securely and destroyed one month after the research ends

\section{What will the project produce?}

The information from my research will be used to produce my Masters thesis. This study may be published, and or presented at conferences.

\section{If you accept this invitation, what are your rights as a research participant?}

You do not have to accept this invitation if you don't want to. If you do decide to participate, you have the right to:

- $\quad$ choose not to answer any question;

- $\quad$ ask for the recorder to be turned off at any time during the interview;

- $\quad$ withdraw from the study before March $30^{\text {th }} 2018$

- $\quad$ ask any questions about the study at any time;

- $\quad$ receive a copy of your interview recording;

- $\quad$ receive a copy of your interview transcript;

- be able to read any reports of this research by emailing the researcher to request a copy.

If you have any questions or problems, who can you contact?

If you have any questions, either now or in the future, please feel free to contact either:

\section{Student:}

Name: Rachel Thomas

University email address:

\section{Supervisor:}

Name: Dr. Wokje Abrahamse

Role: Senior Lecturer 


\section{Human Ethics Committee information}

If you have any concerns about the ethical conduct of the research you may contact the Victoria University HEC Convenor: Associate Professor Susan Corbett. Email susan.corbett@vuw.ac.nz or telephone +64-4-463 5480.

\section{Appendix 9. Consent form for adult interviews}

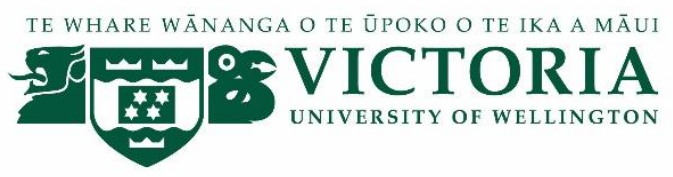

\section{Environmental Engagement: Using behaviour change tools to influence litter reduction in intermediate aged schools \\ CONSENT TO INTERVIEW FOR ADULT}

This consent form will be held for 1 year.

Researcher: Rachel Thomas, School of Geography, Environment and Earth Sciences, Victoria University of Wellington.

- I have read the Information Sheet and the project has been explained to me. My questions have been answered to my satisfaction. I understand that I can ask further questions at any time.

- I agree to take part in an audio recorded interview.

I understand that:

- I may withdraw from this study at any point before March $30^{\text {th }} 2018$, and any information that I have provided will be returned to me or destroyed.

- $\quad$ The identifiable information I have provided will be destroyed on August $18^{\text {th }} 2018$.

- $\quad$ Any information I provide will be kept confidential to the researcher.

- I understand that the results will be used for a Masters report and a summary of the results may be used in academic reports and/or presented at conferences. 
- $\quad$ My name will not be used in reports. However I consent to information or opinions which I have given being attributed to my school in any reports on this research and have the authority to agree to this on behalf of the organisation:

- I would like a copy of the recording of my interview:

- I would like a copy of the transcript of my interview:

- I would like to receive a copy of the final report and have added my email Yes address below.

Signature of participant:

Name of participant:

Date:

Contact details:

\section{Appendix 10. Information sheet for parents RNI School}
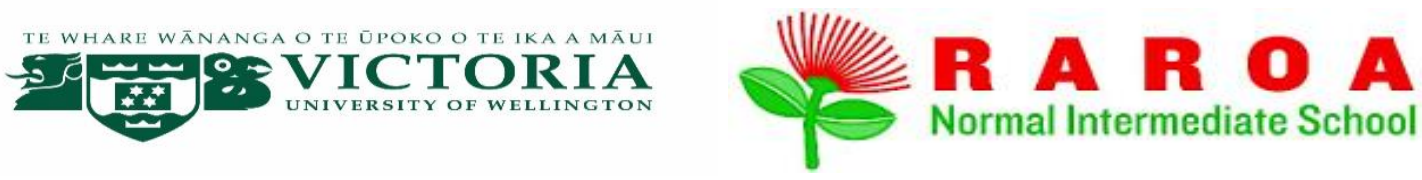

\section{Wrapperless Lunches}

\section{Raroa Intermediate School Goal:}

Raroa Intermediate wants to set a school wide goal of $60 \%$ of all lunchboxes to be wrapperless by the end of term 1, and the whole school to have wrapperless lunches by the end of the year. Therefore we need help from all out students and parents to achieve this goal!

\section{What is a wrapperless lunch?}

A wrapperless lunch contains no throwaway packaging. The typical homemade wrapperless lunch is packed in a lunch box or backpack. The food is put in reusable containers rather than wrapped in disposable packaging. A drink is packed in a refillable bottle. Cloth napkins and stainless-steel utensils replace disposables. All containers are resealable, so that leftover food and drink can be saved for later.

Why is a wrapperless lunch important? 
A wrapperless lunch policy will reduce our food packaging waste, which hopefully will influence our daily packaging consumption. By reducing our packaging waste we will help support the positive effects associated with reducing our packaging such as reducing climate change, landfill production, and marine and terrestrial pollution.

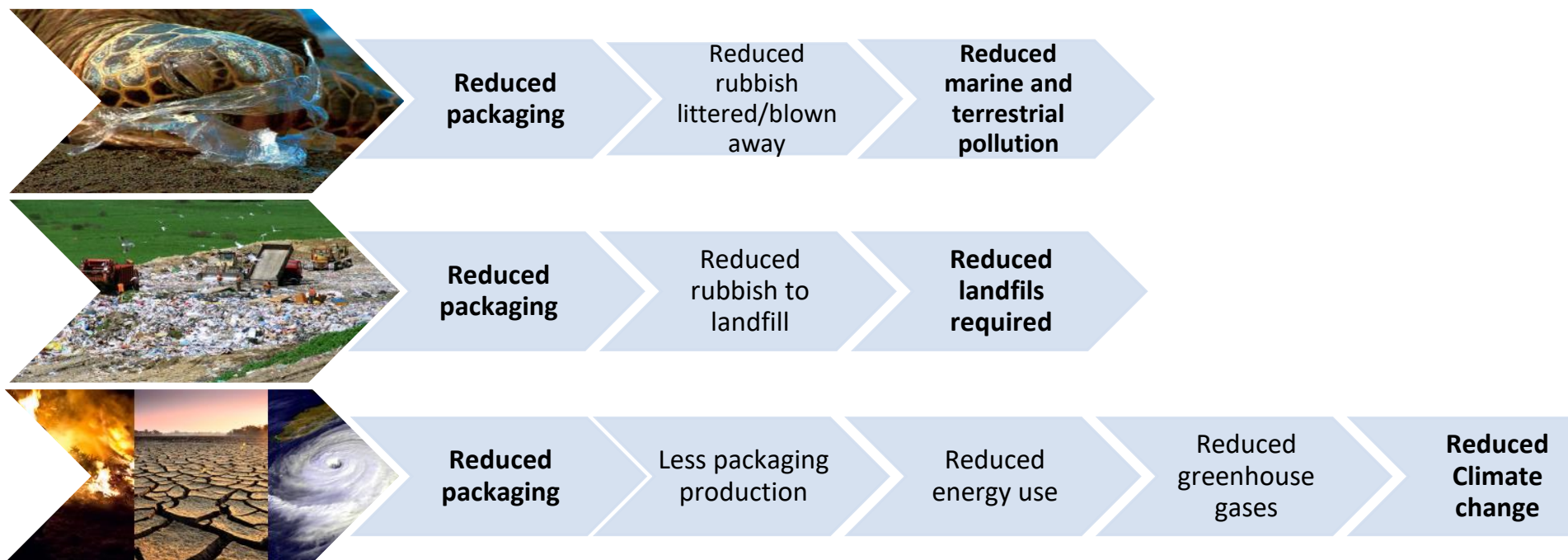

\section{What can you do to pack a wrapperless lunch?}

- Avoid using throwaway bags, plastic wrap, foil, polystyrene, single use cans, cartons, and napkins.

- Pack lunches in lunch boxes, small packs, or cloth bags.

- Include items that can be purchased in bulk, so there is less packaging per item, such as dried fruit and nuts

- Include items that come in their own natural biodegradable wrapping, such as bananas, oranges, carrots and hard boiled eggs.

- Pack water in a reusable bottle instead of prepacked drinks or juices (healthier and less expensive).

- Use reusable containers for food instead of bags or wraps, and reusable utensils that will be brought back home and reused.

- Purchase or make honeywraps, perfect for replacing gladwrap.

- Make your own, if you have time this can be an awesome activity for children to get involved in, such as making your own muesli bars or sweet and savoury treats.

- Prepare extra food at dinnertime and use as leftovers for lunches 


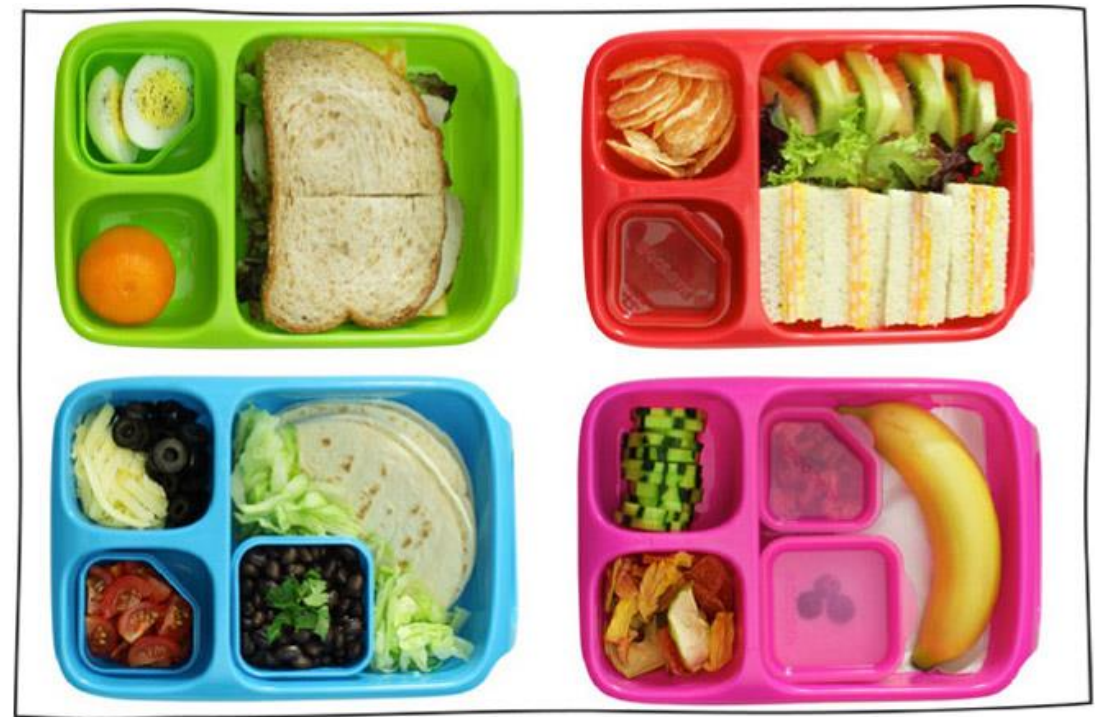

Reducing wrappers in lunch boxes with planning and commitment will be rewarding for your family and your future! Once you have achieved wrapperless lunches you can take steps to reduce more packaging from your lives, don't forget we are not alone in this, talk to family and friends to learn extra tips and tricks, pass on your advice, and try to remain positive about the change you can make!

\section{Appendix 11. Education presentation for RNI School}

Slide $1 \& 2$
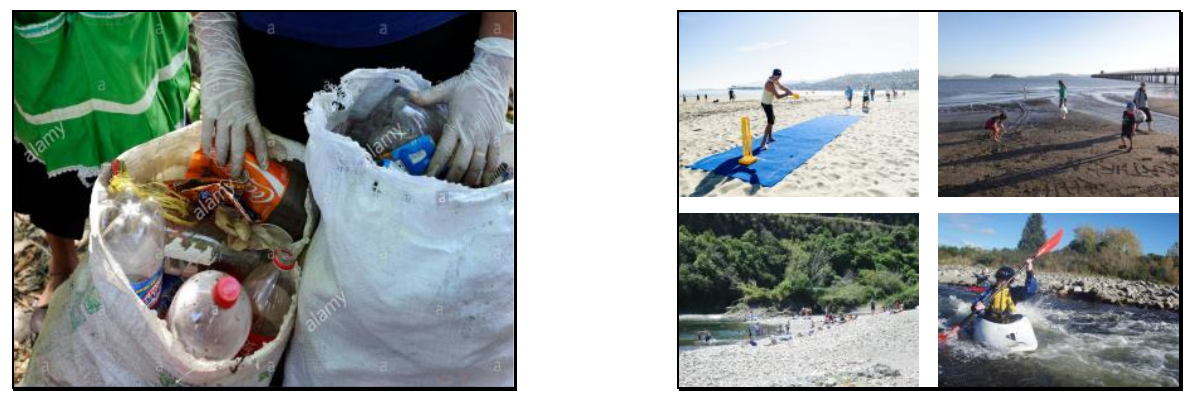
Slide $3 \& 4$

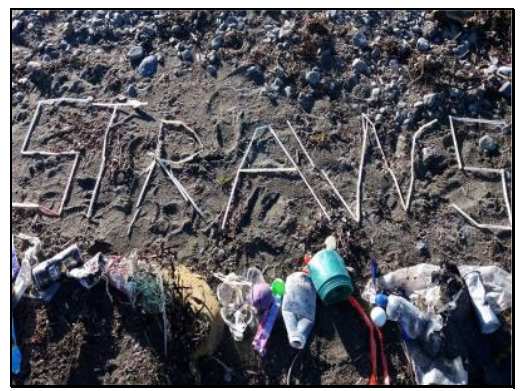

Slide 5 \& 6

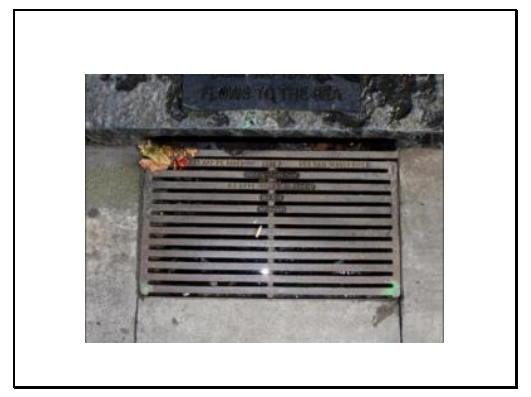

Slide $7 \& 8$

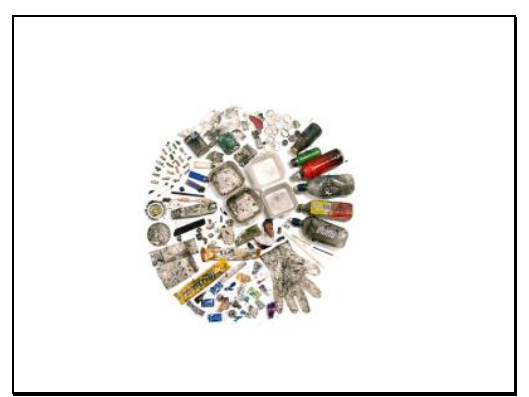

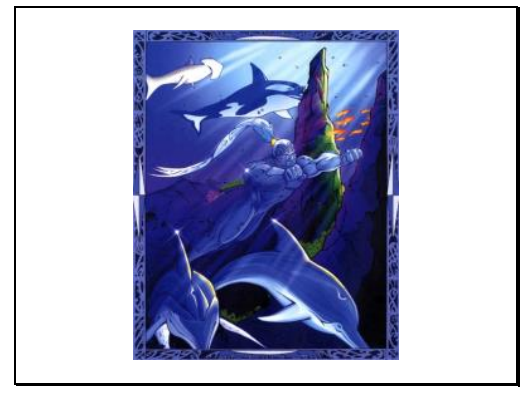

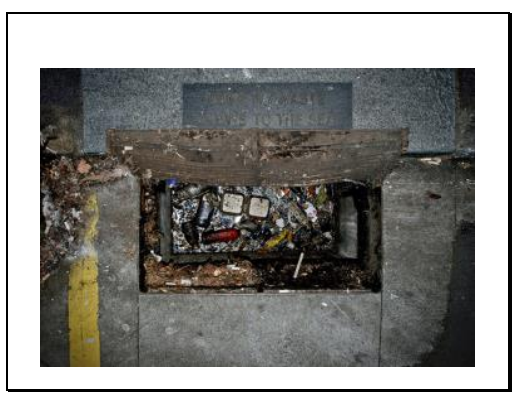

- https://www.youtube.com/watch?v=1zUuEA8 s9qE\&feature=youtu.be 
Slide 9 \& 10

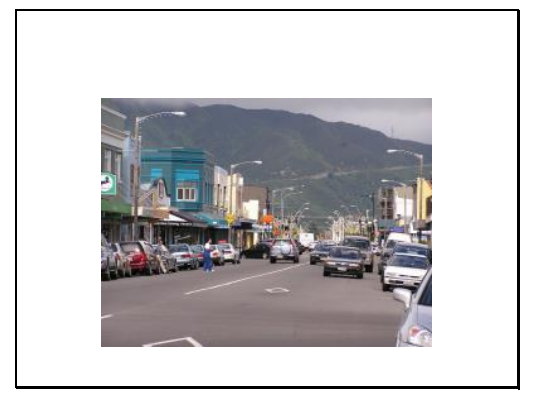

Slide 11 \&

12

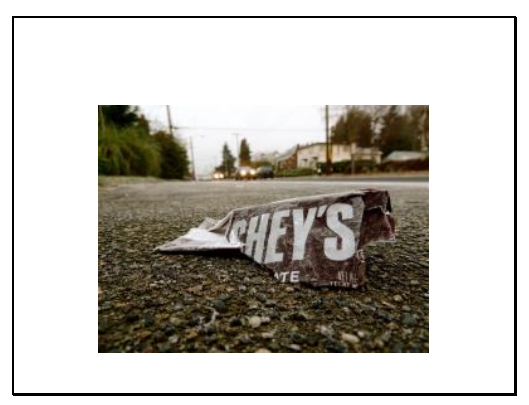

Slide 13 \& 14

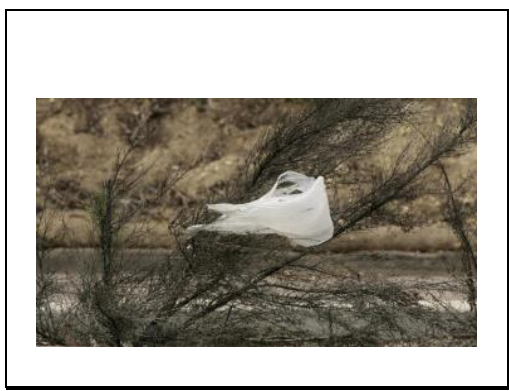

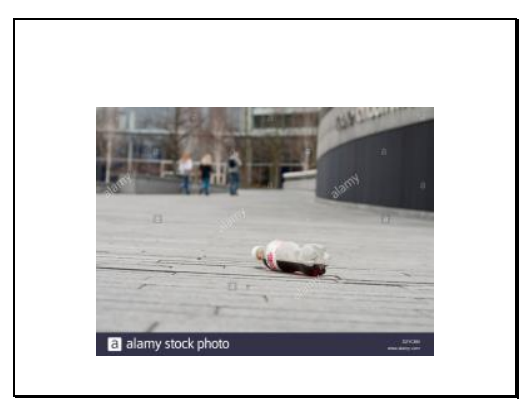
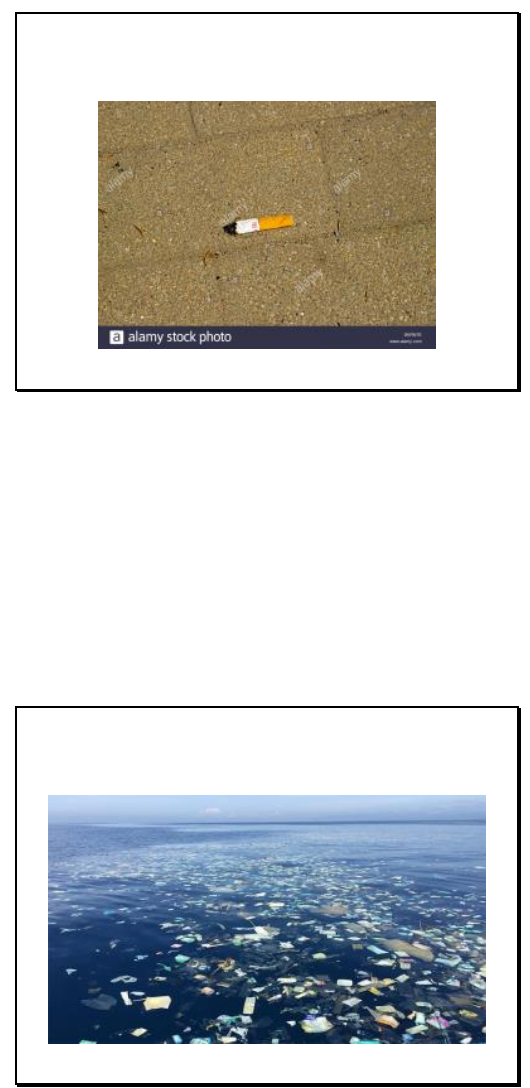
Slide 15 \& 16

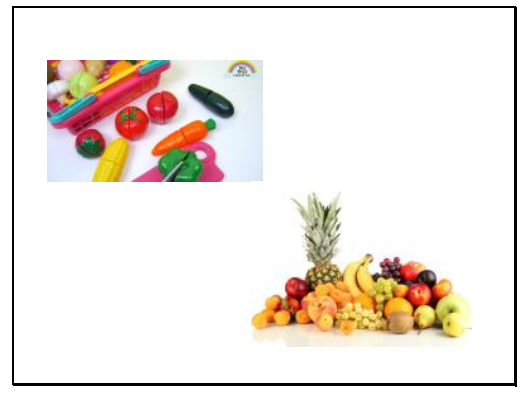

Slide 17 \& 18

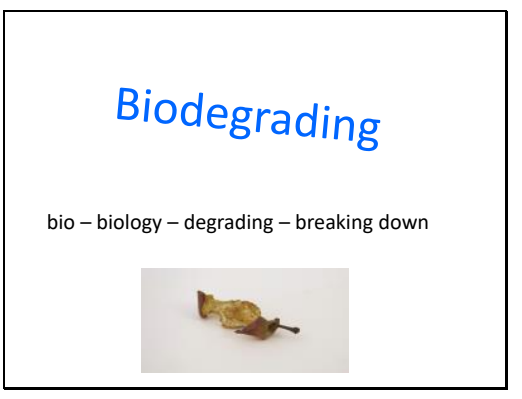

Slide 19 \& 20

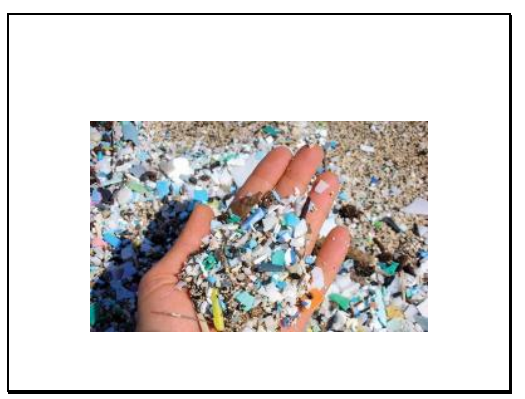

- https://www.youtube.com/watch?v=S12zZhd $\underline{\text { Ockc }}$

- https://www.youtube.com/watch?v=2408C24 $\mathrm{yH} 3 \mathrm{Y}$
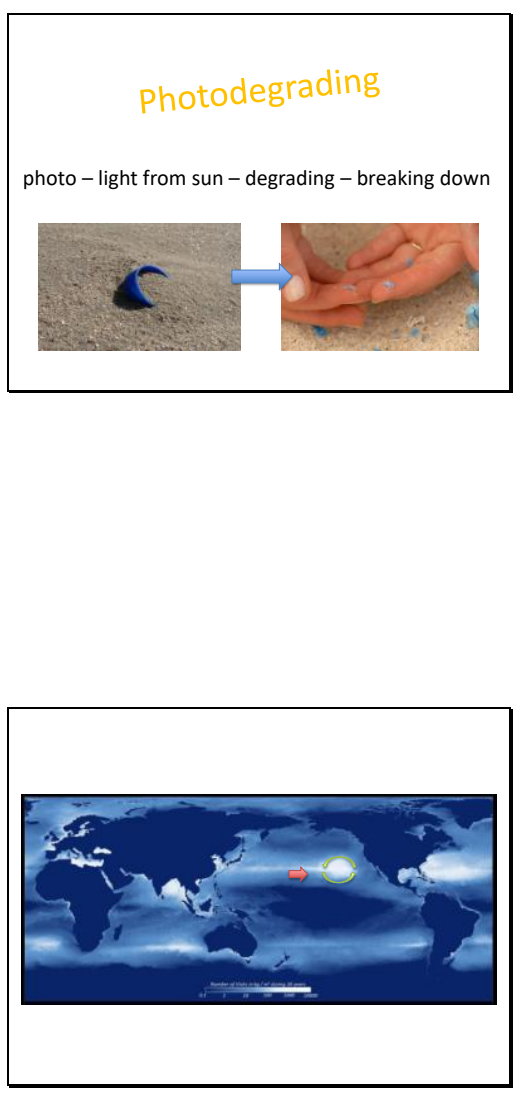
Slide $21 \&$ 22

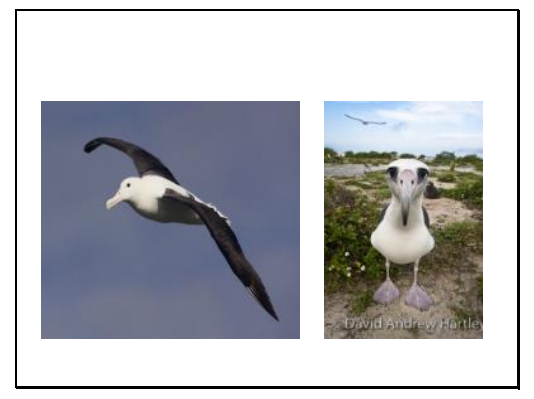

Slide 23 \& 24

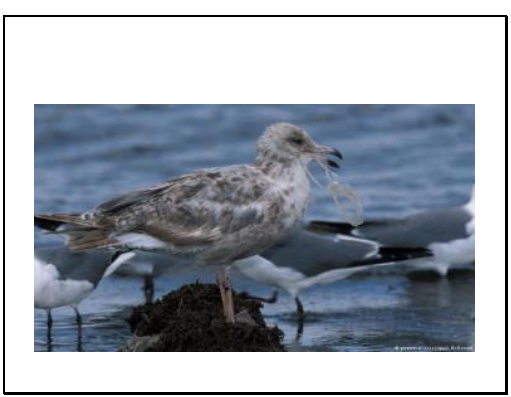

Slide 25 \& 26
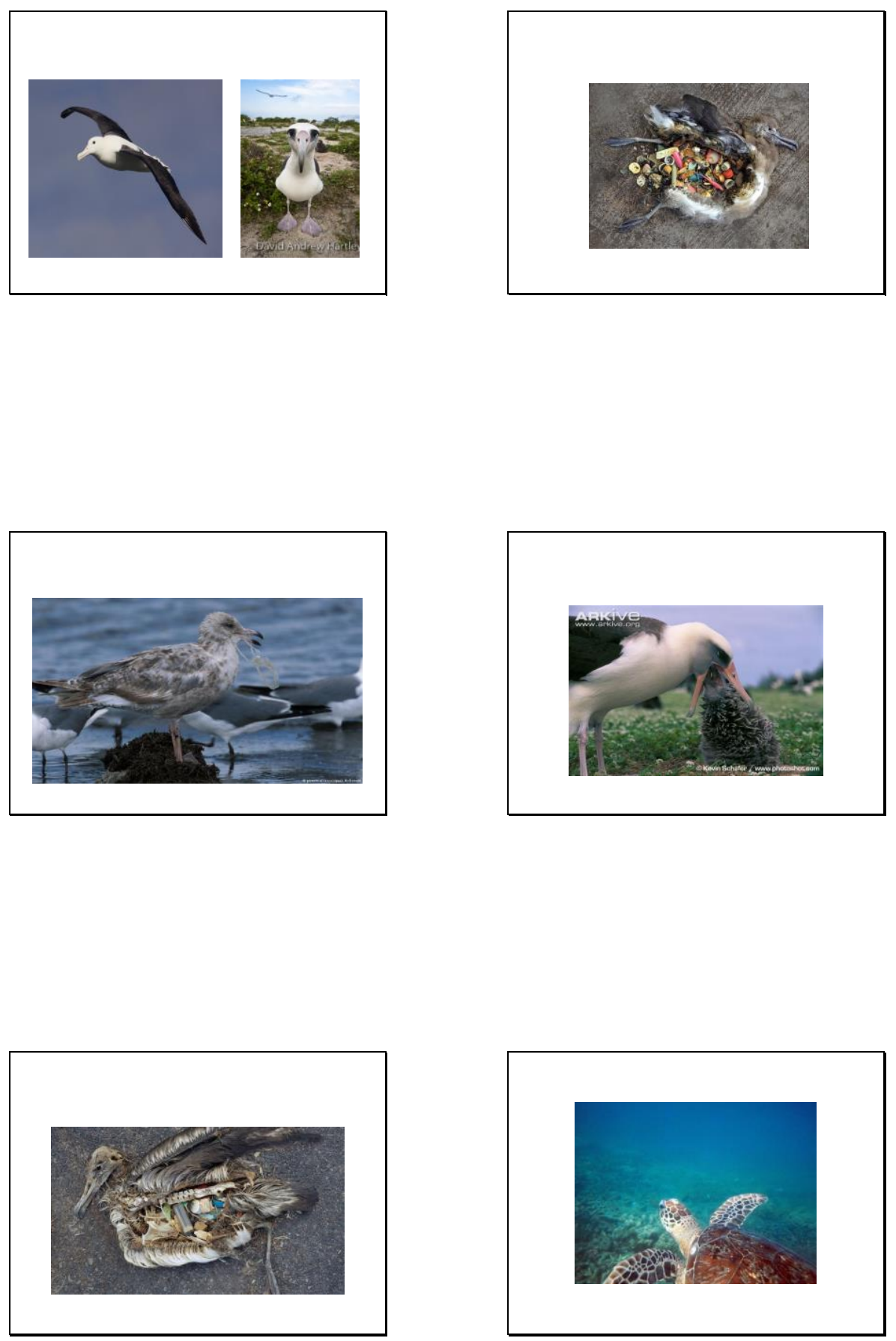
Slide 27 \& 28

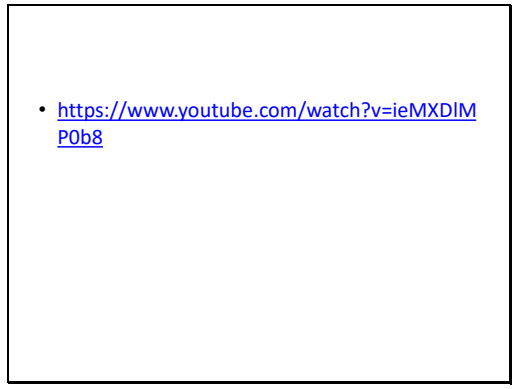

Slide 29

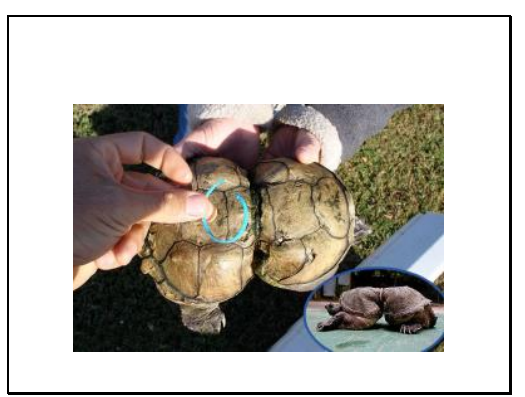

Slide 31 \& 32

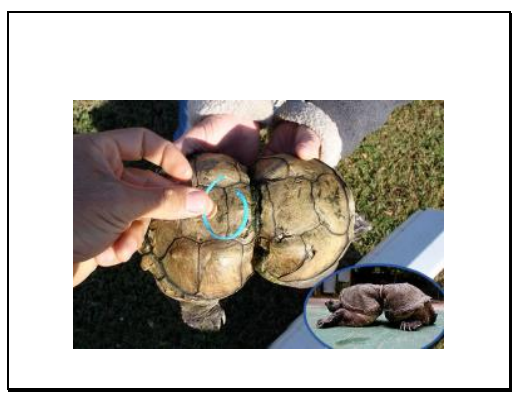

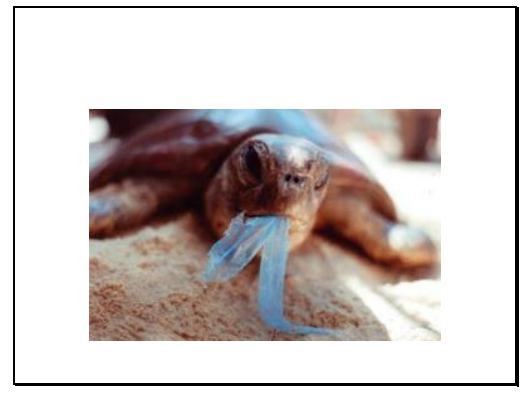
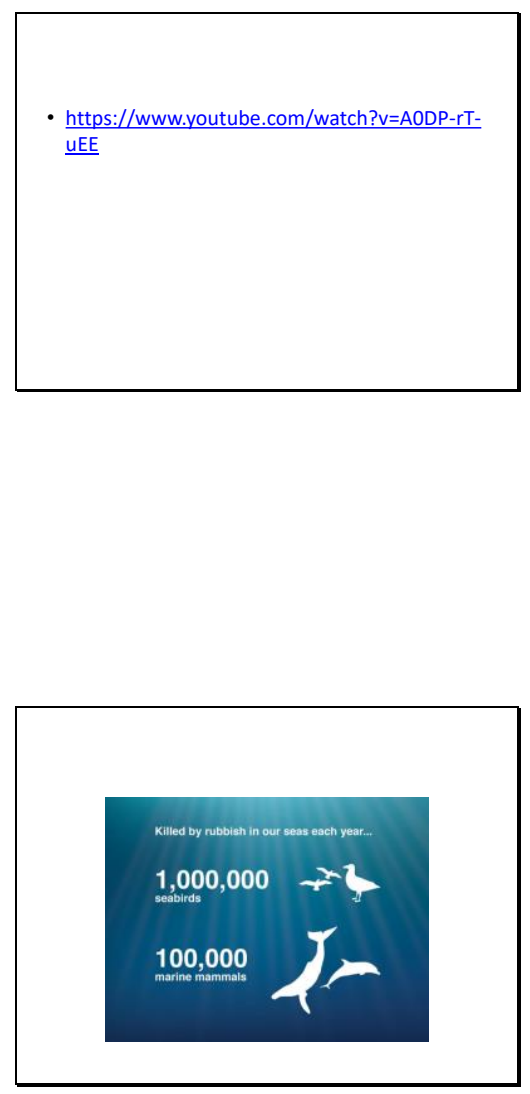
Slide 33 \& 34

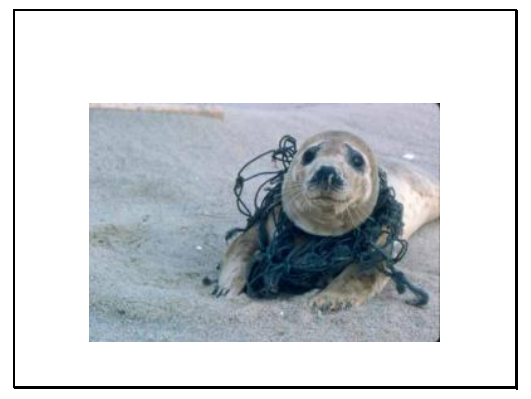

Slide 35 \& 36

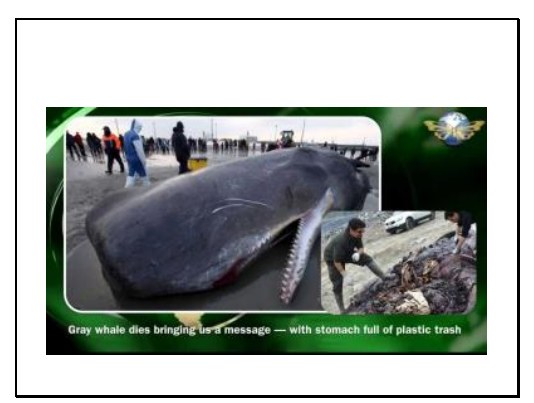

Slide 37 \& 38
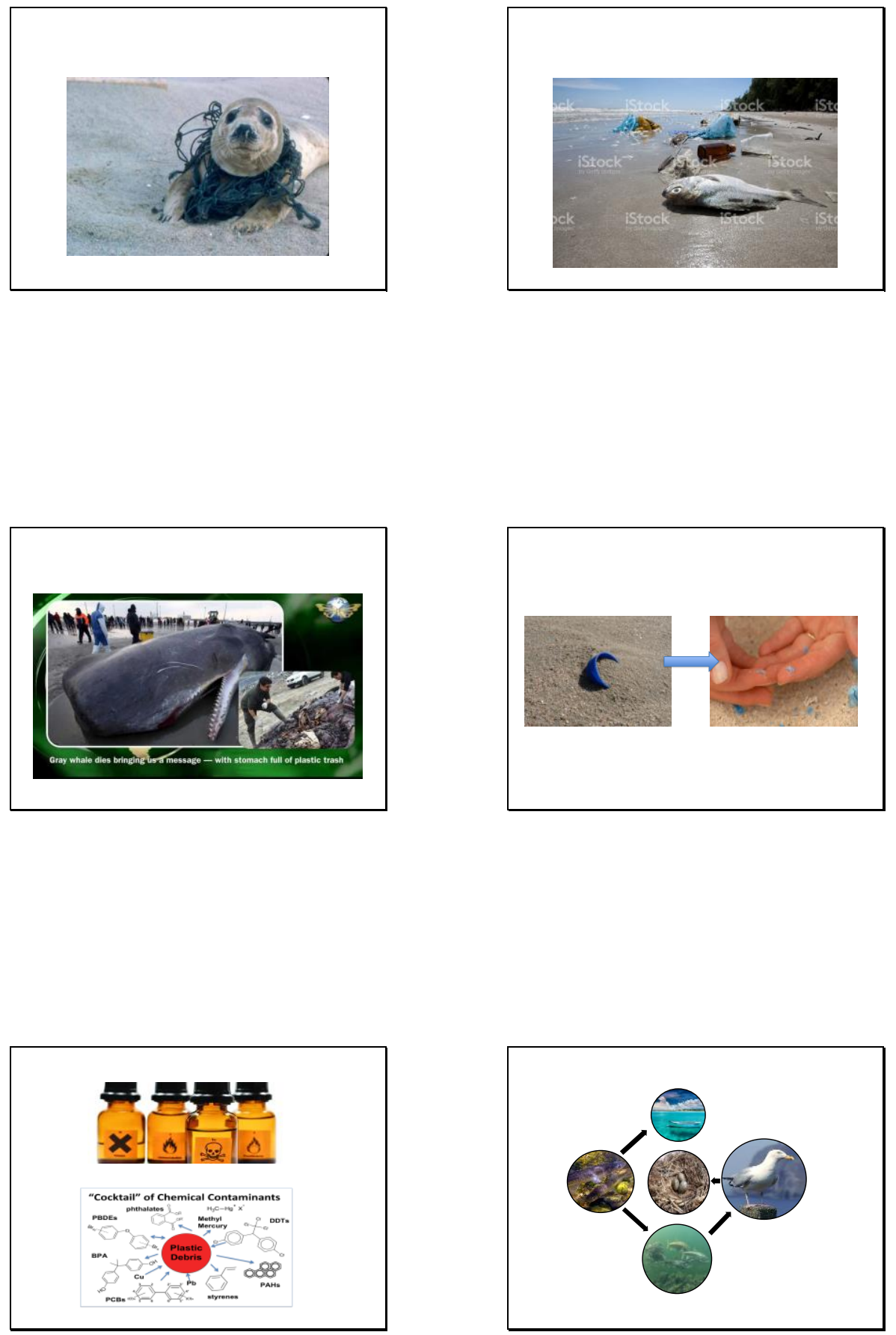
Slide 39 \&

40
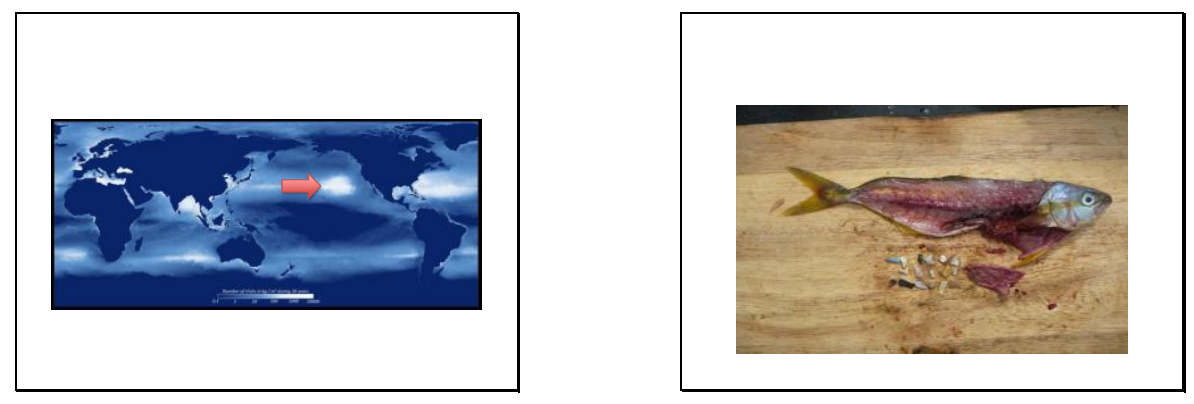

Slide 41 \& 42
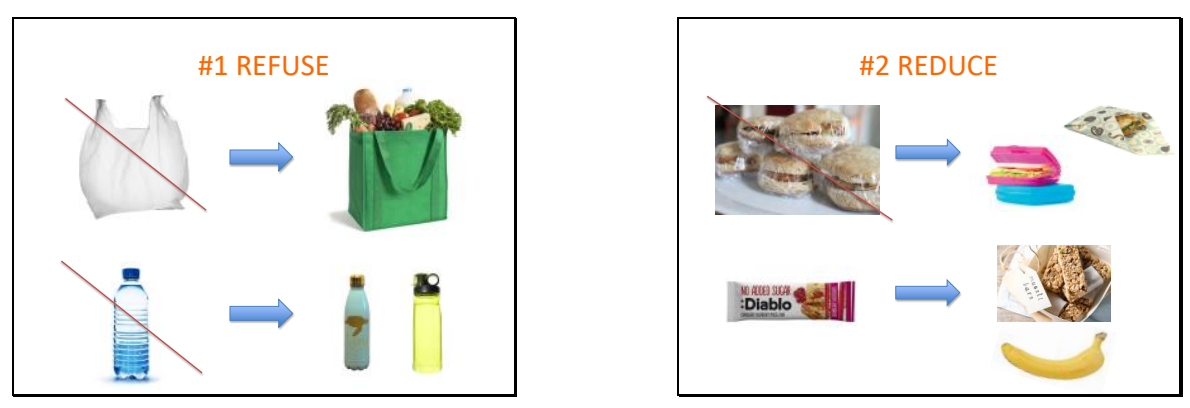

Slide 43 \& 44

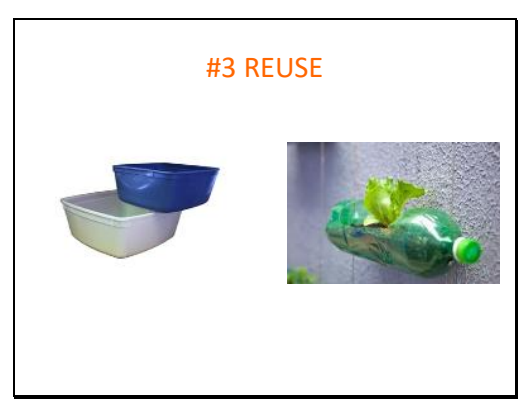

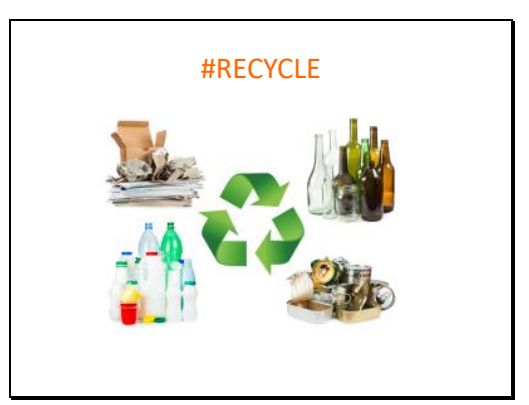


Slide 45 \& 46

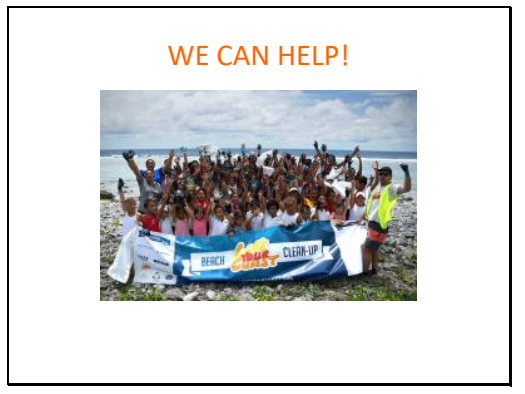

Slide 47 \& 48

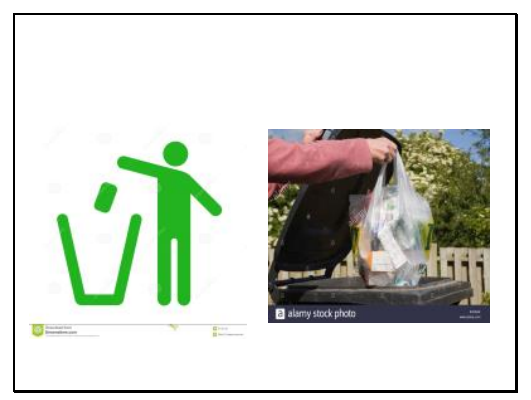

Slide 49 \& 50

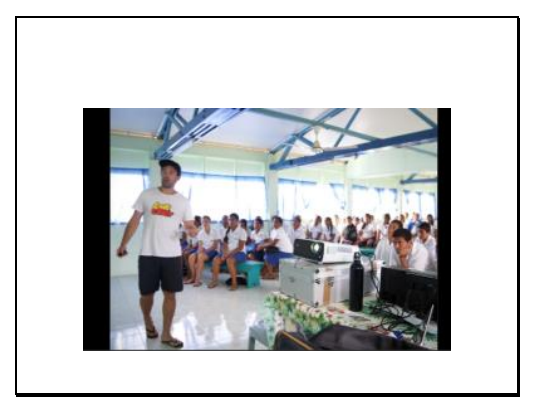

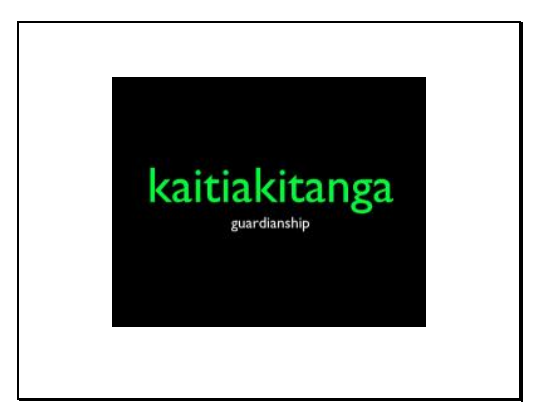
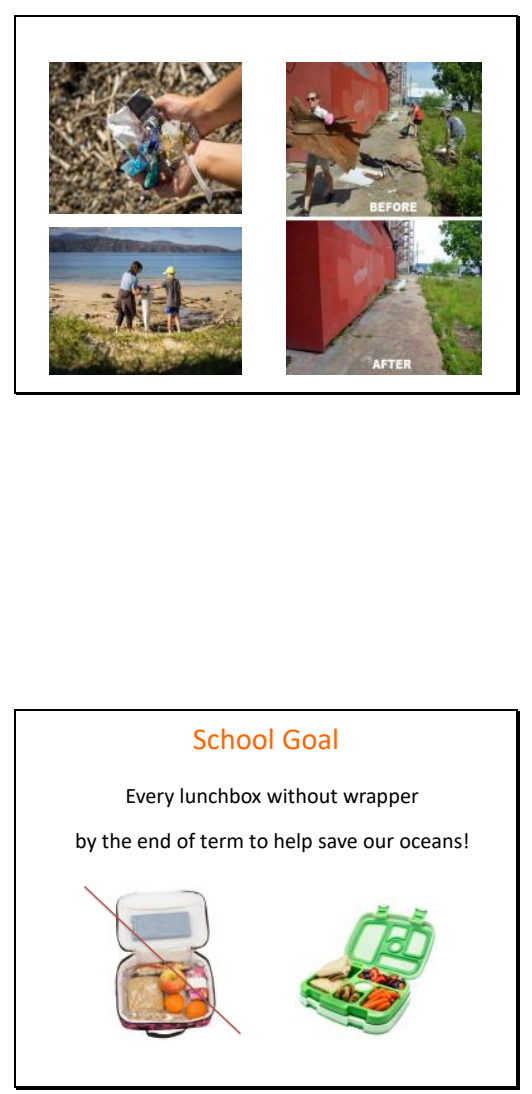
Slide $51 \&$ 52
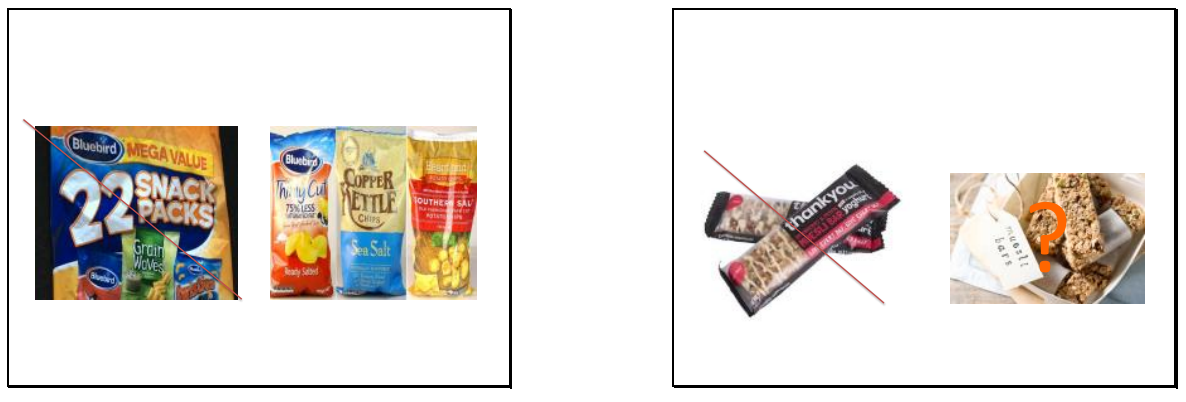

Slide 53 \& 54

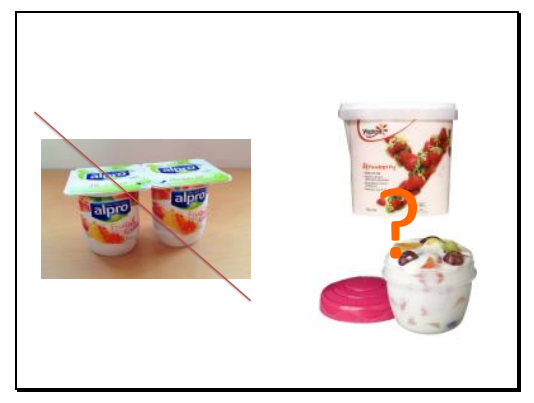

\section{My lunch plan:}

Sandwiches in gladwrap Sandwiches in container

Yoghurt pot Yoghurt in container/ piece of

Crackers in gladwrap Crackers in container/ nuts in

Banana Banana

Muesli bar in wrapper Home-made muesli bar in

container

Either replace wrapped item with wrapperless item, or change to different food that comes with no wrap

\section{Slide 55}

\begin{tabular}{l|}
\hline \multicolumn{1}{|c|}{ Goal } \\
- Refuse and reduce our wrappers \\
- No dropping rubbish \\
- Pick up rubbish \\
\\
\hline
\end{tabular}




\title{
Appendix 12. Information sheet and consent form RNI School
}

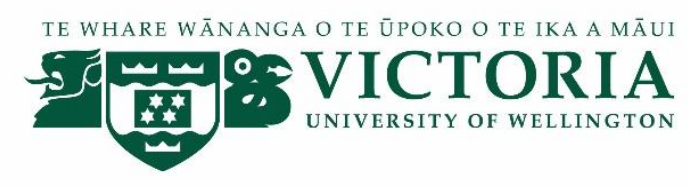

\section{Environmental Engagement: Using behaviour change tools to influence litter reduction in intermediate aged schools}

\author{
INFORMATION SHEET FOR PARENTS OR LEGAL GUARDIAN OF STUDENT \\ Researcher: Rachel Thomas, School of Geography, Environment and Earth Sciences, \\ Victoria University of Wellington
}

\begin{abstract}
About this project
I am a Masters student in Environmental Studies at Victoria University of Wellington. As part of this degree, I am undertaking a research project leading to a thesis. This project aims to assess the effectiveness of the behaviour change tools goal setting and education, through the observation of litter amounts in Raroa Intermediate school grounds. This study may be published, and or presented at conferences.
\end{abstract}

This research project has received approval from the Raroa Intermediate School board and principal, and Victoria University Human Ethics Committee, Ethics Approval: 0000025377.

\section{What is involved?}

I am working alongside Raroa Intermediate, Raroa Intermediate is including this project into their curriculum to engage the children environmental awareness. As a part of my study I am inviting child participants, aged 9-12, as well as selected teachers to take part in this research. As part of this research project the children will participate in a presentation highlighting the effects of rubbish on our environment and their community, they will also participate in goal setting activity all taking approximately 1 hour to complete. This research will be supplemented by conversations with child participants and teachers, to offer perspective and opinion on the project.

Your child will be asked if they would like to participate in the project and may be asked to supply opinions and thoughts on the project (random selection). They will be giving their consent by completing the project and answering questions. Audio recorded conversations will be kept on a locked computer, and will be destroyed one month after completion.

Examples of the conversation questions are: 
1. What did you think of the project today?

2. Do you think today has influenced how you feel about rubbish and wrapper?

If you have any questions or problems, who can you contact?

If you have any questions, either now or in the future, please feel free to contact either:

\section{Student:}

Name: Rachel Thomas

University email address:

thomasrach2@myvuw.ac.nz

\section{Supervisor:}

Name: Dr. Wokje Abrahamse

Role: Senior Lecturer

School: Geography, Environment and Earth Sciences

Phone: 044635217

wokje.abrahamse@vuw.ac.nz

\section{Human Ethics Committee information}

If you have any concerns about the ethical conduct of the research you may contact the Victoria University HEC Convenor: Associate Professor Susan Corbett. Email susan.corbett@vuw.ac.nz or telephone +64-4-463 5480. 


\title{
Environmental Engagement: Using behaviour change tools to influence litter reduction in intermediate aged schools
}

\author{
PROJECT FORM FOR PARENTS OR LEGAL GUARDIAN OF STUDENT
}

Researcher: Rachel Thomas, School of Geography, Environment and Earth Sciences, Victoria University of Wellington

Raroa Intermediate is including this project into their curriculum to engage the children in environmental awareness, Raroa Intermediate expects all children to participate. Although an explanation of this research has been provided, if you would like any of the information explained further or have additional questions, please contact the researcher. If do you agree to your child's participation in this research, your child must too agree on the day to participate in the research.

Any information your child provides will be kept confidential to the researcher, and the supervisor. This study may be published, and or presented at conferences. The published results will not use your child's name, and the results of the study will not be attributed to them in any way that will identify them. The primary material such as recorded conversations will be kept safe, locked in a computer and wiped from the recording device.

Please tick this box if you would like a copy of your child's conversation (if they are involved in one). If you have indicated that you would like to be sent this document, please provide your contact details below and have your child return this slip to the school. If you do not have an email address or would prefer a posted copy, please input your postal address instead.

Email/Postal address:

If/ or if not after having the opportunity to ask questions and have them answered to your satisfaction you wish for your son or daughter to be withdrawn from participating in the 
project and or conversation, please contact the researcher.

Nga mihi,

Rachel Thomas

Appendix 13. Semi-structured interview information sheet for adults RNI School

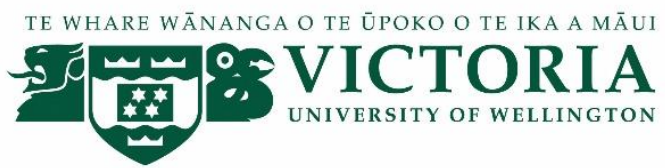

\section{Environmental Engagement: Using behaviour change tools to influence litter reduction in intermediate aged schools}

\section{INFORMATION SHEET FOR ADULT}

You are invited to take part in this research. Please read this information before deciding whether or not to take part. If you decide to participate, thank you. If you decide not to participate, thank you for considering this request.

\section{Who am I?}

My name is Rachel Thomas and I am a Masters student in Environmental Studies at Victoria University of Wellington. This research project is working towards my thesis.

What is the aim of the project?

This project aims to assess the effectiveness of the behaviour change tools goal setting and education, and a wrapperless lunch policy through the observation of litter amounts in Raroa Intermediate school grounds.

This research project has received approval from the Raroa Intermediate School board and principal, and Victoria University Human Ethics Committee, Ethics Approval: 0000025377.

\section{How can you help?}

If you agree to take part, I will interview you at your school. I will ask you questions about your experience and perceptions of the Wrapperless Lunch Project. The interview will take approximately 30 minutes. I will record the interview and write it up later. You can stop the interview at any time, without a given reason. You can withdraw from the study by contacting me at any point before the March $30^{\text {th }} 2018$. If you withdraw, the information you provided will be destroyed or returned to you.

What will happen to the information you give? 
This research is confidential. You will not be named in the final report. Only my supervisors and I will read the notes or transcript of the interview. The interview transcripts, summaries and any recordings will be kept securely and destroyed one month after the research ends

\section{What will the project produce?}

The information from my research will be used to produce my Masters thesis. This study may be published, and or presented at conferences.

\section{If you accept this invitation, what are your rights as a research participant?}

You do not have to accept this invitation if you don't want to. If you do decide to participate, you have the right to:

- $\quad$ choose not to answer any question;

- $\quad$ ask for the recorder to be turned off at any time during the interview;

- $\quad$ withdraw from the study before March $30^{\text {th }} 2018$

- $\quad$ ask any questions about the study at any time;

- $\quad$ receive a copy of your interview recording;

- $\quad$ receive a copy of your interview transcript;

- be able to read any reports of this research by emailing the researcher to request a copy.

If you have any questions or problems, who can you contact?

If you have any questions, either now or in the future, please feel free to contact either:

\section{Student:}

Name: Rachel Thomas

University email address:

thomasrach2@myvuw.ac.nz

\section{Supervisor:}

Name: Dr. Wokje Abrahamse

Role: Senior Lecturer

School: Geography, Environment and Earth Sciences

Phone: 044635217

wokje.abrahamse@vuw.ac.nz

\section{Human Ethics Committee information}

If you have any concerns about the ethical conduct of the research you may contact the Victoria University HEC Convenor: Associate Professor Susan Corbett. Email susan.corbett@vuw.ac.nz or telephone +64-4-463 5480.

\section{Appendix 13. Semi-structured interview consent form for adults RNI School}




\section{Environmental Engagement: Using behaviour change tools to influence litter reduction in intermediate aged schools \\ CONSENT TO INTERVIEW FOR ADULT}

This consent form will be held for 1 year.

Researcher: Rachel Thomas, School of Geography, Environment and Earth Sciences, Victoria University of Wellington.

- I have read the Information Sheet and the project has been explained to me. My questions have been answered to my satisfaction. I understand that I can ask further questions at any time.

- I agree to take part in an audio recorded interview.

I understand that:

- I may withdraw from this study at any point before March $30^{\text {th }} 2018$, and any information that I have provided will be returned to me or destroyed.

- $\quad$ The identifiable information I have provided will be destroyed on August $18^{\text {th }} 2018$.

- $\quad$ Any information I provide will be kept confidential to the researcher.

- I understand that the results will be used for a Masters report and a summary of the results may be used in academic reports and/or presented at conferences.

- $\quad$ My name will not be used in reports. However I consent to information or opinions which I have given being attributed to my school in any reports Yes No on this research and have the authority to agree to this on behalf of the organisation:

- I would like a copy of the recording of my interview:

Yes No

- I would like a copy of the transcript of my interview:

- I would like to receive a copy of the final report and have added my email Yes address below.

Signature of participant:

Name of participant: 
Date:

Contact details:

Appendix 15. Ethics approval from the Victoria University Human Ethics Committee

MEMORANDUM

Phone $\quad 0-4-4636028$

Email judith.loveridge@vuw.ac.nz

\begin{tabular}{l|l}
\hline TO & Rachel Thomas \\
\hline FROM & Dr Judith Loveridge, Convenor, Human Ethics Committee \\
\hline DATE & 13 December 2017 \\
\hline PAGES & 1 \\
\hline \multicolumn{2}{|l}{} \\
\hline SUBJECT & $\begin{array}{l}\text { Ethics Approval: } 0000025377 \\
\text { Litter Reduction }\end{array}$ \\
\hline
\end{tabular}

Thank you for your application for ethical approval, which has now been considered by the Human Ethics Committee.

Your application has been approved from the above date and this approval is valid for three years. If your data collection is not completed by this date you should apply to the Human Ethics Committee for an extension to this approval.

Best wishes with the research.

Kind regards

Judith Loveridge

Convenor, Victoria University Human Ethics Committee 
